Florida International University

FIU Digital Commons

FIU Electronic Theses and Dissertations

University Graduate School

$11-13-2020$

\title{
Bacterial Mechanisms of Toxicity and Resistance to Organoarsenicals
}

\author{
Luis D. Garbinski \\ Florida International University, Igarb004@fiu.edu
}

Follow this and additional works at: https://digitalcommons.fiu.edu/etd

Part of the Biochemistry Commons, Environmental Microbiology and Microbial Ecology Commons, and the Molecular Biology Commons

\section{Recommended Citation}

Garbinski, Luis D., "Bacterial Mechanisms of Toxicity and Resistance to Organoarsenicals" (2020). FIU Electronic Theses and Dissertations. 4549.

https://digitalcommons.fiu.edu/etd/4549

This work is brought to you for free and open access by the University Graduate School at FIU Digital Commons. It has been accepted for inclusion in FIU Electronic Theses and Dissertations by an authorized administrator of FIU Digital Commons. For more information, please contact dcc@fiu.edu. 


\title{
FLORIDA INTERNATIONAL UNIVERSITY
}

\author{
Miami, Florida
}

\section{BACTERIAL MECHANISMS OF TOXICITY AND RESISTANCE TO ORGANOARSENICALS}

\author{
A dissertation submitted in partial fulfillment of \\ the requirements for the degree of \\ DOCTOR OF PHILOSOPHY \\ in \\ BIOMEDICAL SCIENCES \\ by \\ Luis D Garbinski
}


To: Dean Robert Sackstein

Herbert Wertheim College of Medicine

This dissertation, written by Luis D Garbinski, and entitled Bacterial Mechanisms of Toxicity and Resistance to Organoarsenicals, having been approved in respect to style and intellectual content, is referred to you for judgement.

We have read this dissertation and recommend that it be approved.

Irina Agoulnik

Jun-yong Choe

Krishnaswamy Jayachandran

Masafumi Yoshinaga, Co-Major Professor

Barry Rosen, Co-Major Professor

Date of Defense: November 11, 2020

The dissertation of Luis D Garbinski is approved.

Dean Robert Sackstein Herbert Wertheim College of Medicine

Andres G. Gil Vice president for Research and economic development And Dean of University Graduate School

Florida International University, 2020 


\section{DEDICATION}

To my mentors, my family, and my friends who made this possible. 


\section{ACKNOLWEDGMENTS}

It is difficult to properly thank the many people who have helped me put this dissertation together. Firstly, I want to recognize the efforts, patience, and genuine desire for my success of my advisors, Drs. Barry P. Rosen and Masafumi Yoshinaga. Since I first joined the Rosen lab in 2014 as an undergraduate student, they have dedicated their time and funding to nurture my interest and passion for science. Within the Rosen lab I must also thank Drs. Shashank Pawitwar and Yu Yan, who as Ph.D. students at the time, helped cement my decision to pursue my own Ph.D. and showed me how to succeed in graduate school. I would also like to thank Dr. Jian Chen, who has been a role model for experimental design, productivity, and has been my co-author on several publications.

My graduate committee, composed of my two advisors, Dr. Irina Agoulnik, Dr. Krishnaswamy Jayachandran, Dr. Yong Cai, and Dr. Jun-yong Choe, has been instrumental in guiding my research efforts, coursework planning, and ultimately helping me graduate in 4 years. The advice and help of Dr. Alexander Agoulnik and Ms. Odalys De La Rosa were also critical in helping me achieve this goal as director, and coordinator of the graduate program respectively.

Lastly, I cannot overstate the support that my parents, Mr. Luis and Mrs. Mercedes Garbinski, and my girlfriend, Ms. Anjali Tripathi have given me. The time that I was able to commit to this dissertation was mostly afforded by their efforts, making sure I am well mentally and physically. In the same vein, my closest friends Messrs. (soon to be Drs.) Abdul Rahim Ansari and Alex Sarracino have also played a major role in this regard. 


\section{ABSTRACT OF THE DISSERTATION \\ BACTERIAL MECHANISMS OF TOXICITY AND RESISTANCE TO \\ ORGANOARSENICALS}

by

Luis D Garbinski

Florida International University, 2020

Miami, Florida

Professor Barry P. Rosen, Co-Major Professor

Professor Masafumi Yoshinaga, Co-Major Professor

Arsenic is a toxic element prevalent in the environment since the origin of life on Earth. Bacteria evolved in an arsenic-rich environment, where they developed ways to both overcome arsenic toxicity and harness it to compete with other organisms. These mechanisms include chemical modifications (e.g. oxidation, methylation), degradation, and efflux. The goal of this dissertation is to better characterize these mechanisms, illuminating the arsenic biogeocycle and allowing us to harness organoarsenical toxicity for novel antibiotics. A goal of my research was to elucidate the antibiotic properties of $\operatorname{MAs}(\mathrm{III})$, which is synthesized by bacteria to thrive over other bacteria, by identifying cellular targets involved in its toxicity. I identified MurA, a key enzyme in bacterial cell wall synthesis, as a potential target. I determined that MurA is inhibited by organoarsenicals, but not by inorganic $A s(\mathrm{III})$, suggesting that these antibiotics kill bacteria by inhibiting cell wall formation. I also determined that MAs(III) inhibits MurA differently than fosfomycin, the conventional MurA-inhibitory antibiotic, highlighting the potential 
that organoarsenicals have as antibiotics. The most efficient bacterial resistance mechanism to $\mathrm{MAs}(\mathrm{III})$ is efflux from cells, catalyzed by the ArsP permease. While ArsP can transport aromatic organoarsenicals like trivalent roxarsone (Rox(III)), it transports $\mathrm{MAs}(\mathrm{III})$ most efficiently. To further characterize ArsP, I probed its substrate binding site by mutagenesis. I found that several conserved residues hypothesized to be required for transport are in fact not required for resistance to organoarsenicals. Furthermore, I determined that the higher affinity of Rox(III) for cysteine pairs does not play a role in selectivity for MAs(III). Aromatic arsenicals are widely used as growth promoters in animal husbandry and understanding their degradation to $\mathrm{As}$ (III) by soil bacteria is critical to minimizing their environmental hazards. We characterized their biotransformation by Sinorhizobium meliloti, and identified an enzyme, MdaB, that catalyzes the first step of aromatic organoarsenical degradation. Overall, we show how S. meliloti can activate benign pentavalent aromatic arsenicals into more toxic species. Characterizing enzymes and transporters involved in organoarsenical toxicity and resistance will help us design novel arsenic bioremediation strategies, as well as develop effective arsenic-based antibiotics that will contribute to human health and safety. 


\section{TABLE OF CONTENTS}

CHAPTER

PAGE

CHAPTER 1. INTRODUCTION ...............................................

1.1 Arsenic sources in the environment...................................

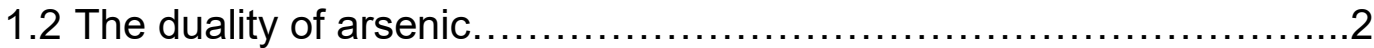

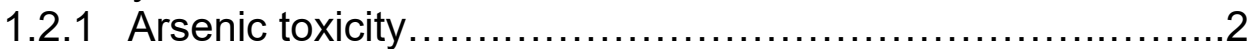

1.2.2 Arsenic as a medicine ......................................

1.3 Organoarsenicals and bacterial arsenic biotransformations..............9

1.4 Bacterial arsenic transport............................................

1.4.1 As(III) efflux systems ..................................... 13

$1.4 .2 \mathrm{As}(\mathrm{V})$ efflux systems....................................16

1.4.3 Organoarsenical transporters..............................17

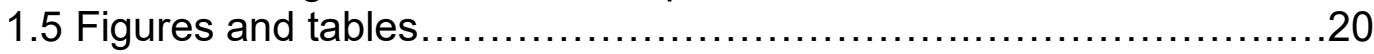

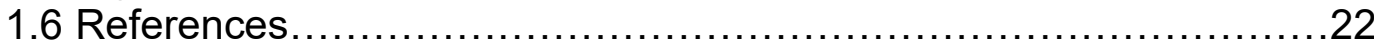

CHAPTER 2. PROBLEM STATEMENT AND OBJECTIVES........................34

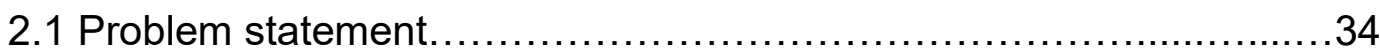

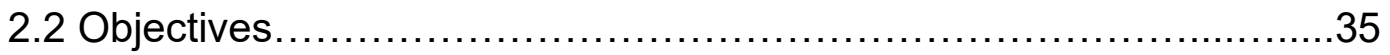

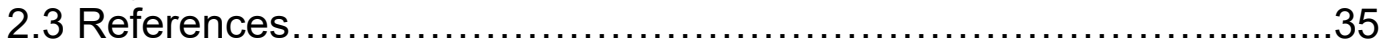

CHAPTER 3. REDUCTION OF ORGANOARSENICAL HERBICIDES AND ANTIMICROBIAL GROWTH PROMOTERS BY THE LEGUME SYMBIONT

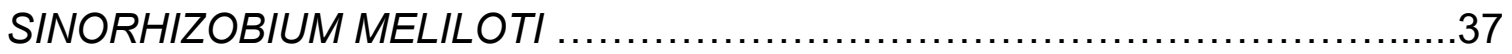

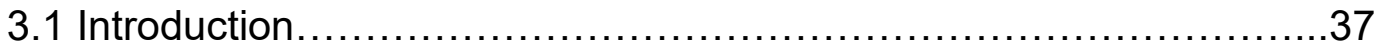

3.2 Materials and methods ............................................. 40

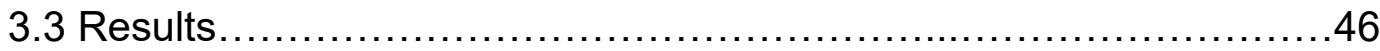

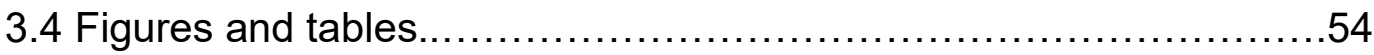

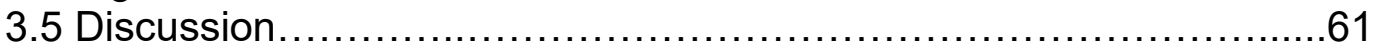

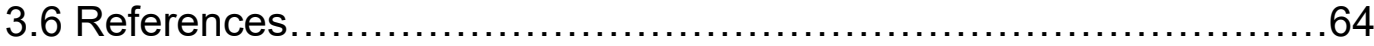

CHAPTER 4. ORGANOARSENICALS INHIBIT BACTERIAL

PEPTIDOGLYCAN BIOSYNTHESIS BY TARGETING THE ESSENTIAL

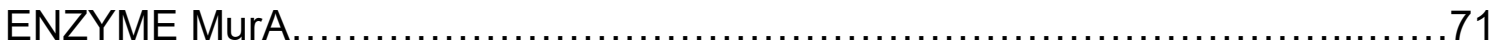

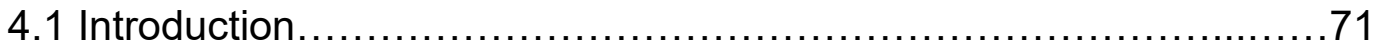

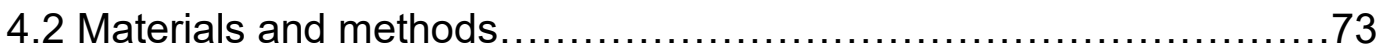

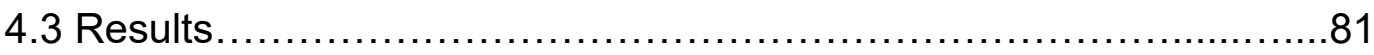

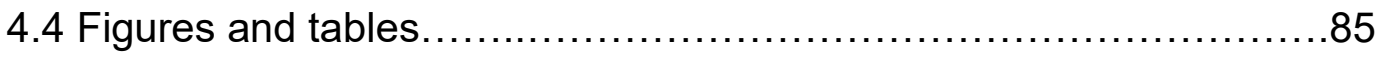

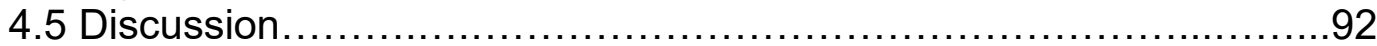

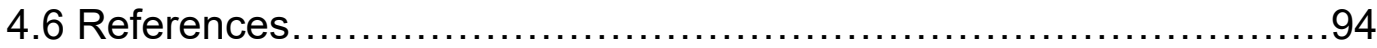

CHAPTER 5. A PRELIMINARY STUDY ON THE SUBSTRATE SELECTIVITY OF THE TRIVALENT ORGANOARSENICAL PERMEASE ArsP ..................99

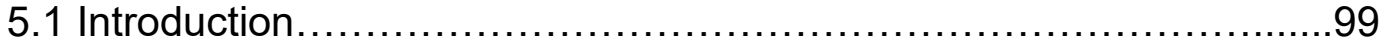




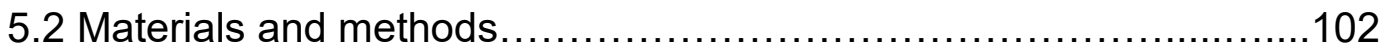

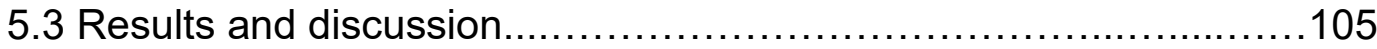

5.4 Figures and tables............................................... 108

5.5 Significance and future directions ............................... 110

5.6 References......................................................... 112

CHAPTER 6. SIGNIFICANCE AND FUTURE PROSPECTS....................117

6.1 Organoarsenic-based antibiotics .................................117

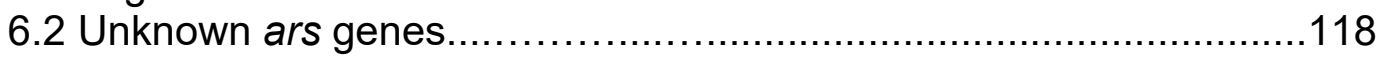

6.3 Conclusions and significance.....................................119

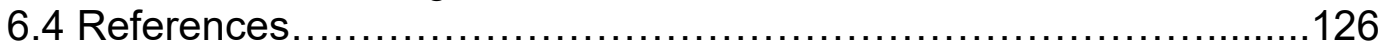

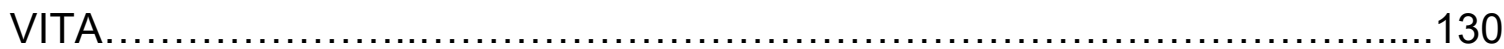




\section{LIST OF FIGURES}

FIGURE

PAGE

Figure 1. Anthropogenic sources of arsenic and their biotransformations in the environment. Metabolism of organoarsenicals in the body.

Figure 2. Oxidation of trivalent organoarsenicals.

Figure 3. Chemical structure of arsenicals.

Figure 4. Organoarsenical reduction by S. meliloti Rm1021.

55

Figure 5. Bacterial transformation of aromatic arsenicals.

Figure 6. Time-course analysis of the transformation of nitroaromatic arsenicals by $S$. meliloti Rm1021.

Figure 7. Nitroreduction of nitroaromatic arsenicals by a S. meliloti ars operon deletion strain.

Figure 8. Nitroreduction of Rox(III) by E. coli AW3110 cells expressing candidate nitroreductase genes.

Figure 9. Roxarsone nitroreductase activity of SmMdaB in vivo.

Figure 10. SmMdaB exhibits NADPH-dependent FAD reductase activity.

Figure 11. Roxarsone nitroreductase activity of SmMdaB in vitro.

Figure 12. Nitroreduction of Nit(III) by SmmdaB-expressing AW3110 cells.

Figure 13. Nitroreduction of Nit(V) in vitro.

Figure 14. Degradation of pentavalent aromatic arsenicals by an aerobic microbial community is a multistep process.

Figure 15. DNA isolated from an S. putrefaciens 200 genomic library confers MAs(III) resistance.

Figure 16. Arsenic transformation by fragment isolated from 
Figure 17. Expression of murA confers resistance to $\mathrm{MAs}(\mathrm{III})$ in vivo. 86

Figure 18. SpMurA is selectively inhibited by organoarsenicals. 86

Figure 19. MurA sequence alignment of bacterial strains. 87

Figure 20. In vivo and in vitro inhibition of wild-type and C117D 88

S. putrefaciens 200 SpMurA by fosfomycin.

Figure 21. Cys117 is not required for organoarsenical inhibition. $\quad 89$

Figure 22. NEM modification of cysteine residues in SpMurA 90 results in loss of activity.

Figure 23. In vitro inhibition of S. aureus SH1000 MurA (SaMurA) 90 by fosfomycin.

Figure 24. A MurA ortholog with a single conserved cysteine confers trivalent organoarsenical resistance.

Figure 25. MAs(III) liquid media resistance profile of E. coli AW3110 108 containing ArsP wild-type and proline mutants.

Figure 26. Rox(III) liquid media resistance profile of E. coli AW3110 109 containing ArsP and proline mutants.

Figure 27. Effect of site-directed mutagenesis on conserved serine 109 residue in predicted substrate binding site on MAs(III) resistance phenotype.

Figure 28. Effect of site-directed mutagenesis on conserved serine 110 residue in predicted substrate binding site on Rox(III) resistance phenotype. 


\section{ABBREVIATIONS AND ACRONYMS}

\begin{tabular}{ll} 
ABBREVIATION & FULL NAME \\
APL & Acute promyelocytic leukemia \\
AQP & Aquaporin \\
As(III) & Arsenite \\
As(V) & Arsenate \\
AST & Arsinothricin \\
ATO & Arsenic trioxide \\
DMAs(V) & Dimethylarsenate \\
EPA & Environmental Protection Agency \\
FDA & Food and Drug Administration \\
GAPDH & Glyceraldehyde-3-phosphate dehydrogenase \\
GOE & Great oxidation event \\
ICP-MS & Inductively coupled plasma mass spectrometry \\
HAPA(III) & 4-hydroxy-3-aminophenylarsenite \\
MAs(III) & Methylarsenite \\
MFS & Major facilitator superfamily \\
Nit(III) & Trivalent nitarsone \\
p-ASA(III) & Trivalent p-arsanilic acid \\
PI3K & Phosphoinositide 3-kinase \\
PNP & Purine nucleoside phosphorylase \\
ROS & Reactive oxygen species \\
Rox(III) & Trivalent roxarsone \\
SAM & S-adenosyl methionine \\
TRX & Thioredoxin \\
USDA & United States Department of Agriculture \\
& \\
\hline &
\end{tabular}




\section{CHAPTER 1. INTRODUCTION}

\subsection{Arsenic sources in the environment}

Arsenic is the most pervasive environmental toxin, consistently ranked by the Environmental Protection Agency (EPA) and Agency for Toxic Substances and Disease Registry (ATSDR) as the highest priority pollutant based on its occurrence and toxicity in contaminated national priority list (NPL) sites (https://www.atsdr.cdc.gov/spl/index.html). While mostly found in natural geology (Christophersen et al., 2013), arsenic is a versatile element most commonly found in four chemical forms: arsenate $(+5)$, arsenite $(+3)$, elemental arsenic (0), and arsine (-3) (Oremland and Stolz, 2003). Under oxic conditions such as in aerobic soils and surface waters, arsenic is found primarily in its pentavalent form as arsenate $(\mathrm{As}(\mathrm{V}))$. Under reducing conditions, like those inside living organisms and in flooded soils or anaerobic sediments, it is mostly found in its trivalent state as arsenite (As(III)) (Zhu et al., 2014).

Importantly, arsenic is also introduced into the environment anthropogenically (Figure 1), including synthetic organoarsenicals used as antimicrobial growth promoters in livestock and as herbicidal agents, and as alloys with other metals in various industrial processes such as semiconductor manufacturing, chemical treatment of lumber, and the production of paints and pharmaceuticals (Adachi, 1985; Razo et al., 2004; Khan et al., 2011; Christophersen et al., 2013; Matteson et al., 2014). In particular, methylated arsenicals like MSMA (monosodium salt of methylarsenate (MAs $(\mathrm{V})$ ) have long been used as herbicides. Organic arsenical herbicides were widely used when 
they were introduced in the 1950 s due to their low cost and toxicity compared to the lead arsenate compounds they replaced (Zandstra and De Kryger, 2007). MSMA was commonly applied in cotton fields, golf courses, and on turf and lawn. Roughly 1.3 million kilograms of MSMA used in the US until EPA restrictions were placed in 2014 (Chen et al., 2020a). The pentavalent aromatic arsenical roxarsone $(\operatorname{Rox}(\mathrm{V}))$, was approved by the U.S. Food and Drug Administration (FDA) in 1944 as an additive for poultry feed, where it acts as an antimicrobial and a growth promoter (Fisher et al., 2015). The USDA estimated that in $2010,88 \%$ of the approximately 9 billion chickens raised for human consumption in the US were treated with roxarsone. Furthermore, a U.S. sample of raw and cooked chickens showed that over $50 \%$ of the chicken meat analyzed contained arsenic concentrations over $10 \mu \mathrm{g}$ per $\mathrm{kg}$ (Nachman et al., 2013). It has been well established that roxarsone is not fully metabolized by poultry and accumulates in chicken litter (Jackson and Bertsch, 2001). Arsenic speciation of chicken litter samples shows that roxarsone is degraded into As(III), among other species (Rosal et al., 2005). Due to the environmental health concerns associated with roxarsone usage, the FDA withdrew its approval in the US, though it continues to be used worldwide.

\subsection{The duality of arsenic}

\subsubsection{Arsenic toxicity}

Due to its ubiquity, humans are frequently exposed to arsenic through the food chain, in drinking water supply, and by contaminated soils. Around the world, exposure to arsenic has been linked to cardiovascular disease (Wang et al., 2011; 
Chen et al., 2013), diabetes mellitus (Del Razo et al., 2011; Mendez et al., 2016), and peripheral neuropathies (Mukherjee et al., 2003). Arsenic is classified as a group 1 human carcinogen by the International Agency for Research on Cancer (IARC), and has been linked to increased risks of liver, bladder, lung, and skin cancer, among others (Chung et al., 2013; Gilbert-Diamond et al., 2013). Furthermore, infant mortality, issues with fetal development, and neurological defects have been associated with arsenic exposure. A cohort study in Bangladesh described a significant correlation between sources of drinking water above $50 \mu \mathrm{g}$ per liter (or parts per million, ppm) and fetal loss (Rahman et al., 2007). For children surviving birth in arsenic-contaminated environments, exposure is associated with lowered cognitive and motor function (Calderón et al., 2001; Parvez et al., 2011). As a response, the FDA has issued guidance limiting the concentration of arsenic to 100 parts per billion (ppb) in infant foods, and $10 \mathrm{ppb}$ in fluids like apple juice and bottled water with the intent to lower the risk of these outcomes. The FDA also regularly tests various at-risk products such as infant rice cereals to ensure these limits are enforced (https://www.fda.gov/food/metals-andyour-food/arsenic-food-and-dietary-supplements). Arsenic toxicity is also variable depending on its chemical form. In general (with few exceptions) trivalent organoarsenicals are the most toxic, followed by $\mathrm{As}(\mathrm{III})$, and the least toxic being pentavalent arsenicals and organoarsenicals (Petrick et al., 2000).

Arsenic poisoning can be acute or chronic, with the latter being more pervasive (Ratnaike, 2003). Acute arsenic exposure is most commonly caused by accidental ingestion of arsenic-containing pesticides or herbicides. Arsenic is also 
a potent agent used in poisons, and it is dubbed "the king of poisons" and "poison of kings." The primary arsenic species historically used for poisoning is arsenic trioxide $\left(\mathrm{As}_{2} \mathrm{O}_{3}\right)$, as it is colorless, odorless, and readily water-soluble. (Parascandola, 2012). These poisons were popular among European nobility around the fifteenth century, generally used for political or financial gain. Acute arsenic toxicity is characterized by nausea, vomiting, and diarrhea (Ratnaike, 2003) and mortality is generally attributed to severe fluid loss due to increased blood vessel permeability, renal failure, and pulmonary edema. The lethal dose for this type of exposure is between 100 and $300 \mathrm{mg}$, though certain clinical cases with many-fold higher doses reported temporary survival (Logemann et al., 1990; Ghariani et al., 1991). Interestingly, acute arsenic poisoning by external use, in contrast to ingestion, has also been reported (Zheng et al., 2019). Absorption of ingested trivalent arsenic generally occurs in the GI tract, where aquaporins mediate uptake from the lumen into epithelial cells (AQP7/10), and subsequently transported into the bloodstream (AQP3) (Roggenbeck et al., 2016). It is unclear whether at this step, the microbiome protects against arsenic toxicity or exacerbates it. Recent reports have shown that arsenic species found in seafood are more readily taken up and metabolized to more toxic intermediates in the presence of the microbiota (Calatayud et al., 2018), while other studies show that germ-free mice accumulate arsenic in tissues more readily after acute exposure, and identify members of the microbiota that can rescue the sensitive phenotype (Coryell et al., 2018). 
Due to its affinity for dithiol groups (Shen et al., 2013), several molecular targets and pathways are inhibited by trivalent arsenic. Particularly, mitochondrial redox proteins involved in apoptotic signaling and oxidative stress protection are suggested to be targets of trivalent arsenicals (Ralph, 2008). Mitochondrial thioredoxins (TRXs) 1 and 2 contain vicinal thiol groups which bind the proapoptotic protein ASK1, inactivating it. In the presence of tumor necrosis factor (TNF) mitochondrial production of reactive oxygen species (ROS) is increased, leading to oxidation of TRX1 and TRX2, which in turn activates ASK1 and initiates apoptosis (Zhang et al., 2004). Trivalent arsenicals, especially MAs(III), bind with very high affinity to TRX1/2 and TRX reductase, which also has a dithiol group (Hansen et al., 2006), suggesting that ROS-mediated oxidative stress takes place and can induce apoptosis similarly to TNF. Another mitochondrial apoptotic pathway affected by trivalent arsenicals involves the voltage dependent anion channel (VDAC) and the adenine nucleotide transporter (ANT) which together form part of the mitochondrial permeability transition pore (MPTP) (Marzo et al., 1998). Both of these proteins contain cysteine residues, and the redox state of thiol groups has been linked to activation of mitochondrial permeability transition (Costantini et al., 1996; Costantini et al., 2000). Furthermore, thiol-reactive compounds like phenylarsine oxide (PAO), which has the highest affinity for arsenic-binding enzymes of known trivalent species (Pawitwar et al., 2017), have been shown to affect mitochondrial permeability by cross-linking two cysteines which lock ANT in its open conformation (McStay et al., 2002), facilitating mitochondrial apoptosis. 
While arsenic-driven ROS production in mitochondria has also been linked to carcinogenesis (Huang et al., 2004), other oncogenic pathways can be altered by chronic arsenic exposure. The phosphoinositide 3-kinase (PI3K)/protein kinase B (AKT)/mammalian target of rapamycin (mTOR) pathway is a key pathway involved in regulation of physiological processes such as cell proliferation, metabolism and growth (Martini et al., 2014). Unsurprisingly, dysregulation of this pathway is strongly linked to several hallmarks of cancer (Fruman et al., 2017). As(III) has been shown to stimulate upstream genes such as the epidermal growth factor receptor (EGFR) by inducing the assembly of EFGR-Shc-Grb2 complexes, resulting in phosphorylation of EGFR. (Chen et al., 1998; Tanaka - Kagawa et al., 2003), While EGFR had been hypothesized to activate PI3K-AKT signaling by interactions with the p85 regulatory subunit of PI3K, the effectors in the signaling cascade were not well understood (Wen et al., 2010; Carpenter and Jiang, 2013). Recently, EGFR was shown to activate the PI3K pathway by acetylation, and subsequent phosphorylation of the platelet isoform of phosphofructokinase 1 (PFKP) (Lee et al., 2018). Phosphorylated PFKP directly interacts with the regulatory subunit $\mathrm{p} 85$ of $\mathrm{PI} 3 \mathrm{~K}$, recruiting it to the plasma membrane and thus activating PI3K. This activation was shown to promote tumor cell proliferation and brain tumorigenesis. Interestingly, organoarsenicals such as roxarsone can also activate the PI3K/Akt pathway in mice, and that it acts a driver of angiogenesis, explaining its activity as a growth promoter (Wang et al., 2016). 
Arsenate $(\operatorname{As}(\mathrm{V}))$ is significantly less toxic than $\mathrm{As}(\mathrm{III})$; however, it is the most environmentally ubiquitous species of the two. $\mathrm{As}(\mathrm{V})$ is chemically similar to phosphate, thus it can hijack many cellular processes which utilize phosphate. One of the best characterized mechanisms of $A s(V)$ toxicity is impairment of energy metabolism. Early studies hypothesized that in mitochondria, $\mathrm{As}(\mathrm{V})$ is incorporated into ADP-arsenate, which acts as a substrate of with glycolytic enzymes such as hexokinase and glyceraldehyde 3-phosphate dehydrogenase (GAPDH), forming glucose 6-arsenate and 1-arseno-3-phosphoglycerate. These arsenate-based sugars are unstable and hydrolyze rapidly, potentially explaining how $\mathrm{As}(\mathrm{V})$ depletes cellular ATP (Byers et al., 1979; Gresser, 1981). Interestingly, GAPDH acts as an arsenate reductase in the presence of glutathione (GSH) and its canonical substrate, glyceraldehyde-3-phosphate (G3P) (Gregus and Németi, 2005), and has been described as part of a novel arsenate resistance mechanism in bacteria when coupled to the transporter ArsJ (Chen et al., 2016).

\subsubsection{Arsenic as a medicine}

Throughout history, arsenic has also been used as a medicine. From ancient Greeks using pastes made from natural arsenic-containing minerals such as realgar $\left(\mathrm{As}_{4} \mathrm{~S}_{4}\right)$ and orpiment $\left(\mathrm{As}_{2} \mathrm{~S}_{3}\right)$ to treat ulcers (Healy, 1981), to the advent of modern medicine with Paul Ehrlich's "magic bullet" Salvarsan as a miraculous cure to syphilis (Lloyd et al., 2005), arsenic-based drugs continue to be used today as first-line therapies for several diseases. An example is arsenic trioxide, or ATO, which when administered in combination with all-trans retinoic acid (ATRA) safely treats acute promyelocytic leukemia (APL) (Kozono et al., 2018). In this 
combination therapy, ATO degrades the peptidyl-prolyl isomerase Pin1, which has been characterized as a cell-cycle protein and involved in the regulation of several oncogenes. ATRA upregulates aquaporin-9 (AQP9), which increases the cellular uptake of ATO, enhancing its effects. Another possible explanation for the dual modality of arsenic is that in comparison to normal cells, cancer cells are already in a hyperproliferative state where the AKT/mTOR pathway is stimulated; thus, ROS production by arsenic toxicity decreases phosphorylation of AKT and promotes apoptosis. This has been demonstrated in osteosarcoma (Wang et al., 2017), human gastric cancer cells (Gao et al., 2014), and in leukemia cells (Estañ et al., 2012). The extent of this effect is highly dependent on arsenic species and concentration (Wang et al., 2016). In fact, it has been suggested that the true prodrug when administering ATO to treat APL is MAs(III), as ATO is likely rapidly methylated by AS3MT and redistributed in the bloodstream (Maimaitiyiming et al., 2020). Lastly, as seen with Salvarsan, arsenic-based drugs have great potential as antimicrobial agents. Recently, our lab found that a newly discovered organoarsenical compound, arsinothricin (Kuramata et al., 2016), is able to inhibit the growth of several antibiotic-resistant pathogens (Nadar et al., 2019), by a novel mechanism of action which will be discussed later. In contrast to the body of data on molecular mechanisms of arsenic toxicity in mammalian cells, no bacteriaspecific target for arsenic antibiotics produced in the environment such as MAs(III) has been described so far. 


\subsection{Organoarsenicals and bacterial arsenic biotransformations}

Since life first appeared on Earth it has been exposed to substantial concentrations of inorganic arsenic, which over time, provided selective pressure for the evolution of arsenic resistance pathways, and gave an opportunity for members of microbial communities to harness its toxicity for their own competitive advantage (Zhu et al., 2014; Chen et al., 2019a). Genes involved in bacterial arsenic metabolism are generally found in ars operons (Table 1) (Silver et al., 1981), and over the last decades, microbial arsenic transformations such as redox cycling, methylation, thiolation, and incorporation into complex organic molecules like arsenosugars and arsenolipids have been identified (Zhu et al., 2017). Prior to the Great Oxidation Event (GOE) roughly 2.4 billion years ago, bacteria had to detoxify mainly As(III), through either the As(III)-specific efflux pump Acr3, or the As(III) S-adenosylmethionine methyltransferase (SAM) ArsM, where As(III) would undergo three methylation cycles and become trimethylarsine (TMAs(III)), which is a non-toxic gas (Qin et al., 2006; Fu et al., 2009; Chen et al., 2020b). Later, bacteria evolved ArsP, an efflux pump that selectively transports the singlemethylated intermediate product of ArsM, methylarsenite (MAs(III)) (Chen et al., 2015b). Recently, bacteria have been shown to gain a competitive advantage in microbial communities when expressing both ArsM and ArsP, suggesting that MAs(III) acted a primordial antibiotic (Chen et al., 2019a). Following the GOE, As(III) in the environment would mostly be oxidized to $\mathrm{As}(\mathrm{V})$, reducing its toxicity.

Similarly, MAs(III) produced in bacterial communities would be oxidized to $\mathrm{MAs}(\mathrm{V})$, a relatively benign organoarsenical. To regain their competitive advantage, 
bacteria evolved yet-to-be identified $\mathrm{MAs}(\mathrm{V})$ reductases which could "re-activate" the antimicrobial activity of MAs(III) that was oxidized (Yoshinaga et al., 2011). As a countermeasure, MAs(III)-sensitive bacteria evolved various mechanisms to detoxify MAs(III) such as oxidases (Chen et al., 2015a) and C-As bond lyases (Yoshinaga and Rosen, 2014), as well as acquiring ars $P$ via horizontal gene transfer.

In the last century, synthetic aromatic arsenic compounds such as roxarsone $(\operatorname{Rox}(\mathrm{V}))$, nitarsone $(\operatorname{Nit}(\mathrm{V})), p$-arsanilic acid $(p-\mathrm{ASA}(\mathrm{V}))$ and others, were used as growth promoters and antimicrobial drugs in animal husbandry. Interestingly, MAs(III) detoxifying enzymes thought to evolve over billions of years also detoxify these new organoarsenicals. In fact, species such as Sinorhizobium meliloti reduce aromatic arsenicals to trivalent forms to activate their antibiotic properties (Yan et al., 2019), whereas other bacteria such as Burkholderia sp. MR1 and Pseudomonas putida KT2440 which are able to reduce $\mathrm{MAs}(\mathrm{V})$ to $\mathrm{MAs}(\mathrm{III})$ (Yoshinaga et al., 2011), cannot reduce aromatic arsenicals. Recently, a threegene cluster (arsEFG) from Shewanella putrefaciens 200 conferring resistance to trivalent aromatic arsenicals was identified (Chen et al., 2019b). Every gene was required for resistance to Rox(III), and cells expressing this cluster were observed to reduce the nitro group of Rox(III). This reduction is likely catalyzed by both ArsE and ArsF, though the exact mechanism of reduction is not yet known. Neither of these proteins are related to the well-studied families of $N A D(P) H$-dependent nitroreductases, and it is likely that they belong to a new class of nitroreductases. However, as suggested by Yan et al, if reduction of the nitro group of aromatic 
arsenicals activates their antimicrobial properties, how could this cluster confer resistance? An explanation may be that the third gene, ars $G$, encodes a membrane protein that reduces intracellular accumulation of the products of ArsE and ArsF. This transporter will be discussed in more detail later (Chen et al., 2019b). Interestingly, a nitroreductase from Pseudomonas putida has recently been shown to confer resistance to trivalent aromatic arsenicals when expressed in arsenic-hypersensitive E. coli (Chen and Rosen, 2020). This brings to question whether nitroreductases can both play a part in aromatic organoarsenical detoxification pathways, as well as activating their antibiotic properties.

In marine environments, arsenic-containing ribosides, also known as arsenosugars are synthesized by coupling As(III) methylation to the addition of a deoxyribose moiety by the radical SAM protein ArsS was identified in cyanobacteria (Xue et al., 2018). As arsenosugars are nontoxic to marine plants or animals, this process is considered a detoxification mechanism. Similarly, arsenic can be incorporated into lipid-soluble long aliphatic chains such as hydrocarbons, fatty acids, and phospholipids, generally termed arsenolipids. Though several species of arsenolipids have been identified (Chen et al., 2020a), and arsenosugar-containing phospholipids have been observed in certain alga (suggesting a linked metabolic pathway between arsenosugar and arsenolipid production), their biosynthetic pathway remains unclear. While arsenosugars and arsenolipids are nontoxic to marine life, degradation of these compounds to inorganic As has been reported in marine bacteria (Foster and Maher, 2010). Furthermore, the primary metabolite of microbiome-mediated degradation of these 
compounds is dimethylated arsenic (DMAs) (Figure 1) (Francesconi et al., 2002), which can be thiolated to dimethyl monothiol arsenate (DMMTAs $(V))$, shown to be highly toxic in human cell cultures (Naranmandura et al., 2009).

Recently, a novel arsenic-containing glutamate analog was isolated from the rice rhizosphere bacterium Burkholderia gladioli GSRB05 (Kuramata et al., 2016). This compound, named arsinothricin (AST), is an arsenic analog of the phosphonate compound phosphinothricin (PT) which has herbicidal and bactericidal properties (Hoerlein, 1994). AST acts as a glutamine synthetase inhibitor because it mimics the $\mathrm{Y}$-phosphoglutamate transition state intermediate, and has higher antibiotic properties compared to PT, and even to As(III), which is unusual for pentavalent organoarsenicals (Nadar et al., 2019). In addition, arsN1, a gene present in many ars operons encodes an $\mathrm{N}$-acetyltransferase that confers resistance to AST, and is selective for AST over PT. This recent finding demonstrates that there are likely many yet-to-be discovered arsenic-based antibiotics which could be harnessed to combat the rising threats of antimicrobial resistance.

\subsection{Bacterial arsenic transport}

Bacteria evolved efflux pumps and transporters that confer resistance to toxic compounds ( $\mathrm{Li}$ et al., 2015). Having been exposed to arsenic, a toxic, nonessential element since the dawn of life, bacteria have evolved efflux transporters with varying substrate selectivity/specificity (Garbinski et al., 2019). Nearly every ars operon contains a gene encoding for either or both known inorganic As transporters, the As(III)-specific antiporter Acr3, which is widely distributed among 
bacteria, plants, and fungi (Fu et al., 2009), and the $\mathrm{As}(\mathrm{III}) / \mathrm{Sb}$ (III) antiporter ArsB (Rosen, 1990; Fu et al., 2009; Zhu et al., 2014; Chen et al., 2020b). Biosynthesis of MAs(III) in microbial communities also applied evolutionary pressure for bacteria to evolve efflux mechanisms selective for this organoarsenical antibiotic. The first organoarsenical transporter in bacteria to be identified and characterized was ArsP (Shen et al., 2014; Chen et al., 2015b). ArsP catalyzes extrusion of MAs(III), providing resistance to the producer strain of this ancient antibiotic. Recently three other organoarsenical efflux permeases have been identified. First, ArsK is a permease for both MAs(III) and As(III) (Shi et al., 2018). Second, ArsJ is an efflux transporter for the unstable organoarsenical 1-arseno-3-phosphoglycerate (1As3PGA), which is produced by the enzyme glyceraldehyde 3-phosphate dehydrogenase (GAPDH), a novel As(V) resistance pathway (Chen et al., 2016). The third is ArsG, a 3-amino-4-hydroxybenzene arsonic acid (HAPA)/p-arsanilic $(p-A S A)$ efflux permease that is part of a $\operatorname{Rox}(\mathrm{III}) / \mathrm{Nit}(\mathrm{V})$ detoxification pathway (Chen et al., 2019b).

\subsubsection{As(III) efflux systems}

The arsB gene, which encodes the ArsB efflux transporter, was among the first identified bacterial arsenic resistance genes (Tisa and Rosen, 1990). Originally isolated from the E. coli R-factor R773, which showed reduced intracellular accumulation of As(III) (Rosen and Borbolla, 1984), ArsB is the membrane spanning subunit of the ArsAB ATPase, which transports As(III) and

$\mathrm{Sb}$ (III) (Rosen et al., 1999). ArsB belongs to the ion transporter superfamily (Achour et al., 2007), though predictions of its membrane topology and early 
studies suggest that it has 12 membrane spanning domains (Wu et al., 1992; Garbinski et al., 2019) raising the possibility that it belongs to the major facilitator superfamily (MFS) of transporters. ArsB is unique among arsenic transporters in two ways: it has two distinct mechanisms of transport depending whether or not it is coupled to the ArsA ATPase. The As(III) binding site in ArsB has not been identified. It has no required cysteine residues, which frequently form As(III) binding sites (Chen et al., 1996). By itself, ArsB is an antiporter which utilizes the proton motive force to exchange protons for $\mathrm{As}(\mathrm{III}) / \mathrm{Sb}$ (III) (Meng et al., 2004). Furthermore, when everted vesicles expressing ArsB are exposed to both As(III) and $\mathrm{Sb}(\mathrm{III}), \mathrm{As}(\mathrm{III})$ inhibits $\mathrm{Sb}(\mathrm{III})$ uptake while $\mathrm{Sb}(\mathrm{III})$ stimulates $\mathrm{As}(\mathrm{III})$ uptake (Meng et al., 2004); a paradoxical finding which suggests trihydroxides are not the substrates of ArsB. Instead, it is possible these substrates polymerize like their phosphate analogs, which has been observed for As(III) (Hampson and Stosick, 1938), and are transported by ArsB as polymeric species. When the ArsA ATPase is present, $A r s A B$ acts as an ATP-driven $A s(I I I) / S b(I I I)$ efflux pump, greatly increasing the rate of transport and resistance in E. coli (Dey and Rosen, 1995). The ArsA metal-binding sites is comprised of three conserved cysteines (Cys422, Cys113, and Cys172), that on substrate binding induce a conformational change which brings two nucleotide-binding domains (NBD) close enough together to catalyze ATP hydrolysis (Zhou et al., 2000). Individual cysteine-to-serine mutations of these residues yielded lower affinities for $\mathrm{Sb}$ (III) and $\mathrm{As}$ (III) compared to the wild-type, suggesting that each residue is involved in catalysis (Bhattacharjee et al., 1995). 
Acr3 is the most ancient known As efflux transporter having evolved well before the GOE, presumably as one of the first As(III) resistance mechanisms (Chen et al., 2020b). While ArsB and Acr3 are both efflux systems for As(III), they have key functional and structural differences. Acr3 is smaller than ArsB ( 357 residues vs. $\sim 429$ of ArsB), and belongs to the bile/arsenite/riboflavin transporter (BART) superfamily, which consists of bile salt and anion transporters, as well as sensory proteins such as kinases (Mansour et al., 2007). As(III) is transported out of cells by Acr3 as an As(III)/ $/ \mathrm{H}^{+}$antiporter (Villadangos et al., 2012). Heterologous expression of Acr3 from Corynebacterium glutamicum (CgAcr3) in Escherichia coli confers As(III) resistance, while E. coli cells expressing CgAcr3 with the highly conserved Cys 138 mutated to serine or alanine are sensitive to As(III), suggesting that Cys138 is essential for CgAcr3 to be functional (Fu et al., 2009). Everted vesicles prepared from E. coli cells expressing wild-type CgAcr3 accumulate As(III), whereas those of C138S/A mutant cells accumulate no As(III), which further supports the critical role of Cys 138 for $\mathrm{CgAcr} 3$. Members of the BART superfamily are predicted to either have ten membrane-spanning segments, or two subunits of five membrane-spanning segments (Mansour et al., 2007). The topology of CgAcr3 is congruent with these predictions, and has been shown to have ten membrane-spanning segments (Fu et al., 2009). In addition, many arsenic-binding proteins, including efflux transporters, can also bind antimonite $(\mathrm{Sb}(\mathrm{III}))$ (Rosen, 1990; Wu and Rosen, 1991); however, Acr3 is As(III)-specific, and cannot transport nor confer resistance to $\mathrm{Sb}(\mathrm{III})$. There are conflicting reports on $\mathrm{Sb}$ (III) accumulation and resistance in Acr3 homologs found outside of bacteria, such as 
the Saccharomyces cerevisiae ACR3 (Ghosh et al., 1999; MaciaszczykDziubinska et al., 2011). Interestingly, the yeast ACR3 has 9 cysteines compared to the 3 of bacterial Acr3 proteins like that of $A$. metalliredigens (Fu et al., 2009).

\subsubsection{As(V) efflux systems}

With the exception of AST and thiolated species, pentavalent arsenicals are significantly less toxic than their trivalent counterparts. However, arsenate (As(V)) is a mimetic of phosphate, and can be taken up by bacterial phosphate transporters adventitiously (Garbinski et al., 2019). With As(V) being the most environmentally prevalent species of arsenic especially in the oxic environment (Zhu et al., 2014), it is likely that bacteria encounter toxic concentrations of it frequently. A pair of genes always found together in ars operons, ars $J$ and gapdh, encoding a major facilitator superfamily (MFS) protein and Glyceraldehyde 3phosphate dehydrogenase, respectively, were isolated from Pseudomonas aeruginosa DK2 and characterized (Chen et al., 2016). Both genes are required tp confer $E$. coli $\mathrm{As}(\mathrm{V})$ resistance. ArsJ-mediated $\mathrm{As}(\mathrm{V})$ uptake into everted vesicles was found to be energized by the proton motive force, and required GAPDH, $\mathrm{NAD}^{+}$, and 1,3-biphosphoglycerate (G3P), the substrate for the GAPDH reaction. GAPDH normally catalyzes the conversion of G3P and $\mathrm{NAD}^{+}$to $1,3-$ bisphosphoglycerate (1,3-BPG) and $\mathrm{NADH}$, but in the presence of $\mathrm{As}(\mathrm{V})$ it can form the highly unstable organoarsenical 1-arseno-3-phosphoglycerate (1As3PGA) (Byers et al., 1979). Because the transport reaction requires both GAPDH and NAD+ (Chen et al., 2016), it is likely that 1As3PGA is the physiological substrate of ArsJ. This is an unusual example of how bacteria adapt existing 
proteins to fit physiological needs, as evolving a direct $\mathrm{As}(\mathrm{V})$ transporter would likely deplete bacterial cells of necessary phosphate. This is the only identified As(V)-specific efflux mechanism.

\subsubsection{Organoarsenical transporters}

While Acr3 and ArsB are the primary efflux systems for As(III), they do not transport organoarsenicals. In addition to ArsJ, there are several more known organoarsenical efflux permeases - ArsP, ArsK and ArsG. The arsP gene was first identified from poultry isolates of the food-borne pathogen Campylobacter jejuni (Wang et al., 2009). Initially, it was described as encoding a roxarsone/nitarsone resistance mechanism (Shen et al., 2014), as these organoarsenicals were commonly used as antimicrobials and growth promoters in the poultry industry. However, further studies demonstrated that the physiological substrates of ArsP are not pentavalent organoarsenicals but trivalent forms and the true substrate of ArsP is likely to be MAs(III), as the transport efficiency and resistance conferred by ArsP to MAs(III) was significantly greater than to trivalent roxarsone/nitarsone (Chen et al., 2015b). Furthermore, two conserved cysteine residues (Cys65 and Cys67) were identified as the putative arsenic-binding site, as mutating these residues to serine ablated transport and resistance while retaining expression. ArsP is hypothesized to belong to the major facilitator superfamily (MFS) of transporters (Garbinski et al., 2019); however, this is a topic of debate as transmembrane topology prediction algorithms predict that ArsP only has eight membrane-spanning helices, compared to the usual twelve of MFS transporters. ArsP is hypothesized to transport organoarsenicals in a two-step 
mechanism, with the first step being an inward-facing conformation where the conserved cysteines are close enough for arsenic binding, followed by an outwardfacing conformation where the cysteines separate, and substrate is carried out of the cell (Chen et al., 2015b). This hypothesis also predicts that bulkier organoarsenical compounds like roxarsone and nitarsone are transported with lower efficiency due to steric hindrance of the substrate binding site. Further studies are required to comprehensively elucidate the transport mechanism of ArsP.

Recently, ArsK, an organoarsenical transporter with wider substrate specificity, was identified in the soil bacterium Agrobacterium tumefaciens GW4 (Shi et al., 2018). This permease transports both trivalent inorganic and organic arsenicals, as well as inorganic antimony, out of cells. Phylogenetic analysis suggest that ArsK is an MFS transporter but is classified in a new subgroup in the family of MFS transporters (Garbinski et al., 2019). ArsK is found in ars operons that encode resistance mechanisms to both inorganic and organic arsenicals (Shi et al., 2018). In contrast to ArsP, ArsK is observed to transport trivalent aromatic arsenicals such as Rox(III) with higher efficiency than MAs(III), suggesting that there are yet-to-be discovered aromatic arsenic natural products which may be its primary substrate. There are conserved cysteine residues found in ArsK (Cys97 and Cys182); however, it remains unclear whether they play a role in transport.

Aromatic arsenical compounds like roxarsone, nitarsone, and $p$-arsanilic acid ( $p$-ASA) are synthetic organic compounds used only since the last century, so it is unlikely that bacteria had time to evolve specific resistance genes but more 
likely adapted existing genes. As mentioned above, recently a three gene cluster, arsEFG, of unknown function, was identified in the versatile arsenic-metabolizing soil bacterium Shewanella putrefaciens 200 (Chen et al., 2019b). These three genes, encode a two-step pathway for resistance to trivalent nitroaromatic arsenicals: 1) reduction of the nitro $\left(\mathrm{NO}_{2}\right)$ group to an amino $\left(\mathrm{NH}_{2}\right)$ group, and 2) efflux of the trivalent product. ArsG was identified as a permease that transports the final product out of the cell. Interestingly, ArsG is specific for trivalent HAPA(III) over Rox(III), suggesting that the ArsG substrate-binding site is not solely dependent on soft metal thiol chemistry. Further studies are necessary to confirm the efflux mechanism of ArsG, as no residues critical for transport have been identified yet. The existence of this aromatic arsenical-specific detoxification mechanisms suggests that: 1) bacteria are able to acquire resistance to environmentally prevalent toxins much quickly than previously thought, or 2) there are natural, yet-to-be discovered aromatic arsenical compounds that are synthesized in microbial communities which are the true substrates of ArsEFG. 


\subsection{Figures and tables}

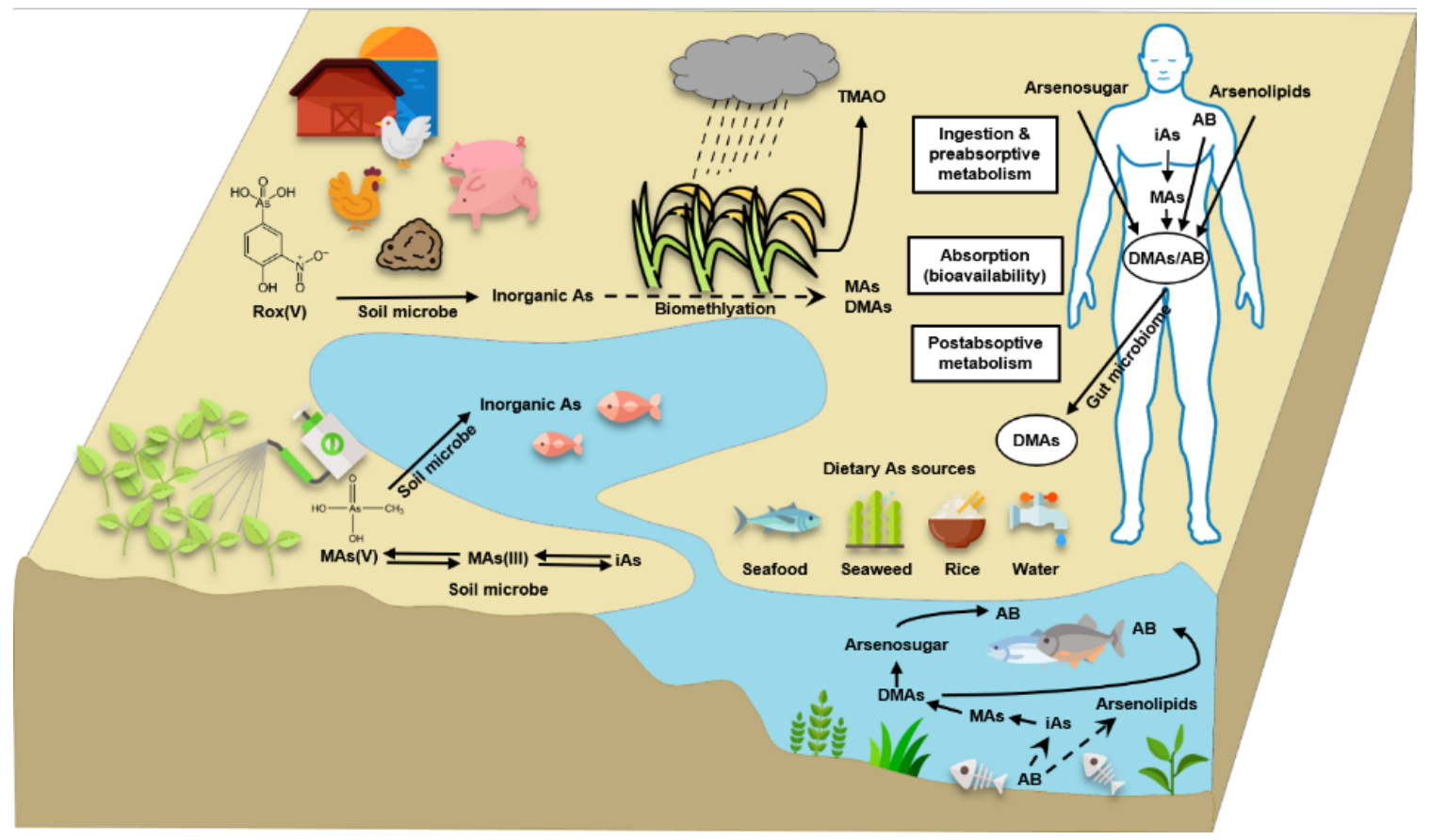

Figure 1: Anthropogenic sources of arsenic and their biotransformations in the environment. Metabolism of organoarsenicals in the body. 
Table 1. List of ars genes, the proteins they encode, and their functions.

\begin{tabular}{|c|c|c|c|}
\hline Gene & Protein & Function & Reference \\
\hline $\operatorname{ars} A$ & $\begin{array}{l}\text { Catalytic subunit of ArsAB As(III) } \\
\text { ABC transporter }\end{array}$ & Energize As(III) efflux by ATP hydrolysis & (Rosen, B.P., et al. 1999) \\
\hline $\operatorname{ars} B$ & $\begin{array}{c}\text { Membrane subunit of the } \operatorname{Ars} A B \\
A B C \text { transporter, } \mathrm{H}^{+} / \mathrm{As}(\mathrm{III}) / \mathrm{Sb}(\mathrm{III}) \\
\text { antiporter }\end{array}$ & Efflux of $\mathrm{Sb}(\mathrm{III}) / \mathrm{As}(\mathrm{III})$ & (Kuroda, M., et al. 1997) \\
\hline $\operatorname{arsC}$ & Grx/Trx-dependent As(V) reductase & $\begin{array}{c}\text { Detoxify } \mathrm{As}(\mathrm{V}) \text { by reduction to } \mathrm{As}(\mathrm{III}) \text { followed } \\
\text { by efflux }\end{array}$ & (Martin, P., et al. 2001) \\
\hline $\operatorname{ars} D$ & $\mathrm{As}(\mathrm{III}) / \mathrm{Sb}$ (III) metallochaperone & Transfer $\mathrm{As}(\mathrm{III}) / \mathrm{Sb}$ (III) to ArsA for efflux & (Lin, Y-F., et al. 2006) \\
\hline $\operatorname{ars} E$ & $\begin{array}{l}\text { Trx-like Nit(III)/Rox(III) } \\
\text { nitroreductase }\end{array}$ & $\begin{array}{l}\text { Nitroreduction of Rox(III) and Nit(III) to } \\
\text { HAPA(III) and } p \text {-ASA(III), respectively }\end{array}$ & (Chen, J., et al., 2019) \\
\hline $\operatorname{arsF}$ & $\begin{array}{l}\text { Trx-like Nit(III)/Rox(III) } \\
\text { nitroreductase }\end{array}$ & $\begin{array}{l}\text { Nitroreduction of Rox(III) and Nit(III) to } \\
\text { HAPA(III) and } p \text {-ASA(III), respectively }\end{array}$ & (Chen, J., et al., 2019) \\
\hline $\operatorname{ars} G$ & LysE superfamily transporter & $p$-ASA(III)/HAPA(III) efflux & (Chen, J., et al., 2019) \\
\hline arsH & $\begin{array}{l}\text { NADPH-dependent FMN } \\
\text { oxidoreductase }\end{array}$ & $\begin{array}{l}\text { Detoxify trivalent organoarsenicals by } \\
\text { oxidation to pentavalent state }\end{array}$ & (Chen, J., et al., 2015) \\
\hline arsl & $\begin{array}{l}\text { Nonheme iron-dependent } \\
\text { dioxygenase }\end{array}$ & $\begin{array}{l}\text { Detoxification of trivalent organoarsenicals by } \\
\text { C-As bond cleavage }\end{array}$ & $\begin{array}{c}\text { (Yoshinaga, M. and Rosen, } \\
\text { B.P., 2014) }\end{array}$ \\
\hline arsJ & MFS transporter & $\begin{array}{l}\text { Efflux of 1As3PGA product of GAPDH as part of } \\
\text { As(V) resistance pathway }\end{array}$ & (Chen, J., et al., 2016) \\
\hline arsk & MFS transporter & Efflux of $\operatorname{As}(I I I), S b(I I I), \operatorname{Rox}(I I I)$, and $\operatorname{MAs}(I I I)$ & (Shi, K., et al., 2018) \\
\hline $\operatorname{arsL}$ & Radical SAM protein & Synthesis of the glutamate analog AST & Not yet published \\
\hline $\operatorname{ars} M$ & As(III)-S-adenosylmethyltransferase & $\begin{array}{l}\text { Detoxification of As(III) by three rounds of } \\
\text { methylation to gaseous TMA(III) }\end{array}$ & (Qin, J., et al., 2006) \\
\hline $\operatorname{ars} N$ & AST-selective $N$-acetyltransferase & $\begin{array}{l}\text { Confers resistance to AST by acetylation of } \alpha \text { - } \\
\text { amino group }\end{array}$ & (Nadar, V.S., et al., 2019) \\
\hline $\operatorname{arsO}$ & $\begin{array}{c}\text { Putative } \\
\text { oxidoreductase/monooxygenase }\end{array}$ & Function unknown & $\begin{array}{l}\text { (Maizel, D., et al., 2016) } \\
\text { (Wang, L., et al., 2006) }\end{array}$ \\
\hline $\operatorname{ars} P$ & MAs(III)-selective efflux permease & $\begin{array}{c}\text { Detoxifies trivalent aliphatic and aromatic } \\
\text { organoarsenicals by efflux }\end{array}$ & (Chen, J., et al., 2015) \\
\hline $\operatorname{ars} Q$ & Putative MFS transporter & Function unknown & (Chauhan, N.S., et al., 2009) \\
\hline $\operatorname{ars} R$ & ArsR/SmtB metalloregulator & Transcriptional repressor of ars operons & (Wu, J. and Rosen, B.P., 1993) \\
\hline $\operatorname{arss}$ & Radical SAM protein & $\begin{array}{l}\text { Transfer of a deoxyadenosyl group from SAM } \\
\text { to DMAs for arsenosugar biosynthesis }\end{array}$ & (Xue, X-M., et al., 2019) \\
\hline $\operatorname{arsT}$ & Putative thioredoxin reductase & Function unknown & (Achour, A., et al., 2010) \\
\hline $\operatorname{ars} U$ & $\begin{array}{l}\text { Putative arsenic resistance } \\
\text { mechanism }\end{array}$ & Function unknown & (Zhang, X., et al., 2016) \\
\hline $\operatorname{ars} X$ & Putative thioredoxin & Function unknown & (Achour, A., et al., 2010) \\
\hline $\operatorname{ars} Y$ & $\mathrm{H}^{+} / \mathrm{As}(\mathrm{III})$ antiporter $(\mathrm{Acr} 3)$ & Detoxify As(III) by gradient-dependent efflux & (Yang, Y., et al., 2015) \\
\hline
\end{tabular}




\subsection{References}

Achour, A.R., Bauda, P., and Billard, P. (2007). Diversity of arsenite transporter genes from arsenic-resistant soil bacteria. Research in Microbiology, 158:128-137.

Adachi, S. (1985). GaAs, AlAs, and Al x Ga1- x As: Material parameters for use in research and device applications. Journal of Applied Physics, 58:R1-R29.

Bhattacharjee, H., Li, J., Ksenzenko, M.Y., and Rosen, B.P. (1995). Role of cysteinyl residues in metalloactivation of the oxyanion-translocating ArsA ATPase. Journal of Biological Chemistry, 270:11245-11250.

Byers, L.D., She, H.S., and Alayoff, A. (1979). Interaction of phosphate analogs with glyceraldehyde-3-phosphate dehydrogenase. Biochemistry, 18:24712480 .

Calatayud, M., Xiong, C., Du Laing, G., Raber, G., Francesconi, K., and van de Wiele, T. (2018). Salivary and Gut Microbiomes Play a Significant Role in in Vitro Oral Bioaccessibility, Biotransformation, and Intestinal Absorption of Arsenic from Food. Environmental Science \& Technology, 52:1442214435.

Calderón, J., Navarro, M.E., Jimenez-Capdeville, M.E., Santos-Diaz, M.A., Golden, A., Rodriguez-Leyva, I., Borja-Aburto, V., and Díaz-Barriga, F. (2001). Exposure to Arsenic and Lead and Neuropsychological Development in Mexican Children. Environmental research, 85:69-76.

Carpenter, R.L., and Jiang, B.-H. (2013). Roles of EGFR, PI3K, AKT, and mTOR in heavy metal-induced cancer. Current cancer drug targets, 13:252-266.

Chen, J., Bhattacharjee, H., and Rosen, B.P. (2015a). ArsH is an organoarsenical oxidase that confers resistance to trivalent forms of the herbicide monosodium methylarsenate and the poultry growth promoter roxarsone. Molecular Microbiology, 96:1042-1052.

Chen, J., Garbinski, L.D., Rosen, B., Zhang, J., Xiang, P., and Ma, L.Q. (2020a). Organoarsenical compounds: Occurrence, toxicology and 
biotransformation. Critical Reviews in Environmental Science and Technology, 50:217-243.

Chen, J., Madegowda, M., Bhattacharjee, H., and Rosen, B.P. (2015b). ArsP: a methylarsenite efflux permease. Molecular Microbiology, 98:625-635.

Chen, J., and Rosen, B.P. (2020). The Pseudomonas putida NfnB nitroreductase confers resistance to roxarsone. Science of the total environment, 748:141339.

Chen, J., Yoshinaga, M., Garbinski, L.D., and Rosen, B.P. (2016). Synergistic interaction of glyceraldehydes - 3 - phosphate dehydrogenase and ArsJ, a novel organoarsenical efflux permease, confers arsenate resistance. Molecular Microbiology, 100:945-953.

Chen, J., Yoshinaga, M., and Rosen, B.P. (2019a). The antibiotic action of methylarsenite is an emergent property of microbial communities. Molecular Microbiology, 111:487-494.

Chen, J., Zhang, J., and Rosen, B.P. (2019b). Role of ArsEFG in roxarsone and nitarsone detoxification and resistance. Environmental Science \& Technology, 53:6182-6191.

Chen, S.-C., Sun, G.-X., Yan, Y., Konstantinidis, K.T., Zhang, S.-Y., Deng, Y., Li, X.-M., Cui, H.-L., Musat, F., Popp, D., Rosen, B.P., and Zhu, Y.-G. (2020b). The Great Oxidation Event expanded the genetic repertoire of arsenic metabolism and cycling. Proceedings of the National Academy of Sciences.

Chen, W., Martindale, J.L., Holbrook, N.J., and Liu, Y. (1998). Tumor promoter arsenite activates extracellular signal-regulated kinase through a signaling pathway mediated by epidermal growth factor receptor and Shc. Molecular and Cellular Biology, 18:5178-5188.

Chen, Y., Wu, F., Liu, M., Parvez, F., Slavkovich, V., Eunus, M., Ahmed, A., Argos, M., Islam, T., and Rakibuz-Zaman, M. (2013). A prospective study of arsenic exposure, arsenic methylation capacity, and risk of cardiovascular disease in Bangladesh. Environmental health perspectives, 121:832-838. 
Christophersen, O., Lyons, G., Haug, A., Steinnes, E., and Alloway, B., 2013. Heavy metals in soils: trace metals and metalloids in soils and their bioavailability. Springer, Dordrecht.

Chung, C.-J., Huang, Y.-L., Huang, Y.-K., Wu, M.-M., Chen, S.-Y., Hsueh, Y.-M., and Chen, C.-J. (2013). Urinary arsenic profiles and the risks of cancer mortality: a population-based 20-year follow-up study in arseniasis-endemic areas in Taiwan. Environmental research, 122:25-30.

Coryell, M., McAlpine, M., Pinkham, N.V., McDermott, T.R., and Walk, S.T. (2018). The gut microbiome is required for full protection against acute arsenic toxicity in mouse models. Nature Communications, 9:5424.

Costantini, P., Belzacq, A.-S., Vieira, H.L., Larochette, N., de Pablo, M.A., Zamzami, N., Susin, S.A., Brenner, C., and Kroemer, G. (2000). Oxidation of a critical thiol residue of the adenine nucleotide translocator enforces Bcl2-independent permeability transition pore opening and apoptosis. Oncogene, 19:307-314.

Costantini, P., Chernyak, B.V., Petronilli, V., and Bernardi, P. (1996). Modulation of the mitochondrial permeability transition pore by pyridine nucleotides and dithiol oxidation at two separate sites. Journal of Biological Chemistry, 271:6746-6751.

Del Razo, L.M., García-Vargas, G.G., Valenzuela, O.L., Castellanos, E.H., Sánchez-Peña, L.C., Currier, J.M., Drobná, Z., Loomis, D., and Stýblo, M. (2011). Exposure to arsenic in drinking water is associated with increased prevalence of diabetes: a cross-sectional study in the Zimapan and Lagunera regions in Mexico. Environmental Health, 10:73.

Dey, S., and Rosen, B.P. (1995). Dual mode of energy coupling by the oxyaniontranslocating ArsB protein. Journal of Bacteriology, 177:385-389.

Estañ, M.C., Calviño, E., de Blas, E., del Carmen Boyano-Adánez, M., Mena, M.L., Gómez-Gómez, M., Rial, E., and Aller, P. (2012). 2-Deoxy-D-glucose cooperates with arsenic trioxide to induce apoptosis in leukemia cells: involvement of IGF-1R-regulated Akt/mTOR, MEK/ERK and LKB-1/AMPK signaling pathways. Biochemical pharmacology, 84:1604-1616. 
Fisher, D.J., Yonkos, L.T., and Staver, K.W. (2015). Environmental Concerns of Roxarsone in Broiler Poultry Feed and Litter in Maryland, USA. Environmental Science \& Technology, 49:1999-2012.

Foster, S., and Maher, W. (2010). Degradation of arsenoribosides from marine macroalgae in simulated rock pools.

Francesconi, K.A., Tanggaar, R., McKenzie, C.J., and Goessler, W. (2002). Arsenic metabolites in human urine after ingestion of an arsenosugar. Clinical chemistry, 48:92-101.

Fruman, D.A., Chiu, H., Hopkins, B.D., Bagrodia, S., Cantley, L.C., and Abraham, R.T. (2017). The PI3K Pathway in Human Disease. Cell, 170:605-635.

Fu, H.-L., Meng, Y., Ordóñez, E., Villadangos, A.F., Bhattacharjee, H., Gil, J.A., Mateos, L.M., and Rosen, B.P. (2009). Properties of arsenite efflux permeases (Acr3) from Alkaliphilus metalliredigens and Corynebacterium glutamicum. Journal of Biological Chemistry, 284:19887-19895.

Gao, Y.-H., Zhang, H.-P., Yang, S.-M., Yang, Y., Ma, Y.Y., Zhang, X.-Y., and Yang, Y.-M. (2014). Inactivation of Akt by arsenic trioxide induces cell death via mitochondrial-mediated apoptotic signaling in SGC-7901 human gastric cancer cells. Oncology reports, 31:1645-1652.

Garbinski, L.D., Rosen, B.P., and Chen, J. (2019). Pathways of arsenic uptake and efflux. Environment International, 126:585-597.

Ghariani, M., Adrien, M., Raucoules, M., Bayle, J., Jacomet, Y., and Grimaud, D., 1991. Subacute arsenic poisoning. Annales Françaises d'Anesthesie et de Reanimation. Elsevier Publishing, pp. 304-307.

Ghosh, M., Shen, J., and Rosen, B.P. (1999). Pathways of As(III) detoxification in Saccharomyces cerevisiae. Proceedings of the National Academy of Sciences, 96:5001-5006.

Gilbert-Diamond, D., Li, Z., Perry, A.E., Spencer, S.K., Gandolfi, A.J., and Karagas, M.R. (2013). A population-based case-control study of urinary arsenic species and squamous cell carcinoma in New Hampshire, USA. Environmental health perspectives, 121:1154-1160. 
Gregus, Z., and Németi, B. (2005). The Glycolytic Enzyme Glyceraldehyde-3Phosphate Dehydrogenase Works as an Arsenate Reductase in Human Red Blood Cells and Rat Liver Cytosol. Toxicological Sciences, 85:859-869.

Gresser, M.J. (1981). ADP-arsenate. Formation by submitochondrial particles under phosphorylating conditions. Journal of Biological Chemistry, 256:5981-5983.

Hampson, G.C., and Stosick, A.J. (1938). The molecular structure of arsenious oxide, $\mathrm{As}_{4} \mathrm{O}_{6}$, phosphorus trioxide, $\mathrm{P}_{4} \mathrm{O}_{6}$, phosphorus pentoxide, $\mathrm{P}_{4} \mathrm{O}_{10}$, and hexamethylenetetramine, $\left(\mathrm{CH}_{2}\right) 6 \mathrm{~N}_{4}$, by electron diffraction. Journal of the American Chemical Society, 60:1814-1822.

Hansen, J.M., Zhang, H., and Jones, D.P. (2006). Differential oxidation of thioredoxin-1, thioredoxin-2, and glutathione by metal ions. Free Radical Biology and Medicine, 40:138-145.

Healy, J.F. (1981). Pliny the Elder and Ancient Mineralogy. Interdisciplinary Science Reviews, 6:166-180.

Hoerlein, G., 1994. Glufosinate (phosphinothricin), a natural amino acid with unexpected herbicidal properties. Reviews of environmental contamination and toxicology. Springer, pp. 73-145.

Huang, C., Ke, Q., Costa, M., and Shi, X. (2004). Molecular mechanisms of arsenic carcinogenesis. Molecular and cellular biochemistry, 255:57-66.

Jackson, B.P., and Bertsch, P.M. (2001). Determination of arsenic speciation in poultry wastes by IC-ICP-MS. Environmental Science \& Technology, 35:4868-4873.

Khan, M.S., Zaidi, A., Goel, R., and Musarrat, J., 2011. Biomanagement of metalcontaminated soils. Springer Science \& Business Media.

Kozono, S., Lin, Y.-M., Seo, H.-S., Pinch, B., Lian, X., Qiu, C., Herbert, M.K., Chen, C.-H., Tan, L., and Gao, Z.J. (2018). Arsenic targets Pin1 and cooperates with retinoic acid to inhibit cancer-driving pathways and tumor-initiating cells. Nature Communications, 9:1-17. 
Kuramata, M., Sakakibara, F., Kataoka, R., Yamazaki, K., Baba, K., Ishizaka, M., Hiradate, S., Kamo, T., and Ishikawa, S. (2016). Arsinothricin, a novel organoarsenic species produced by a rice rhizosphere bacterium. Environmental Chemistry, 13:723-731.

Lee, J.-H., Liu, R., Li, J., Wang, Y., Tan, L., Li, X.-J., Qian, X., Zhang, C., Xia, Y., and Xu, D. (2018). EGFR-phosphorylated platelet isoform of phosphofructokinase 1 promotes PI3K activation. Molecular cell, 70:197210. e197.

Li, X.-Z., Plésiat, P., and Nikaido, H. (2015). The Challenge of Efflux-Mediated Antibiotic Resistance in Gram-Negative Bacteria. Clinical Microbiology Reviews, 28:337-418.

Lloyd, N.C., Morgan, H.W., Nicholson, B.K., and Ronimus, R.S. (2005). The composition of Ehrlich's salvarsan: resolution of a century - old debate. Angewandte Chemie International Edition, 44:941-944.

Logemann, E., Krützfeldt, B., and Pollak, S. (1990). Suicidal administration of elemental arsenic. Archiv für Kriminologie, 185:80-88.

Maciaszczyk-Dziubinska, E., Migocka, M., and Wysocki, R. (2011). Acr3p is a plasma membrane antiporter that catalyzes As (III)/H+ and $\mathrm{Sb}(\mathrm{III}) / \mathrm{H}+$ exchange in Saccharomyces cerevisiae. Biochimica et Biophysica Acta (BBA)-Biomembranes, 1808:1855-1859.

Maimaitiyiming, Y., Zhu, H.-H., Yang, C., and Naranmandura, H. (2020). Biotransformation of arsenic trioxide by AS3MT favors eradication of acute promyelocytic leukemia: revealing the hidden facts. Drug Metabolism Reviews, 52:425-437.

Mansour, N.M., Sawhney, M., Tamang, D.G., Vogl, C., and Saier Jr, M.H. (2007). The bile/arsenite/riboflavin transporter (BART) superfamily. The FEBS journal, 274:612-629.

Martini, M., De Santis, M.C., Braccini, L., Gulluni, F., and Hirsch, E. (2014). PI3K/AKT signaling pathway and cancer: an updated review. Annals of medicine, 46:372-383. 
Marzo, I., Brenner, C., Zamzami, N., Jürgensmeier, J.M., Susin, S.A., Vieira, H.L., Prévost, M.-C., Xie, Z., Matsuyama, S., and Reed, J.C. (1998). Bax and adenine nucleotide translocator cooperate in the mitochondrial control of apoptosis. Science, 281:2027-2031.

Matteson, A.R., Gannon, T.W., Jeffries, M.D., Haines, S., Lewis, D.F., and Polizzotto, M.L. (2014). Arsenic retention in foliage and soil after monosodium methyl arsenate (MSMA) application to turfgrass. Journal of environmental quality, 43:379-388.

McStay, G.P., Clarke, S.J., and Halestrap, A.P. (2002). Role of critical thiol groups on the matrix surface of the adenine nucleotide translocase in the mechanism of the mitochondrial permeability transition pore. Biochemical Journal, 367:541-548.

Mendez, M.A., González-Horta, C., Sánchez-Ramírez, B., Ballinas-Casarrubias, L., Cerón, R.H., Morales, D.V., Terrazas, F.A.B., Ishida, M.C., GutiérrezTorres, D.S., and Saunders, R.J. (2016). Chronic exposure to arsenic and markers of cardiometabolic risk: a cross-sectional study in Chihuahua, Mexico. Environmental health perspectives, 124:104-111.

Meng, Y.-L., Liu, Z., and Rosen, B.P. (2004). As (III) and Sb (III) uptake by GlpF and efflux by ArsB in Escherichia coli. Journal of Biological Chemistry, 279:18334-18341.

Mukherjee, S.C., Rahman, M.M., Chowdhury, U.K., Sengupta, M.K., Lodh, D., Chanda, C.R., Saha, K.C., and Chakraborti, D. (2003). Neuropathy in arsenic toxicity from groundwater arsenic contamination in West Bengal, India. Journal of Environmental Science and Health, Part A, 38:165-183.

Nachman, K.E., Baron, P.A., Raber, G., Francesconi, K.A., Navas-Acien, A., and Love, D.C. (2013). Roxarsone, Inorganic Arsenic, and Other Arsenic Species in Chicken: A U.S.-Based Market Basket Sample. Environmental health perspectives, 121:818-824.

Nadar, V.S., Chen, J., Dheeman, D.S., Galván, A.E., Yoshinaga-Sakurai, K., Kandavelu, P., Sankaran, B., Kuramata, M., Ishikawa, S., and Rosen, B.P. (2019). Arsinothricin, an arsenic-containing non-proteinogenic amino acid analog of glutamate, is a broad-spectrum antibiotic. Communications Biology, 2:1-12. 
Naranmandura, H., Ogra, Y., Iwata, K., Lee, J., Suzuki, K.T., Weinfeld, M., and Le, X.C. (2009). Evidence for toxicity differences between inorganic arsenite and thioarsenicals in human bladder cancer cells. Toxicology and Applied Pharmacology, 238:133-140.

Oremland, R.S., and Stolz, J.F. (2003). The Ecology of Arsenic. Science, 300:939944.

Parascandola, J., 2012. King of poisons: a history of arsenic. Potomac Books, Inc.

Parvez, F., Wasserman, G.A., Factor-Litvak, P., Liu, X., Slavkovich, V., Siddique, A.B., Sultana, R., Sultana, R., Islam, T., Levy, D., Mey, J.L., Geen, A.v., Khan, K., Kline, J., Ahsan, H., and Graziano, J.H. (2011). Arsenic Exposure and Motor Function among Children in Bangladesh. Environmental health perspectives, 119:1665-1670.

Pawitwar, S.S., Nadar, V.S., Kandegedara, A., Stemmler, T.L., Rosen, B.P., and Yoshinaga, M. (2017). Biochemical characterization of Arsl: a novel C-As Lyase for degradation of environmental organoarsenicals. Environmental Science \& Technology, 51:11115-11125.

Petrick, J.S., Ayala-Fierro, F., Cullen, W.R., Carter, D.E., and Aposhian, H.V. (2000). Monomethylarsonous acid (MMAIII) is more toxic than arsenite in Chang human hepatocytes. Toxicology and Applied Pharmacology, 163:203-207.

Qin, J., Rosen, B.P., Zhang, Y., Wang, G., Franke, S., and Rensing, C. (2006). Arsenic detoxification and evolution of trimethylarsine gas by a microbial arsenite S-adenosylmethionine methyltransferase. Proceedings of the National Academy of Sciences, 103:2075-2080.

Rahman, A., Vahter, M., Ekström, E.-C., Rahman, M., Golam Mustafa, A.H.M., Wahed, M.A., Yunus, M., and Persson, L.-Å. (2007). Association of Arsenic Exposure during Pregnancy with Fetal Loss and Infant Death: A Cohort Study in Bangladesh. American Journal of Epidemiology, 165:1389-1396.

Ralph, S.J. (2008). Arsenic-based antineoplastic drugs and their mechanisms of action. Metal-based drugs, 2008. 
Ratnaike, R.N. (2003). Acute and chronic arsenic toxicity. Postgraduate Medical Journal, 79:391-396.

Razo, I., Carrizales, L., Castro, J., Díaz-Barriga, F., and Monroy, M. (2004). Arsenic and heavy metal pollution of soil, water and sediments in a semiarid climate mining area in Mexico. Water, Air, and Soil Pollution, 152:129152.

Roggenbeck, B.A., Banerjee, M., and Leslie, E.M. (2016). Cellular arsenic transport pathways in mammals. Journal of Environmental Sciences, 49:3858.

Rosal, C.G., Momplaisir, G.-M., and Heithmar, E.M. (2005). Roxarsone and transformation products in chicken manure: Determination by capillary electrophoresis-inductively coupled plasma-mass spectrometry. ELECTROPHORESIS, 26:1606-1614.

Rosen, B.P. (1990). The plasmid-encoded arsenical resistance pump: An aniontranslocating ATPase. Research in Microbiology, 141:336-341.

Rosen, B.P., Bhattacharjee, H., Zhou, T., and Walmsley, A.R. (1999). Mechanism of the ArsA ATPase. Biochimica et Biophysica Acta (BBA) - Biomembranes, 1461:207-215.

Rosen, B.P., and Borbolla, M.G. (1984). A plasmid-encoded arsenite pump produces arsenite resistance in Escherichia coli. Biochemical and biophysical research communications, 124:760-765.

Shen, S., Li, X.-F., Cullen, W.R., Weinfeld, M., and Le, X.C. (2013). Arsenic Binding to Proteins. Chemical Reviews, 113:7769-7792.

Shen, Z., Luangtongkum, T., Qiang, Z., Jeon, B., Wang, L., and Zhang, Q. (2014). Identification of a novel membrane transporter mediating resistance to organic arsenic in Campylobacter jejuni. Antimicrobial Agents and Chemotherapy, 58:2021-2029.

Shi, K., Li, C., Rensing, C., Dai, X., Fan, X., and Wang, G. (2018). Efflux transporter ArsK is responsible for bacterial resistance to arsenite, antimonite, trivalent 
roxarsone, and methylarsenite. Appl. Environ. Microbiol., 84:e0184201818.

Silver, S., Budd, K., Leahy, K., Shaw, W., Hammond, D., Novick, R., Willsky, G., Malamy, M., and Rosenberg, H. (1981). Inducible plasmid-determined resistance to arsenate, arsenite, and antimony (III) in escherichia coli and Staphylococcus aureus. Journal of Bacteriology, 146:983-996.

Tanaka - Kagawa, T., Hanioka, N., Yoshida, H., Jinno, H., and Ando, M. (2003). Arsenite and arsenate activate extracellular signal - regulated kinases 1/2 by an epidermal growth factor receptor - mediated pathway in normal human keratinocytes. British Journal of Dermatology, 149:1116-1127.

Tisa, L.S., and Rosen, B.P. (1990). Molecular characterization of an anion pump. The ArsB protein is the membrane anchor for the ArsA protein. Journal of Biological Chemistry, 265:190-194.

Villadangos, A.F., Fu, H.-L., Gil, J.A., Messens, J., Rosen, B.P., and Mateos, L.M. (2012). Efflux permease CgAcr3-1 of Corynebacterium glutamicum is an arsenite-specific antiporter. Journal of Biological Chemistry, 287:723-735.

Wang, G., Zhang, T., Sun, W., Wang, H., Yin, F., Wang, Z., Zuo, D., Sun, M., Zhou, Z., and Lin, B. (2017). Arsenic sulfide induces apoptosis and autophagy through the activation of ROS/JNK and suppression of Akt/mTOR signaling pathways in osteosarcoma. Free Radical Biology and Medicine, 106:24-37.

Wang, L., Jeon, B., Sahin, O., and Zhang, Q. (2009). Identification of an Arsenic Resistance and Arsenic-Sensing System in Campylobacter jejuni. Applied and Environmental Microbiology, 75:5064-5073.

Wang, S.-L., Li, W.-F., Chen, C.-J., Huang, Y.-L., Chen, J.-W., Chang, K.-H., Tsai, L.-Y., and Chou, K.-M. (2011). Hypertension incidence after tap-water implementation: a 13-year follow-up study in the arseniasis-endemic area of southwestern Taiwan. Science of the total environment, 409:4528-4535.

Wang, Y., Yin, D., Xu, C., Wang, K., Zheng, L., and Zhang, Y. (2016). Roxarsone induces angiogenesis via PI3K/Akt signaling. Cell \& bioscience, 6:54. 
Wen, G., Hong, M., Calaf, G., Roy, D., Partridge, M., Li, B., and Hei, T. (2010). Phosphoproteomic profiling of arsenite-treated human small airway epithelial cells. Oncology reports, 23:405-412.

Wu, J., and Rosen, B. (1991). The ArsR protein is a trans - acting regulatory protein. Molecular Microbiology, 5:1331-1336.

Wu, J., Tisa, L.S., and Rosen, B.P. (1992). Membrane topology of the ArsB protein, the membrane subunit of an anion-translocating ATPase. Journal of Biological Chemistry, 267:12570-12576.

Xue, X.-M., Ye, J., Raber, G., Rosen, B.P., Francesconi, K., Xiong, C., Zhu, Z., Rensing, C., and Zhu, Y.-G. (2018). Identification of steps in the pathway of arsenosugar biosynthesis. Environmental Science \& Technology, 53:634641.

Yan, Y., Chen, J., Galván, A.E., Garbinski, L.D., Zhu, Y.-G., Rosen, B.P., and Yoshinaga, M. (2019). Reduction of Organoarsenical Herbicides and Antimicrobial Growth Promoters by the Legume Symbiont Sinorhizobium meliloti. Environmental Science \& Technology, 53:13648-13656.

Yoshinaga, M., Cai, Y., and Rosen, B.P. (2011). Demethylation of methylarsonic acid by a microbial community. Environmental Microbiology, 13:1205-1215.

Yoshinaga, M., and Rosen, B.P. (2014). A C. As lyase for degradation of environmental organoarsenical herbicides and animal husbandry growth promoters. Proceedings of the National Academy of Sciences, 111:77017706.

Zandstra, B.H., and De Kryger, T.A. (2007). Arsenic and lead residues in carrots from foliar applications of monosodium methanearsonate (MSMA): A comparison between mineral and organic soils, or from soil residues. Food Additives \& Contaminants, 24:34-42.

Zhang, R., Al-Lamki, R., Bai, L., Streb, J.W., Miano, J.M., Bradley, J., and Min, W. (2004). Thioredoxin-2 inhibits mitochondria-located ASK1-mediated apoptosis in a JNK-independent manner. Circulation research, 94:14831491. 
Zheng, J., Zhang, K., Liu, Y., and Wang, Y. (2019). Fatal acute arsenic poisoning by external use of realgar: Case report and 30 years literature retrospective study in China. Forensic Science International, 300:e24-e30.

Zhou, T., Radaev, S., Rosen, B.P., and Gatti, D.L. (2000). Structure of the ArsA ATPase: the catalytic subunit of a heavy metal resistance pump. The EMBO journal, 19:4838-4845.

Zhu, Y.-G., Xue, X.-M., Kappler, A., Rosen, B.P., and Meharg, A.A. (2017). Linking genes to microbial biogeochemical cycling: lessons from arsenic. Environmental Science \& Technology, 51:7326-7339.

Zhu, Y.-G., Yoshinaga, M., Zhao, F.-J., and Rosen, B.P. (2014). Earth abides arsenic biotransformations. Annual Review of Earth and Planetary Sciences, 42:443-467. 


\section{CHAPTER 2. PROBLEM STATEMENT AND OBJECTIVES}

\subsection{Problem statement}

The arsenic biogeocycle is a complex network of redox cycles, microbial biotransformations, and human activity. Arsenic is associated with several negative health outcomes, including heart disease, diabetes, neuropathies, and cancer (Kuo et al., 2017), while at the same time being the first line of treatment for diseases such as acute promyelocytic leukemia. Microbial organoarsenic synthesis and metabolism is a relatively new area. Finding novel arsenic detoxification pathways and arsenic-based antibiotics (Nadar et al., 2019) broadly expands our capacity to design better arsenic bioremediation strategies and to harness its toxic properties to fight infectious diseases. Recently, we showed that the synthesis of MAs(III) in bacterial communities confers a competitive advantage to the producer strain (Chen et al., 2019); however, the molecular target in bacteria responsible for its antimicrobial activity has not yet been identified. To understand how trivalent organoarsenicals are so much more toxic than As(III), at least one target specific to MAs(III) must be found. Furthermore, while ArsP has been described as an MAs(III)-selective pump (Chen et al., 2015), neither the basis for its selectivity nor its structural characteristics have been elucidated. These properties are key to explain how enzymes that evolved billions of years ago are able to detoxify synthetic aromatic arsenical compounds only several decades old. Lastly, while the degradation pathways for aliphatic organoarsenicals like $\mathrm{MAs}(\mathrm{V})$ have been outlined (Yoshinaga et al., 2011; Yoshinaga and Rosen, 2014), it is hypothesized that other enzymes and possible separate pathways are involved in 
the degradation of nitroaromatic organoarsenicals like $\operatorname{Rox}(\mathrm{V})$ and $\operatorname{Nit}(\mathrm{V})$. One difference between the degradation of aliphatic versus nitroaromatic organoarsenicals is the observed reduction of the nitro group in aromatic arsenicals. Identifying an enzyme involved in this process will allow us to piece together a more complete picture of how these man-made arsenicals are degraded in soil and help us better predict their potential as environmental pollutants.

\subsection{Project objectives are the following:}

$>$ Describe the organoarsenical biotransformation capacity of S. meliloti Rm1021 and identify one enzyme involved in this process.

Identify a molecular target associated with MAs(III) toxicity and characterize its inhibition by MAs(III).

$>$ Probe the substrate binding site of ArsP and assess whether highly conserved residues impact its selectivity or resistance for MAs(III) over aromatic organoarsenicals.

\subsection{References}

Chen, J., Madegowda, M., Bhattacharjee, H., and Rosen, B.P. (2015). ArsP: a methylarsenite efflux permease. Molecular Microbiology, 98:625-635.

Chen, J., Yoshinaga, M., and Rosen, B.P. (2019). The antibiotic action of methylarsenite is an emergent property of microbial communities. Molecular Microbiology, 111:487-494.

Kuo, C.-C., Moon, K.A., Wang, S.-L., Silbergeld, E., and Navas-Acien, A. (2017). The Association of Arsenic Metabolism with Cancer, Cardiovascular Disease, and Diabetes: A Systematic Review of the Epidemiological Evidence. Environmental health perspectives, 125:087001. 
Nadar, V.S., Chen, J., Dheeman, D.S., Galván, A.E., Yoshinaga-Sakurai, K., Kandavelu, P., Sankaran, B., Kuramata, M., Ishikawa, S., and Rosen, B.P. (2019). Arsinothricin, an arsenic-containing non-proteinogenic amino acid analog of glutamate, is a broad-spectrum antibiotic. Communications Biology, 2:1-12.

Yoshinaga, M., Cai, Y., and Rosen, B.P. (2011). Demethylation of methylarsonic acid by a microbial community. Environmental Microbiology, 13:1205-1215.

Yoshinaga, M., and Rosen, B.P. (2014). A C. As lyase for degradation of environmental organoarsenical herbicides and animal husbandry growth promoters. Proceedings of the National Academy of Sciences, 111:77017706. 


\section{Chapter 3. REDUCTION OF ORGANOARSENICAL HERBICIDES AND ANTIMICROBIAL GROWTH PROMOTERS BY THE LEGUME SYMBIONT SINORHIZOBIUM MELILOTI}

\subsection{Introduction}

The metalloid arsenic, the most pervasive environmental toxin, has exerted selective pressure on organisms since life emerged on the Earth, which has led to the evolution and acquisition of arsenic resistance mechanisms in nearly every extant organism. In particular, bacteria have evolved a variety of unique ars genes (Zhu et al., 2014; Zhu et al., 2017). One such gene is arsM, which encodes the ArsM As(III) S-adenosylmethionine methyltransferase (Qin et al., 2006). ArsM evolved before the GOE and generates reduced methylarsenicals such as methylarsenite (MAs(III)) and dimethylarsenite (DMAs(III)) (Li et al., 2016; Chen et al., 2017). These trivalent methylated arsenic species are much more toxic than the inorganic forms and stable in anoxic environments, and we have proposed that these ancient microbes activated available arsenic into more toxic forms for use as antibiotics to kill competitors (Li et al., 2016; Chen et al., 2019a). In the present oxic biosphere, arsenic methylation primarily functions as a detoxification mechanism because trivalent methylarsenicals are rapidly oxidized to relatively nontoxic methylarsenate $(\mathrm{MAs}(\mathrm{V}))$ and dimethylarsenate $(\mathrm{DMAs}(\mathrm{V}))$ (Qin et al., 2006). In response, other bacteria revived the antibiotic strategy by re-reducing $\operatorname{MAs}(\mathrm{V})$ to the trivalent form. Other bacteria responded by evolving multiple mechanisms of resistance to the antibiotic action of MAs(III): by oxidation, demethylation, or extrusion (Li et al., 2016; Chen et al., 2019a). 
Methylated arsenic species are introduced into the environment not only through biogenic sources but also as a result of anthropogenic activities. In the United States, a massive amount of methylarsenicals, both MAs $(\mathrm{V})$ and $\mathrm{DMAs}(\mathrm{V})$, have been utilized as herbicides since the early 1970s. Although the use of DMAs $(V)$ has been prohibited since the beginning of 2014 under the cancellation order issued by the U.S. Environmental Protection Agency, the monosodium salt of MAs(V), or MSMA, is still allowed for use on cotton fields, golf courses, sod farms, and highway rights of way nationwide except in Florida, where the use is now banned in golf courses (Gannon and Polizzotto, 2016).

In addition to MSMA, synthetic pentavalent aromatic arsenicals, including $\operatorname{Rox}(\mathrm{V})$, nitarsone [4-nitrophenylarsenate; Nit(V)] and p-arsanilic acid [4aminophenylarsenate; $p-A S A(V)$ ] have been widely used since the 1940s, especially in the poultry industry, as a feed additive to control protozoan parasitic diseases and promote growth. Approximately, 2000000 pounds of Rox(V) were released annually into the environment as manure from Rox(V)-fed animals, and the manure was applied as a fertilizer for farm crops (Garbarino et al., 2003). Although use of these aromatic arsenical growth promotors is no longer allowed in the United States (https://www.fda.gov/animal-veterinary/product-safetyinformation/arsenic-based-animal-drugs-and-poultry), these compounds are still in use in other countries (Huang et al., 2019). A large portion of these anthropogenic organoarsenic compounds gradually degrade into more toxic inorganic forms through microbial activities that impact the environment and contaminate our water and food supplies (Feng et al., 2005; D'Angelo et al., 2012; Yao et al., 2016). A 
number of bacterial species, both aerobes (Quinn and McMullan, 1995; Lehr et al., 2003; Maki et al., 2006; Huang et al., 2019) and anaerobes (Fisher et al., 2008; Chen and Rosen, 2016; Han et al., 2017) have been documented to degrade methyl and aromatic arsenicals; however, the pathways and molecular mechanisms for degradation of organoarsenicals remain poorly understood.

We previously identified a microbial community from Florida golf course soil that degrades MAs(V) aerobically (Yoshinaga et al., 2011), where one microbe activates $\operatorname{MAs}(\mathrm{V})$ into highly toxic $\operatorname{MAs}(\mathrm{III})$ that other member subsequently detoxifies into less toxic inorganic As(III). MAs(III) demethylation is catalyzed by ArsI C-As lyase, an Fe(II)-dependent dioxygenase (Yoshinaga and Rosen, 2014). Here, we demonstrate that pentavalent aromatic arsenicals are also biotransformed into inorganic species via sequential reduction and Arsl-catalyzed C-As bond cleavage by aerobic microbial communities, similar to the pathway of demethylation of the MSMA herbicide. The legume symbiont Sinorhizobium meliloti $\mathrm{Rm} 1021$ is a typical soil bacterium and forms nitrogen-fixing symbiosis with alfalfa and other legumes. S. meliloti Rm1021 has been extensively studied as a model organism for the genetic analysis of symbiotic nitrogen fixation and legumemicrobe interaction. Sequencing of the entire genome of S. meliloti Rm1021 has been completed in 2001 (Galibert et al., 2001; Yang et al., 2005). For As metabolism, S. meliloti Rm1021 can utilize a unique detoxification pathway wherein reduction of $\mathrm{As}(\mathrm{V})$ by arsenate reductase (ArsC) is coupled to downhill transport of $\mathrm{As}(\mathrm{III})$ through the aquaglyceroporin (AqpS) channel (Yang et al., 2005). In this study, we demonstrate that $S$. meliloti $R m 1021$ reduces both $M A s(V)$ 
and pentavalent aromatic arsenicals, producing trivalent methyl and aromatic arsenicals. Other Rox(V)-degrading aerobes (Huang et al., 2019) and anaerobes (Fisher et al., 2008; Chen and Rosen, 2016; Han et al., 2017) have been reported to reduce the nitro group of nitroaromatic arsenicals such as $\operatorname{Rox}(\mathrm{V})$ and $\operatorname{Nit}(\mathrm{V})$. We found that S. meliloti Rm1021 also reduces the nitro groups of Rox(V) and $\mathrm{Nit}(\mathrm{V})$ to form the corresponding aromatic amines 4-hydroxy-3aminophenylarseate $(\mathrm{HAPA}(\mathrm{V}))$ and $p-\mathrm{ASA}(\mathrm{V})$, respectively. The arsenic in these species is subsequently reduced, producing trivalent HAPA(III) and p-ASA(III), which are much more toxic compared to the corresponding pentavalent species (Chen et al., 2015a). When cells of S. meliloti Rm1021 were co-cultured with Streptomyces sp. MD1, an MAs(III)-demethylating species isolated from Florida golf course soil (Yoshinaga et al., 2011) degraded both methyl and aromatic pentavalent arsenicals into inorganic As(III). Further, we identified $m d a B$, the gene for the first reduction step, nitroreduction of nitroaromatic arsenicals, and characterized the gene product MdaB (modulator of drug activity $\mathrm{B}$ ) both in vivo and in vitro.

\subsection{Materials and methods}

\subsubsection{Strains and chemicals}

S. meliloti Rm1021 (Meade et al., 1982) and its derivative strain RmP310 that lacks the chromosomal ars operon ( $\Delta$ ars) (Yang, 2008; Chen et al., 2015a), Pseudomonas putida KT2440 (Bagdasarian et al., 1981), Burkholderia sp. MR1, and Streptomyces sp. MD1 (Yoshinaga et al., 2011) were used to analyze biotransformation and uptake of organoarsenicals. Escherichia coli strain TOP10 
(Invitrogen, Waltham, MA) was used for plasmid construction and replication. E. coli strains AW3110(DE3) (Aars) (Carlin et al., 1995) and BL21(DE3) (Novagen, Madison, WI) were used for analysis of activity of nitroreductases in vivo and protein expression, respectively. Except where specified, bacterial strains were cultured aerobically with shaking at $37^{\circ} \mathrm{C}$ (E. coli strains) or $30^{\circ} \mathrm{C}$ (others). Unless otherwise indicated, all chemicals were of analytical or better grade from MilliporeSigma (Burlington, MA). Rox $(V)$ and $\operatorname{HAPA}(V)$ were purchased from Thermo Fisher Scientific (Waltham, MA) and Pfaltz \& Bauer (Waterbury, CT), respectively. The trivalent organoarsenicals [Rox(III), Nit(III), p-ASA(III), and HAPA(III)] were prepared by chemical reduction of their corresponding pentavalent forms as previously described (Yoshinaga and Rosen, 2014). In brief, $0.2 \mathrm{mM}$ pentavalent arsenical was mixed with $27 \mathrm{mM} \mathrm{Na}_{2} \mathrm{~S}_{2} \mathrm{O}_{3}, 66 \mathrm{mM} \mathrm{Na}_{2} \mathrm{~S}_{2} \mathrm{O}_{5}$, and $82 \mathrm{mM}$ $\mathrm{H}_{2} \mathrm{SO}_{4}$, following which the $\mathrm{pH}$ was adjusted to 6 with $\mathrm{NaOH}$. We confirmed by absorption spectroscopy that the chemical reduction method reduces $A s(V)$ to As(III) but does not reduce the nitro group of roxarsone and nitarsone. The methylarsonous acid iodide derivative $\left(\mathrm{MAs}(\mathrm{III}) \mathrm{I}_{2}\right)$ synthesized as described (Stice et al., 2016) was used as MAs(III). For confirmation purpose, prepared MAs(III)I, p-ASA(III), and HAPA(III) were treated with $4.5 \%(\mathrm{v} / \mathrm{v}) \mathrm{H}_{2} \mathrm{O}_{2}$ and incubated first for $10 \mathrm{~min}$ at room temperature and further for $5 \mathrm{~min}$ at $80{ }^{\circ} \mathrm{C}$. Oxidized organoarsenicals were analyzed by HPLC-ICP-MS as described below to confirm they match the corresponding pentavalent species (Figure 2A,C,F). The chemical structures of arsenicals are shown in Figure 3. 


\subsubsection{Biotransformation of organoarsenicals}

S. meliloti Rm1021, S. meliloti RmP310 (Aars), Burkholderia sp. MR1, and $P$. putida $\mathrm{KT} 2440$ were solely cultured with $1 \mu \mathrm{M} \mathrm{MAs}(\mathrm{V})$, $p-\mathrm{ASA}(\mathrm{V})$, Nit(V), or Rox(V) in ST 10-1 medium (Maki et al., 2004) supplemented with $0.2 \%$ D-glucose, $2.5 \mathrm{mM} \mathrm{CaCl}_{2}$, and $2.5 \mathrm{mM} \mathrm{MgSO}_{4}$ for 3 days. As shown by our present results, $S$. meliloti $\mathrm{Rm} 1021$ displayed an activity to reduce $\mathrm{MAs}(\mathrm{V}), p-\mathrm{ASA}(\mathrm{V})$, Nit( $(\mathrm{V})$, and $\operatorname{Rox}(\mathrm{V})$ while it had a poor ability to degrade them into As(III). Our previous study has shown that $\mathrm{C}-$ As lyase (Arsl) is responsible for degradation of trivalent organarsenicals into As(III) (Yoshinaga and Rosen, 2014). Therefore, we cocultured S. meliloti Rm1021 with Streptomyces sp. MD1, a soil bacterium isolated from golf course soils that contains ars/ gene in its genome (Yoshinaga et al., 2011; Yoshinaga and Rosen, 2014) to investigate the complete degradation pathway of pentavalent organoarsenicals into inorganic arsenic. For coculture experiments, S. meliloti Rm1021 and Streptomyces sp. MD1 were first cultured separately for $24 \mathrm{~h}$ and then cocultured in the presence of pentavalent organoarsenicals for an additional 3 days. We independently repeated the bacterial culture/coculture experiment three times. Each culture was centrifuged at $13400 \times g$ for $1 \mathrm{~min}$, and the supernatant solution was immediately filtered by Amicon Ultra Centrifugal Filters with a 3000 Da cut-off membrane (MilliporeSigma). The arsenic species in the filtrates were determined by high-performance liquid chromatography (HPLC) (Series 2000; PerkinElmer, Waltham, MA) coupled to inductively coupled plasma mass spectrometry (ICP-MS) (ELAN DRC-e; PerkinElmer) using the previous instrument parameters (Yoshinaga and Rosen, 
2014). Briefly, $\operatorname{MAs}(V), p-A S A(V), \operatorname{HAPA}(V)$, and their trivalent forms were analyzed with Thermo Fisher Scientific BioBasic 18 LC column $(250 \mathrm{~mm} \times 4.6 \mathrm{~mm}$, $5 \mu \mathrm{m}, 300 \AA$ ) isocratically eluted with a mobile phase consisting of $3 \mathrm{mM}$ malonic acid and $5 \%$ methanol $(\mathrm{v} / \mathrm{v})(\mathrm{pH} 5.95$ for MAs and 5.2 for $p$-ASA and HAPA, adjusted by tetrabutylammonium hydroxide), with a flow rate of $1 \mathrm{~mL} \mathrm{~min}^{-1}$ at 25 ${ }^{\circ} \mathrm{C}$. Nit( $(\mathrm{V}), \operatorname{Rox}(\mathrm{V})$ and their trivalent forms were analyzed with the Inertsil $\mathrm{C} 4$ column (150 mm $\times 2.1 \mathrm{~mm} ; 5 \mu \mathrm{m}$; GL Sciences, Japan) isocratically eluted with a mobile phase consisted with $15 \%$ acetonitrile $(\mathrm{v} / \mathrm{v}), 5 \%$ ethanol $(\mathrm{v} / \mathrm{v})$, and $80 \%$ water $(\mathrm{pH} 1.5$ adjusted by $\mathrm{HCl})(\mathrm{v} / \mathrm{v})$, at a flow rate of 0.3 or $0.6 \mathrm{~mL} \mathrm{~min}^{-1}$ at $60^{\circ} \mathrm{C}$. For confirmation purpose, samples containing MAs(III), p-ASA(III), and HAPA(III) were treated with $4.5 \%(\mathrm{v} / \mathrm{v}) \mathrm{H}_{2} \mathrm{O}_{2}$ and incubated first for 10 min at room temperature and further for $5 \mathrm{~min}$ at $80^{\circ} \mathrm{C}$. Oxidized samples were analyzed by HPLC-ICP-MS to confirm their species (Figure 2B,D,E,G). Each amount of the indicated arsenic species in bacterial culture/coculture samples was quantified from the corresponding peak area using Chromera Chromatography Data System version 2.1 (PerkinElmer) according to standard curves prepared with standard solutions in the range of $0.5-2 \mu \mathrm{M}$ in water. The results from the triplicated independent experiments are summarized in Table S1.

\subsubsection{Plasmid construction}

By conducting a BLAST (Basic Local Alignment Search Tool) search of the genome of S. meliloti 1021, the genes encoding SmAzoR (NCBI accession no.: NP_385442), SmMdaB (NP_387022), SmMsuE (NP_438025), SmNemA (NP_385670), SmAZR (NP_386600), and SmNitB (NP_384119) were chosen as 
candidates responsible for the nitroreduction of roxarsone and nitarsone (See the Results and discussion section). For construction of plasmids for expression of SmazoR, SmnemA, and SmnitB, each gene was PCR-amplified from total genomic DNA of S. meliloti Rm1021 with PfuTurbo DNA polymerase (Agilent Technologies Inc., Santa Clara, CA) using the forward and reverse primers listed in Table 3. Amplicons were digested by Nhel and HindllI (SmazoR) or Ncol and Xhol (SmnemA and SmnitB) and ligated into pET28a, generating the plasmids pET28a-SmazoR, pET28a-SmnemA, and pET28a-SmnitB. The genes of SmmdaB, SmmsuE, and Smazr were chemically synthesized with $5^{\prime} \mathrm{Ncol}$ and 3' Xhol sites and cloned into pET28a by GenScript Biotech Corp. (Piscataway, $\mathrm{NJ}$ ), generating the plasmids pET28a-SmmdaB, pET28a-SmmsuE, and pET28aSmazr.

\subsubsection{In vivo nitroreduction of trivalent nitroaromatic arsenicals}

In vivo nitroreduction of Rox(III) by E. coli AW3110(DE3) cells carrying the constructed plasmids was analyzed spectrophotometrically as described previously (Chen et al., 2019b). Briefly, after overnight growth in LB medium supplemented with $25 \mu \mathrm{g} \mathrm{mL} \mathrm{m}^{-1}$ kanamycin and $0.3 \mathrm{mM}$ isopropyl $\beta-\mathrm{D}-1$ thiogalactopyranoside (IPTG) at $30{ }^{\circ} \mathrm{C}$, the cells were washed once with low phosphate medium (Oden et al., 1994) supplemented with $0.2 \%$ D-glucose and suspended in glucose-free M9 medium (Deininger, 1990) at a cell density of $A_{600 n m}=10.0$. The cell suspensions were then incubated with $60 \mu \mathrm{M} \operatorname{Rox}(\mathrm{III})$ at 30 ${ }^{\circ} \mathrm{C}$ with shaking (200 rpm) for $6 \mathrm{~h}$. The nitroreductase activity of cells was estimated by loss of absorbance at $410 \mathrm{~nm}$ determined with a Synergy H4 Hybrid Multi-Mode 
microplate reader (BioTek Instruments, Inc., Winooski, VT). In vivo nitroreductase activity of SmMdaB was also analyzed by arsenic speciation. Cell suspensions of $E$. coli AW3110(DE3) cells harboring $\mathrm{pET} 28 \mathrm{a}-\mathrm{SmmdaB}$ prepared at a cell density of $A_{600 n m}=2.0$ in the same way were cultured with $4 \mu \mathrm{M}$ Rox(III) or Nit(III) at $30{ }^{\circ} \mathrm{C}$ with shaking for indicated hours, and arsenic species in the culture medium were determined by HPLC-ICP-MS as described above.

\subsubsection{Protein purification}

E. coli $\mathrm{BL} 21(\mathrm{DE} 3)$ cells harboring $\mathrm{pET} 28 \mathrm{a}-\mathrm{SmmdaB}$ were grown in LB medium containing $50 \mathrm{mg} \mathrm{L}^{-1}$ kanamycin. The cells at an $A_{6000 m}$ of 0.6 were induced by $0.3 \mathrm{mM}$ IPTG and further cultured for $4 \mathrm{~h}$. The cells were then harvested, suspended in $5 \mathrm{~mL}$ per gram of wet cells in Buffer $A[50 \mathrm{mM}$ 4morpholinepropanesulfonic acid, $20 \mathrm{mM}$ imidazole, $0.5 \mathrm{M} \mathrm{NaCl}, 10 \mathrm{mM}$ 2mercaptoethanol, and $20 \%$ glycerol (v/v), $\mathrm{pH} 7.5]$, and lysed by a single passage through a French pressure cell at 20000 psi and treated with $2.5 \mu \mathrm{L}$ of diisopropyl fluorophosphate per gram of wet cells. After centrifugation at $150000 \mathrm{~g}$ for $1 \mathrm{~h}$, the resultant supernatant solution was loaded onto a $\mathrm{Ni}^{2+}$-nitrilotriacetic acid column (Qiagen, Hilden, Germany) at a flow rate of $0.5 \mathrm{~mL} \mathrm{~min}-1$. The column was washed with more than 25 column volumes of Buffer A. His-tagged SmMdaB was eluted with Buffer $A$ with increased concentration of imidazole $(0.2 \mathrm{M})$ and the purity was analyzed by sodium dodecyl sulfate polyacrylamide gel electrophoresis. Protein concentrations were estimated from $A_{280 n m}\left(\varepsilon=53910 \mathrm{M}^{-1} \cdot \mathrm{cm}^{-1}\right)$. SmMdaBcontaining fractions were divided into small portions, rapidly frozen, and stored at $-80^{\circ} \mathrm{C}$ until use. 


\subsubsection{FAD reductase activity}

The amount of flavin adenine dinucleotide (FAD) in purified SmMdaB was quantified by absorption at $450 \mathrm{~nm}$ using a molar extinction coefficient of 11300 $\mathrm{M}^{-1} \cdot \mathrm{cm}^{-1}$. Reduction of $\mathrm{FAD}$ by $\mathrm{SmMdaB}$ was assayed in $25 \mathrm{mM}$ Bis-Tris propane buffer $(\mathrm{pH} 7.0)$ containing $1 \mathrm{mM}$ EDTA and $0.1 \mathrm{mg} \mathrm{mL}^{-1}$ bovine serum albumin (BSA) at $37^{\circ} \mathrm{C}$. NADPH $(0.2 \mathrm{mM})$ was incubated with $1 \mu \mathrm{M}$ SmMdaB and/or $25 \mu \mathrm{M}$ FAD and the oxidation of NADPH was monitored by the decrease in absorbance at $340 \mathrm{~nm}\left(\varepsilon=6220 \mathrm{M}^{-1} \cdot \mathrm{cm}^{-1}\right)$.

\subsubsection{In vitro nitroreduction of pentavalent nitroaromatic arsenicals}

Nitroreductase activity of SmMdaB was examined in vitro using purified protein. Rox $(\mathrm{V})$ or Nit( $(\mathrm{V})(4 \mu \mathrm{M})$ was incubated at $37^{\circ} \mathrm{C}$ in the presence or absence of $1 \mu \mathrm{M} \mathrm{SmMdaB}$ in a reaction solution $(25 \mathrm{mM}$ Tris, $25 \mathrm{mM}$ Bis-Tris propane $(\mathrm{pH}$ 7.0), $1 \mathrm{mM}$ EDTA, $0.1 \mathrm{mg} \mathrm{mL}-1 \mathrm{BSA}, 0.2 \mathrm{mM}$ NADPH and $25 \mu \mathrm{M}$ FAD) with or without $5 \mathrm{mM}$ glutathione (GSH) and/or $1 \mathrm{mM}$ tris-(2-carboxyethyl)phosphine (TCEP). Reactions were collected at the indicated time points, and the arsenic species were analyzed by HPLC-ICP-MS as described above.

\subsection{Results}

\subsubsection{Reduction of MAs(V) by S. meliloti}

The pure culture of $S$. meliloti $\mathrm{Rm} 1021$ is able to reduce $\mathrm{MAs}(\mathrm{V})$ to $\mathrm{MAs}(\mathrm{III})$ while the pure culture of Streptomyces sp. MD1 cannot transform MAs(V) (Figure 4A, Table 2). In contrast, co-cultures of $S$. meliloti Rm1021 and the MAs(III)demethylating microbe Streptomyces sp. MD1 degrade $M A s(V)$ to inorganic As(III). These reesults are consistent with our concept that microbial communities 
are capable of sequentially reducing $\mathrm{MAs}(\mathrm{V})$ to $\mathrm{MAs}(\mathrm{III})$ and demethylating the $\operatorname{MAs}(I I I)$ to $\mathrm{As}(\mathrm{III})$.

\subsubsection{Reduction of aromatic arsenicals by S. meliloti}

We previously identified the ars/ gene for MAs(III) demethylation from Bacillus sp. MD1, an MAs(III)-demethylating bacterial isolate from Florida golf course soil (Yoshinaga and Rosen, 2014). Cells of the arsenic-hypersensitive $E$. coli strain AW3110 (Carlin et al., 1995) expressing ars/ degrade trivalent aromatic arsenicals, including p-ASA(III), Nit(III), and Rox(III) into inorganic As(III), suggesting that Arsl also catalyzes aerobic breakdown of these antimicrobial animal growth promoters. It seemed reasonable to consider that pentavalent aromatic arsenicals also undergo sequential reduction and Arsl-catalyzed C-As bond cleavage by microbial communities. This is formally similar to demethylation of the MSMA herbicide by the MAs(V)-reducing Burkholderia sp. MR1 and the MAs(III)-demethylating Streptomyces sp. MD1 from Florida golf course soil. However, neither Burkholderia sp. MR1 nor P. putida KT2440, the other known $\mathrm{MAs}(\mathrm{V})$ reducers, are able to reduce pentavalent aromatic arsenicals (Figure 5). In contrast, S. meliloti Rm1021 reduces them to the trivalent species. As with $\operatorname{MAs}(\mathrm{V})$, S. meliloti Rm1021 converts most of the $p-\mathrm{ASA}(\mathrm{V})$ to trivalent $p-\mathrm{ASA}(\mathrm{III})$ after 3 days (Figure 4B, Table 2). On the other hand, cells of S. meliloti Rm1021 transformed Nit(V) to primarily p-ASA(III) rather than Nit(III) (Figure 4C,D, Table 2). A time-course analysis shows that $S$. meliloti $\mathrm{Rm} 1021$ first reduces the nitro group of Nit(V), forming $p-A S A(V)$ (Figure $6 A, B, 36 \mathrm{~h}$ ), and subsequently reduces the arsenate group of $p-A S A(V)$, forming $p$-ASA(III) (Figure $6 B, 48$ and $60 \mathrm{~h}$ ). 
Similarly, S. meliloti Rm1021 transformed Rox(V) primarily to HAPA(III) rather than Rox(III) (Figure 4E,F, Table 2). The strain first reduces the nitroaromatic group of Rox $(V)$, transforming it into the pentavalent amine derivative 4-hydroxy-3aminophenylarsonate $(\mathrm{HAPA}(\mathrm{V}))$ (Figure $6 \mathrm{C}, \mathrm{D}, 36 \mathrm{~h})$ and subsequently reduces the $\mathrm{As}(\mathrm{V})$ moiety, forming HAPA(III) (Figure 6D, $60 \mathrm{~h}$ ). Two unknown species are also produced from Rox $(\mathrm{V})$ (Figure $6 \mathrm{C}, \mathrm{D})$ but not Nit(V) (Figure 6A,B). In addition, cells of S. meliloti Rm1021 produced small amounts of As(III) over time from both Nit(V) (Figure 6B) and Rox(V) (Figure 6D). Because S. meliloti Rm1021 does not have an ars/ gene, As(III) might be a minor secondary product of reduction of aromatic arsenicals and/or adventitious C-As bond cleavage by other lyases such as C-P (carbon-phosphorus) lyases (Parker et al., 1999). In contrast, neither Burkholderia sp. MR1 nor P. putida KT2440 reduce either the nitro group or As(V) group (Figure 5). The levels of the pentavalent aromatic arsenicals in the cultures of Burkholderia sp. MR1 and P. putida KT2440 are comparable to those in culture medium without cells, suggesting that these strains may not be able to take up pentavalent aromatic arsenicals. As is the case of $\mathrm{MAs}(\mathrm{V})$, a mixed culture of $S$. meliloti Rm1021 and Streptomyces sp. MD1 could degrade p-ASA(V) (Figure 4B), Nit(V) (Figure 4D), and Rox(V) (Figure 4F) into As(III). Given that S. meliloti is a ubiquitous rhizosphere soil bacterium (Galleguillos et al., 2000) and that ars/ genes are widely distributed from thermophiles (Nadar et al., 2016) to cyanobacteria (Yan et al., 2015), we propose that this multiple-step aromatic arsenical degradation pathway exists in the oxic environment and forms a part of the arsenic biogeochemical cycle. 


\subsubsection{Identification of the gene nitroreduction of aromatic arsenicals}

Because S. meliloti 1021 first reduces the nitro group and subsequently reduces the arsenate moiety (Figure 4D,F), we consider the possibility that each reduction uses a different enzyme. Nitroreduction of aromatic arsenicals has been observed in anaerobic degradation (Cortinas et al., 2006; Stolz et al., 2007; Han et al., 2017) indicating that nitroreduction is a critical step in the anaerobic degradation of environmental aromatic arsenicals. The und $A$ and $m t r C$ genes, which are involved in iron reduction in Shewanella putrefaciens W3-18-1 strain (Yang et al., 2013) have been suggested to account in part for anaerobic reduction of $\operatorname{Rox}(\mathrm{V})$ to HAPA(V) by S. putrefaciens CN-32 (Han et al., 2017). From S. putrefaciens 200 , the highly versatile facultative anaerobe carrying a large arsenic island with a number of genes in several ars operons (Chen and Rosen, 2016) we recently found a novel bacterial resistance mechanism for trivalent nitroaromatic arsenicals that is also initiated with nitroreduction (Chen et al., 2019b). Three linked genes widely distributed in ars operons from anaerobes, named arsEFG, confers resistance to Nit(III) and Rox(III) by a combination of nitroreduction of Nit(III) or Rox(III) to $p$-ASA(III) or HAPA(III) by ArsEF and efflux of $p$-ASA(III) or HAPA(III) by ArsG. In contrast, no molecular details are known for nitroreduction of aromatic arsenicals by aerobes. Possibilities include known bacterial nitroreductases and azoreductases that have central roles in reduction of nitroaromatic compounds (Roldán et al., 2008; Suzuki, 2019). Although their physiological roles remain unclear, these enzymes have gained considerable attention because of their potential applications in cancer treatment and 
bioremediation. A number of bacterial nitroreductases and azoreductases have been identified to activate nitroaromatic anticancer prodrugs such as CB1954 (5(aziridine-1-yl)-2,4- dinitrobenzamide) and PR-104A (2-((2-bromoethyl)-2-([(2hydroxyethyl)amino]carbonyl)-4,6-dinitroanilino)ethyl methanesulfonate) (Prosser et al., 2010; Green et al., 2013; Prosser et al., 2013) and nitroaromatic antimicrobial prodrugs nitrofurans such as nitrofrazone and nitrofurantoin (Race et al., 2005; Crescente et al., 2016) and to degrade nitroaromatic environmental contaminants such as 2,4,6-trinitrotoluene (TNT) (Kutty and Bennett, 2005; González-Pérez et al., 2007; Liu et al., 2007) Because these nitroaromatic compounds have similarities with $\operatorname{Rox}(\mathrm{V})$ and $\mathrm{Nit}(\mathrm{V})$, it was reasonable to consider that some are capable of reduction of $\operatorname{Nit}(\mathrm{V})$ and $\operatorname{Rox}(\mathrm{V})$. One candidate is $\mathrm{ArsH}$, which physiologically oxidizes $\operatorname{MAs}(I I I)$ to $\operatorname{MAs}(\mathrm{V})$ for detoxification (Chen et al., 2015a). ArsH from Pseudomonas aeruginosa PAO1 has been demonstrated to reduce a nitroaromatic antibiotic (nitrofurazone) to the hydroxylamine derivative (Crescente et al., 2016). However, a S. meliloti Rm1021 ars operon deletion strain lacking arsH ( $\triangle$ ars) (Yang, 2008; Chen et al., 2015a) retains the ability to reduce nitroaromatic arsenicals (Figure 7), indicating little or no contribution of SmArsH. We conducted a BLAST search of the genome of S. meliloti 1021 to identify orthologs of AzoR, MdaB, MsuE, and NemA enzymes that reduce CB1954 and/or PR-104A to hydroxylamine derivatives (Prosser et al., 2010; Green et al., 2013; Prosser et al., 2013). These include SmAzoR (NCBI accession no.: NP_385442), SmMdaB (NP_387022), SmMsuE (NP_438025), and SmNemA (NP_385670). There are also homologs of AZR and NitB, enzymes that reduce TNT to 
hydroxylamino-dinitrotoluene (Kutty and Bennett, 2005; Liu et al., 2007) including SmAZR (NP_386600) and SmNitB (NP_384119). To examine their potential role in reduction of nitroaromatic arsenicals, each of the above genes were cloned or synthesized and expressed in E. coli AW3110. Some bacteria, including E. coli, take up Rox(III) more effectively than Rox(V) (Chen and Rosen, 2016; Chen et al., $2019 b)$, so reduction of $\operatorname{Rox}(\mathrm{III})$ was examined in vivo. Both pentavalent and trivalent roxarsone absorbs with a $\lambda \max =410 \mathrm{~nm}$ at physiological $\mathrm{pH}$, whereas the corresponding HAPA amine is colorless, which allows nitroreduction to be monitored by loss of absorption at $410 \mathrm{~nm}$ (Figure 8). A significant decrease in A410nm was observed only in the cultures of cells expressing SmmdaB, so we focused on SmMdaB for further characterization. Rox(III) biotransformation by cells expressing SmmdaB was analyzed by HPLC-ICP-MS (Figure 9). In the culture medium of these cells, Rox(III) was mostly converted to HAPA(III), whereas no HAPA was produced in the medium of the control cells. The results are consistent with SmMdaB reduction of roxarsone to HAPA. In T24 human bladder carcinoma cells, the IC50 values for Rox(III) and HAPA(III) are 0.2 and $22 \mu \mathrm{M}$, respectively (Peng et al., 2017), suggesting that nitroreduction of Rox(III) to HAPA(III) could be a detoxification process. However, cells expressing SmmdaB, which transformed Rox(III) to HAPA(III), were not resistant to Rox(III) (data not shown), suggesting that $\operatorname{HAPA}(\mathrm{III})$ is also very toxic to $E$. coli and nitroreduction alone does not detoxify Rox(III) in the E. coli cells. 


\subsubsection{SmMdaB as a nitroaromatic arsenical reductase}

MdaB (modulator of drug activity B) has been shown to be an FAD- and $\mathrm{NADPH}$-dependent quinone reductase with nitroreductase activity with various nitroaromatic compounds (Prosser et al., 2013; Crescente et al., 2016). Nitroreduction by the S. meliloti ortholog SmMdaB was characterized in vitro using purified protein. Purified SmMdaB is yellow and exhibits an absorption spectrum with $\lambda$ max at $450 \mathrm{~nm}$ because of $61.2 \%$ FAD occupancy. However, it still requires supplementation with FAD in addition to NADPH to exhibit FAD reductase activity (Figure 10). SmMdaB requires an additional reducing potential such as $\mathrm{GSH}$ or TCEP for nitroreductase activity with $\operatorname{Rox}(\mathrm{V})$ in addition to FAD and NADPH (Figure 11A). The added reductant may be required to reduce the nitro group all the way to the amine. In contrast, purified MdaB from $P$. aeruginosa PAO1 (PaMdaB) catalyzes nitroreduction of nitrofranzone with only NADPH as the reductant in vitro, but the product is the hydroxylamine derivative and not the amine (Crescente et al., 2016). No nitroreduction was observed without the enzyme (Figure 11B). SmMdaB also reduces nitarsone to $p$-ASA both in vivo (Figure 12) and in vitro (Figure 13). Altogether, our results clearly demonstrate that SmMdaB is a nitroarmoatic arsenical nitroreductase. Because S. meliloti Rm1021 first reduces the nitro group of $\operatorname{Rox}(\mathrm{V})$ and $\operatorname{Nit}(\mathrm{V})$ to form $\mathrm{HAPA}(\mathrm{V})$ and $p-\mathrm{ASA}(\mathrm{V})$ before reducing the arsenate moiety, neither Rox(III) nor Nit(III) are produced throughout the entire transformation process (Figure 6A,C). We propose that nitroreduction by SmMdaB may be required for subsequent reduction of the pentavalent arsenic. Burkholderia sp. MR1 has no MdaB homolog. Although P. putida KT2440 has one 
MdaB homolog (PpMdaB) that shares $41 \%$ identities and $59 \%$ positives with SmMdaB, the strain exhibits no nitroreductase activity with nitroaromatic arsenicals, perhaps due to the poor uptake of those compounds (Figure 5B,C). BLAST analyses show that none of the reported Rox(V)-degrading anaerobes such as Alkaliphilus oremlandii (Fisher et al., 2008) and S. putrefaciens (Chen and Rosen, 2016; Han et al., 2017) carry mdaB genes, whereas Enterobacter sp. CZ1, the only reported Rox (V)-transforming aerobe (Huang et al., 2019), possesses multiple mdaB genes and the gene products share $\sim 40 \%$ identities and $\sim 60 \%$ positives with SmMdaB, suggesting that MdaB plays a role in nitroreduction of Rox $(\mathrm{V})$ and $\mathrm{Nit}(\mathrm{V})$ in that organism. However, MdaB homologs from E. coli (EcMdaB) and Pseudomonas syringae (PsMdaB) share $60 \%$ identities and $74 \%$ positives, nevertheless, only EcMdaB exhibits significant nitroreductase activity with PR-104A (Green et al., 2013), indicating that even minor differences in protein sequences could account for the substrate selectivity of different MdaBs. The $m d a B$ genes are widely distributed among both Gram-positive and Gram-negative bacteria. Structure-function analyses are required to elucidate the determinants of substrate selectivity. This information will shed light on the impact of MdaB on the fate of environmental nitroaromatic arsenicals. In contrast to nitroreduction, the molecular mechanisms of reduction of arsenate group in aromatic arsenicals are completely unknown. Further studies are required to identify new gene(s)/ protein(s) involved in the arsenate reduction of the growth promoters. 


\subsection{Figures and tables}
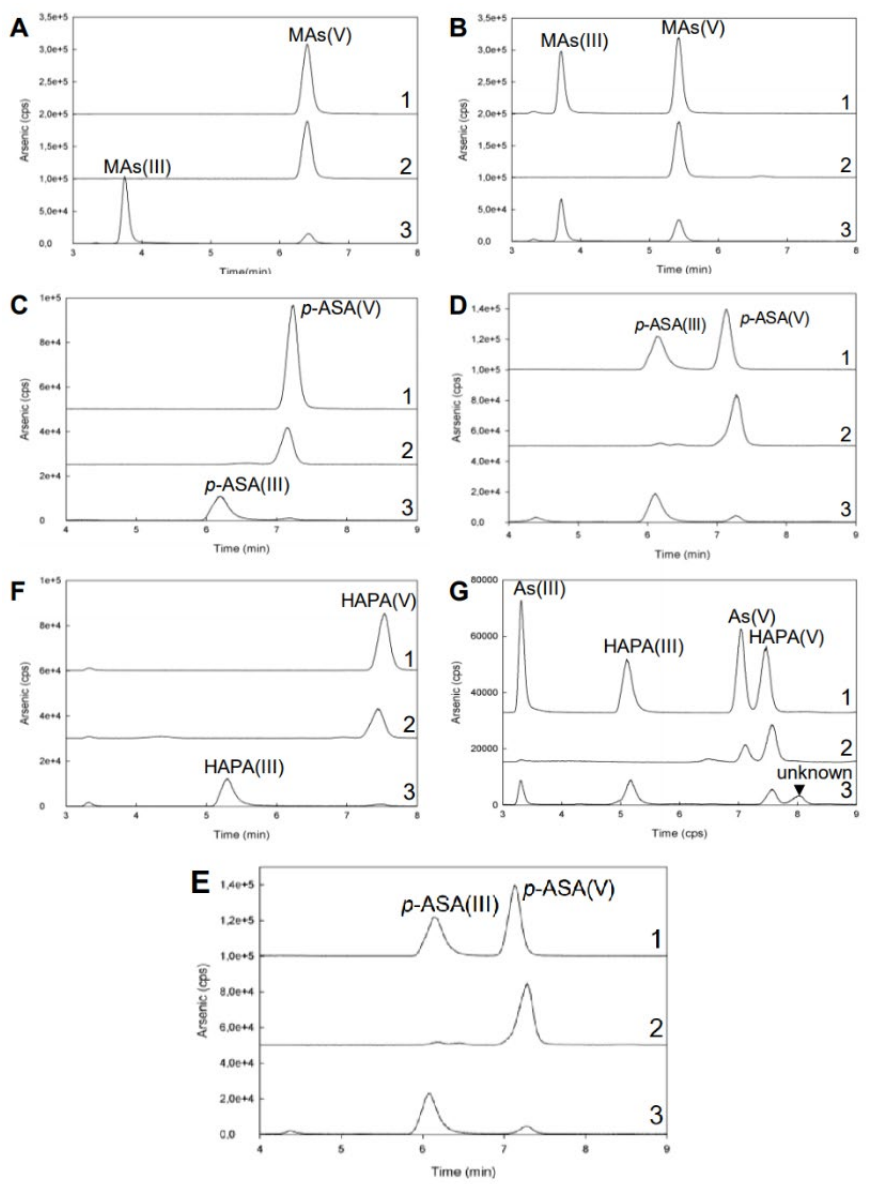

Figure 2. Oxidation of trivalent organoarsenicals. (A, C, F) MAs(III) $\left.\right|_{2}(\mathrm{~A}$, line 3$), p-A S A(I I I)(C$, line 3 ) and $\mathrm{HAPA}(\mathrm{III})(\mathrm{F}$, line 3 ) prepared as described in Materials and methods were oxidized with $\mathrm{H}_{2} \mathrm{O}_{2}$ (line 2) and compared with the corresponding pentavalent species (line 1) using HPLC-ICPMS. (B, D, E, G) The sole culture of $S$. meliloti with $M A s(V)$ (B, line 3), Nit(V) (D, line 3), p-ASA(V) $\left(E\right.$, line 3) and $\operatorname{Rox}(V)\left(G\right.$, line 3) were oxidized with $\mathrm{H}_{2} \mathrm{O}_{2}$ (line 2) and compared with standards (line 1) using HPLC-ICP-MS.<smiles>O=[N+]([O-])c1ccc(S(=O)(=O)O)cc1</smiles><smiles>CC(C)(C)ONc1ccc([As](=O)(O)O)cc1</smiles><smiles>Nc1ccc(O)cc1</smiles><smiles>O=[N+]([O-])c1cc(S(=O)(=O)O)ccc1O</smiles><smiles>Nc1cc(S(=O)(=O)O)ccc1O</smiles><smiles>Nc1cc([As](O)(O)O)ccc1O</smiles>

Nit(V)

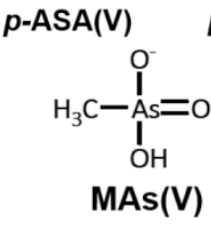<smiles>CO[AsH2]C</smiles>
HAPA(V) HAPA(III)<smiles>O[AsH2](O)O</smiles>

Figure 3. Chemical structure of arsenicals. 
A
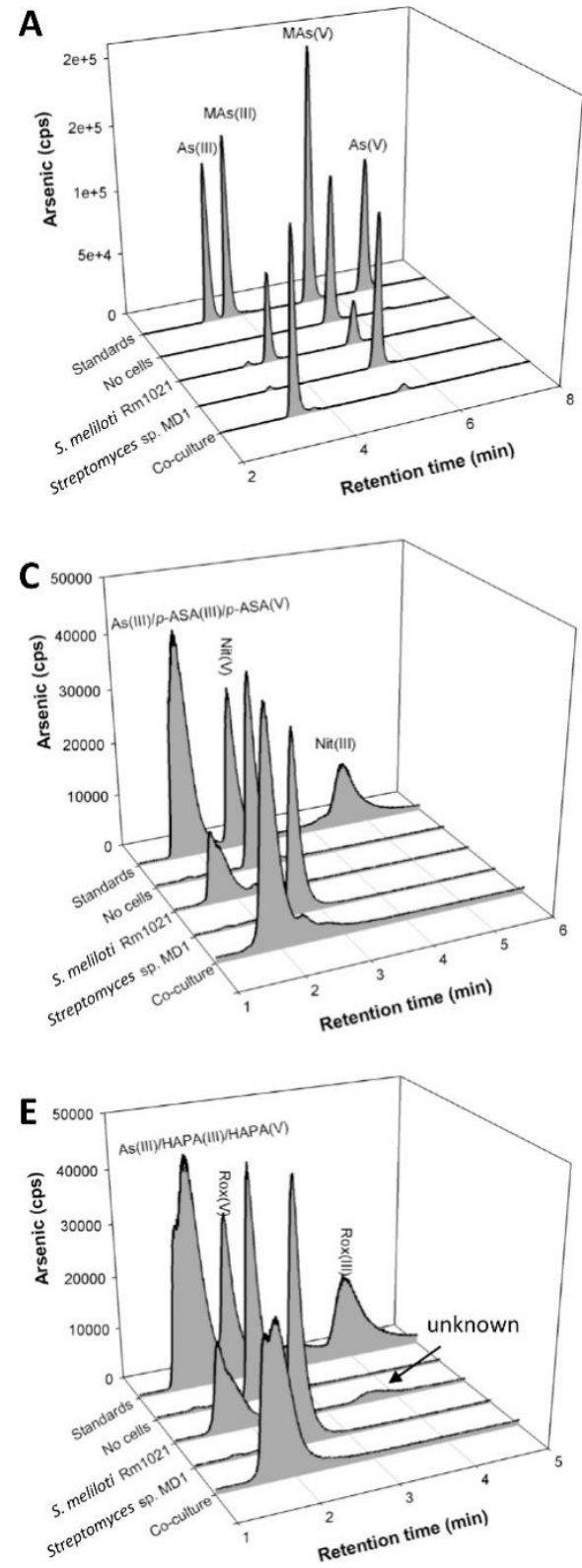

B
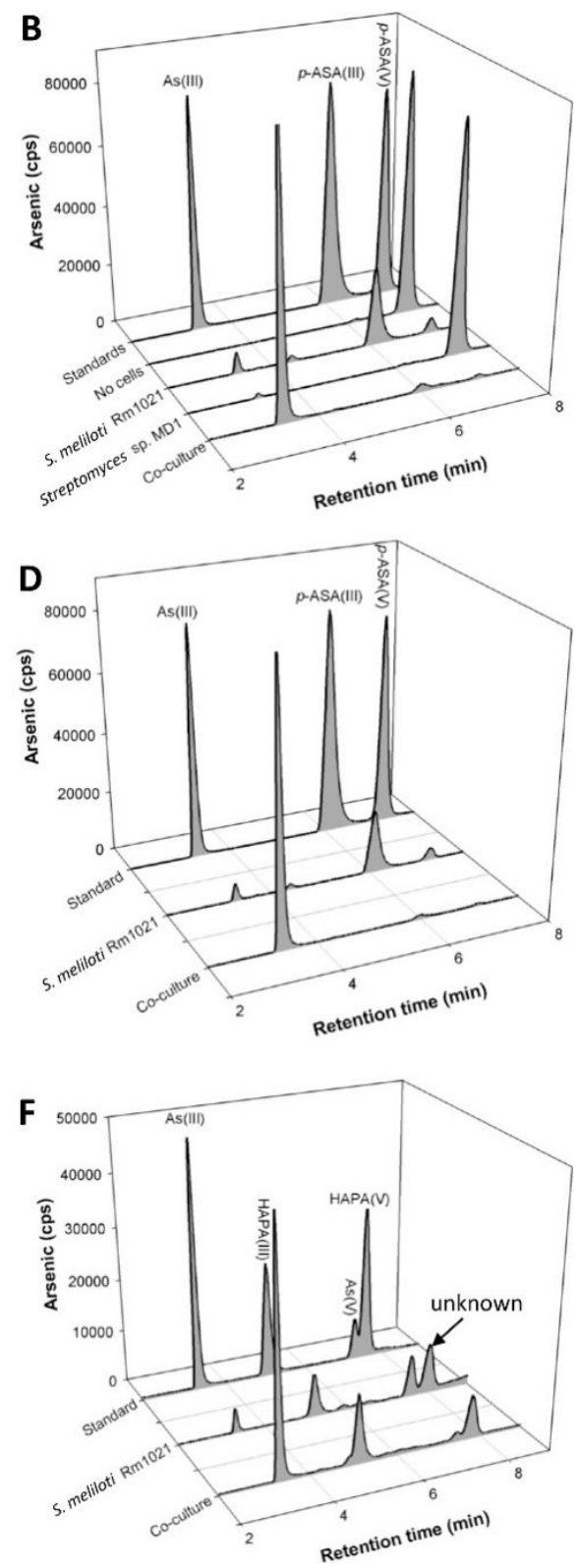

Figure 4. Organoarsenical reduction by $S$. meliloti $\mathrm{Rm} 1021$. Transformation of the indicated organoarsenicals in the presence or absence of S. meliloti Rm1021 and/or Streptomyces sp. MD1 was assayed by HPLC-ICP-MS, as described under the Materials and methods section. (A) Transformation of MAs(V) was analyzed using a C18 reverse-phase column. (B) Transformation of $p$-ASA(V) was analyzed using a C18 reverse-phase column. (C) Transformation of Nit(V) was first analyzed with a C4 reverse-phase column because the retention time of nitroaromatic arsenicals on the $\mathrm{C} 18$ column is much longer than the other species. (D) Transformation of Nit(V) was further analyzed using a C18 column because the C4 column cannot separate As(III), $p$ ASA $(I I I)$, and $p-A S A(V)$. (E) Transformation of Rox $(V)$ was first analyzed with a C4 column because the retention time of nitroaromatic arsenicals on the $\mathrm{C} 18$ column is much longer than the other species. (F) Transformation of Rox(V) was further analyzed with a C18 column to separate As(III), $\operatorname{HAPA}(\mathrm{III})$, and HAPA(V). 
Table 2. Quantification of arsenic biotransformation

\begin{tabular}{|c|c|c|c|c|c|c|}
\hline \multirow{2}{*}{$\begin{array}{l}\text { Substrate } \\
\text { MAs(V) }\end{array}$} & \multirow[t]{2}{*}{$\begin{array}{l}\text { Culture } \\
\text { Condition }\end{array}$} & \multicolumn{4}{|c|}{ Products found in culture medium $(\mu \mathrm{M})^{a}$} & \multirow[b]{2}{*}{ Total } \\
\hline & & $\mathrm{As}(\mathrm{III})$ & MAs(III) & $\mathrm{MAs}(\mathrm{V})$ & & \\
\hline & Media & $\mathrm{ND}^{b}$ & ND & $1.30( \pm 0.03)$ & & $1.24( \pm 0.06)$ \\
\hline & S. meliloti & $0.03( \pm 0.00)$ & $0.52( \pm 0.02)$ & $0.48( \pm 0.07)$ & & $1.03( \pm 0.08)$ \\
\hline & Streptomyces & $0.03( \pm 0.00)$ & ND & $1.22( \pm 0.04)$ & & $1.25( \pm 0.07)$ \\
\hline & Co-culture & $1.02( \pm 0.11)$ & $0.02( \pm 0.01)$ & $0.16( \pm 0.11)$ & & $1.2( \pm 0.06)$ \\
\hline \multirow[t]{5}{*}{$p$-ASA(V) } & & $\mathrm{As}(\mathrm{III})$ & $p-A S A(I I I)$ & $p-A S A(V)$ & & Total \\
\hline & Media & ND & $0.05( \pm 0.02)$ & $1.37( \pm 0.05)$ & & $1.42( \pm 0.10)$ \\
\hline & S. meliloti & $0.06( \pm 0.00)$ & $0.96( \pm 0.37)$ & $0.12( \pm 0.02)$ & & $1.13( \pm 0.61)$ \\
\hline & Streptomyces & ND & $0.03( \pm 0.01)$ & $1.39( \pm 0.03)$ & & $1.43( \pm 0.07)$ \\
\hline & Co-culture & $0.80( \pm 0.04)$ & ND & ND & & $0.81( \pm 0.06)$ \\
\hline \multirow[t]{5}{*}{$\operatorname{Nit}(\mathrm{V})$} & & $\mathrm{As}(\mathrm{III})$ & $p$-ASA(III) & $p-A S A(V)$ & $\operatorname{Nit}(\mathrm{V})$ & Total \\
\hline & Media & ND & ND & ND & $1.43( \pm 0.07)$ & $1.43( \pm 0.07)$ \\
\hline & S. meliloti & $0.06( \pm 0.01)$ & $0.43( \pm 0.34)$ & $0.07( \pm 0.01)$ & ND & $0.56( \pm 0.59)$ \\
\hline & Streptomyces & ND & ND & ND & $1.34( \pm 0.07)$ & $1.34( \pm 0.07)$ \\
\hline & Co-culture & $0.74( \pm 0.01)$ & ND & $0.01( \pm 0.00)$ & ND & $0.76( \pm 0.02)$ \\
\hline \multirow[t]{5}{*}{$\operatorname{Rox}(\mathrm{V})$} & & $\mathrm{As}(\mathrm{III})$ & HAPA(III) & HAPA(V) & $\operatorname{Rox}(\mathrm{V})$ & Total $^{c}$ \\
\hline & Media & ND & ND & ND & $1.44( \pm 0.06)$ & $1.44( \pm 0.06)$ \\
\hline & S. meliloti & $0.06( \pm 0.01)$ & $0.35( \pm 0.06)$ & $\begin{array}{c}0.19 \\
( \pm 0.01)\end{array}$ & $0.25( \pm 0.05)$ & $0.6( \pm 0.10)$ \\
\hline & Streptomyces & ND & ND & ND & $1.44( \pm 0.07)$ & $1.44( \pm 0.07)$ \\
\hline & Co-culture & $0.36( \pm 0.01)$ & $0.81( \pm 0.06)$ & $0.02( \pm 0.00)$ & ND & $1.2( \pm 0.08)$ \\
\hline
\end{tabular}

aTransformations of organoarsenicals in the indicated culture conditions were assayed in ST-10 medium, as described in Materials and methods. Data are the mean \pm SE $(n=3)$. ${ }^{b} N D$ : nondetectable. 'Unknown species are not reflected because their concentrations cannot be determined due to lack of the standard.

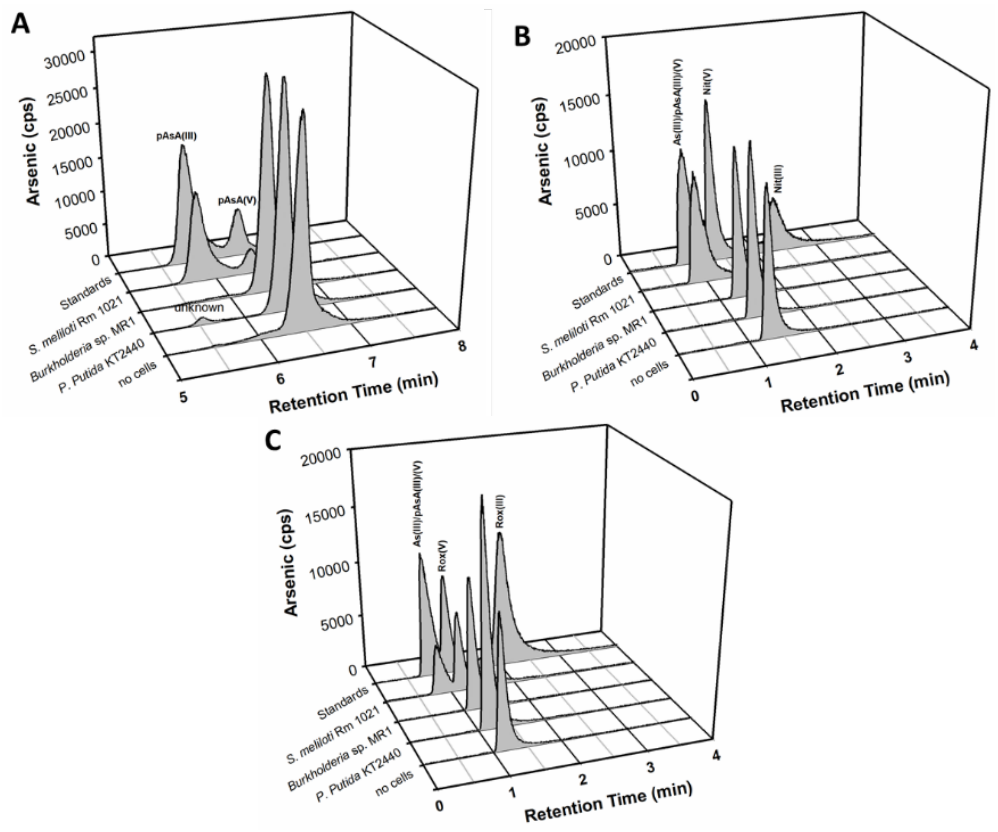

Figure 5. Bacterial transformation of aromatic arsenicals. Transformation of $p-A S A(V)(A), N i t(V)$ (B) and $\operatorname{Rox}(\mathrm{V})(\mathrm{C})$ by S. meliloti Rm1021, Burkholderia sp. MR1 and P. putida KT2440 were assayed by HPLC-ICP-MS with a C18 reverse-phase column (A) or a C4 reverse-phase column (B and $\mathrm{C}$ ) as described under Methods and Materials. 

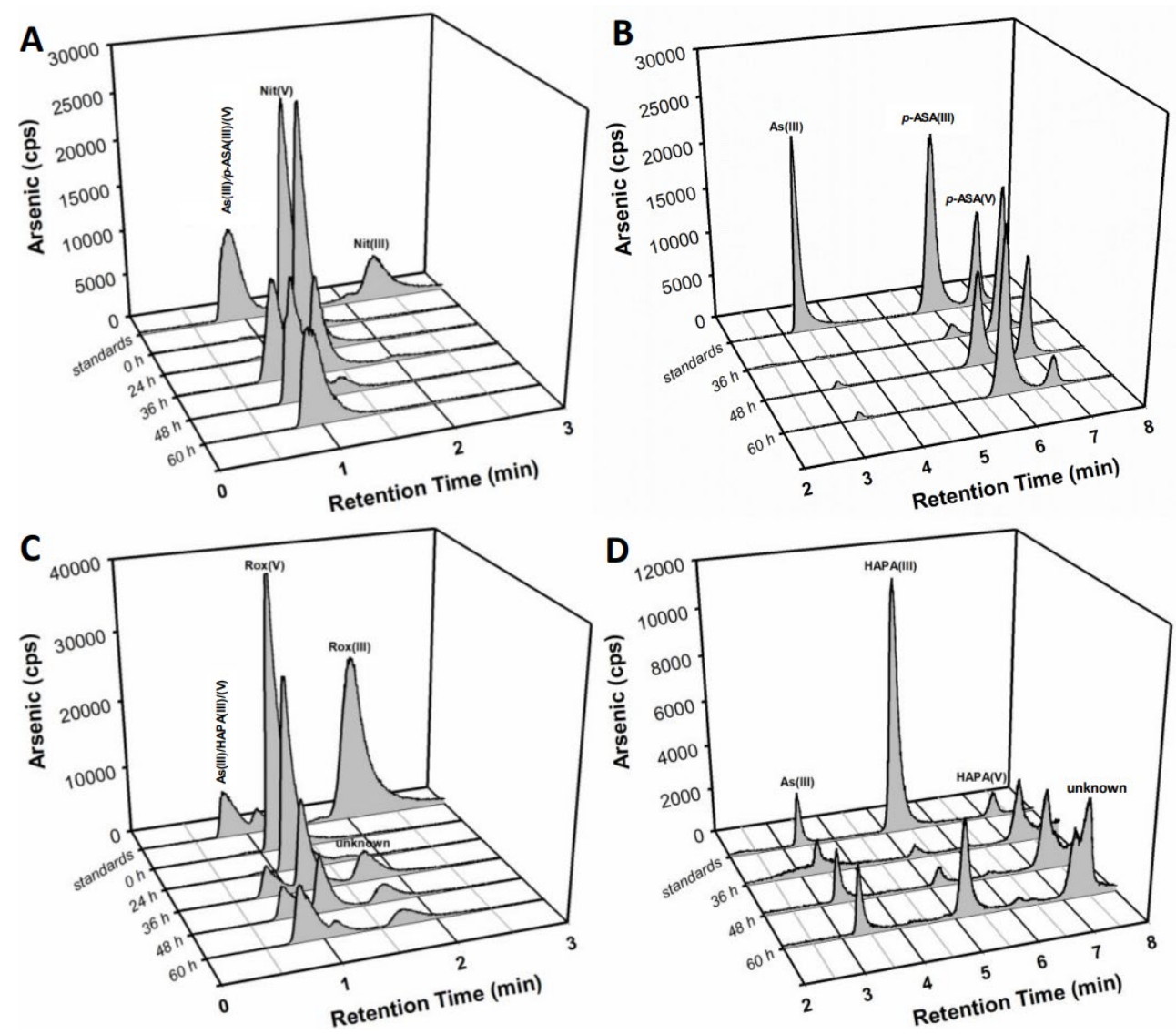

Figure 6. Time-course analysis of the transformation of nitroaromatic arsenicals by $S$. meliloti Rm1021. Transformation of Nit(V) ( $A$ and $B)$ and $\operatorname{Rox}(V)(C$ and $D)$ in cultures of S. meliloti Rm1021 after the indicated times $(0,24,36,48,60 \mathrm{~h})$ was analyzed by HPLC-ICP-MS with a C4 column (A and $C$ ) or a $C 18$ column ( $B$ and $D$ ) as described under Materials and methods.
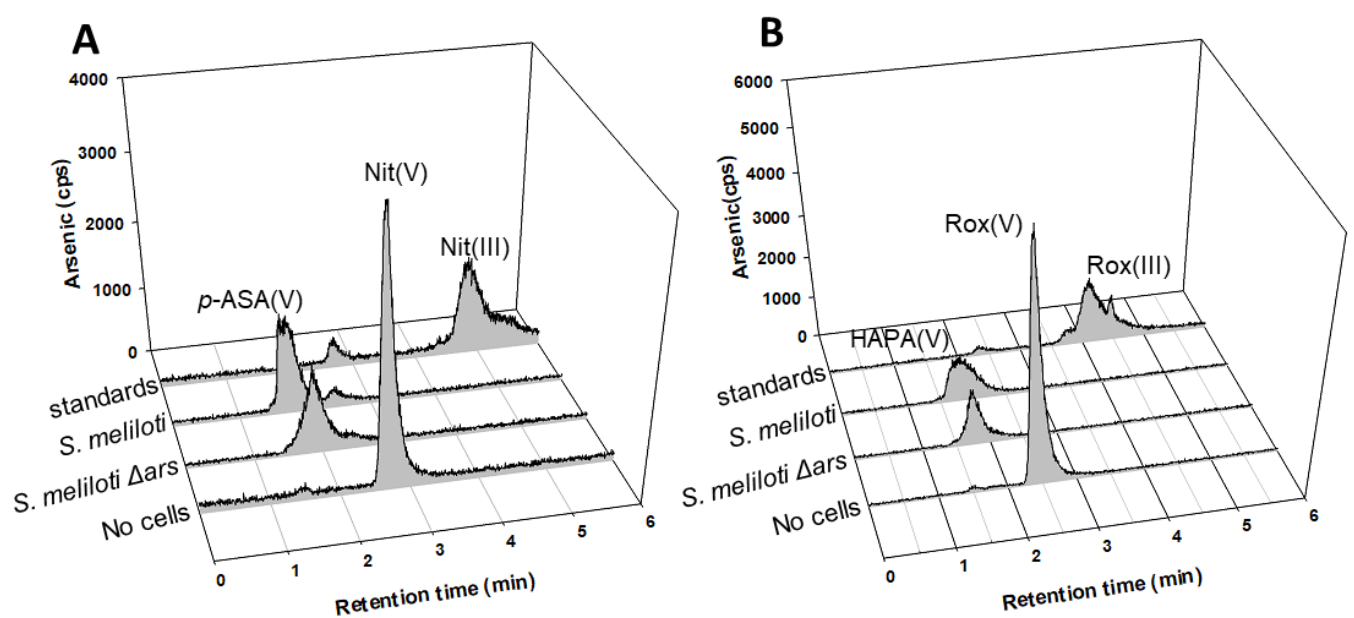

Figure 7. Nitroreduction of nitroaromatic arsenicals by a $S$. meliloti ars operon deletion strain. Transformation of $\operatorname{Nit}(\mathrm{V})(\mathrm{A})$ and $\operatorname{Rox}(\mathrm{V})(\mathrm{B})$ by S. meliloti Rm1021 (S. meliloti) and S. meliloti ars operon deletion strain (S. meliloti $\Delta$ ars) were assayed by HPLC-ICP-MS with a C4 reverse-phase column as described under Methods and Materials. 


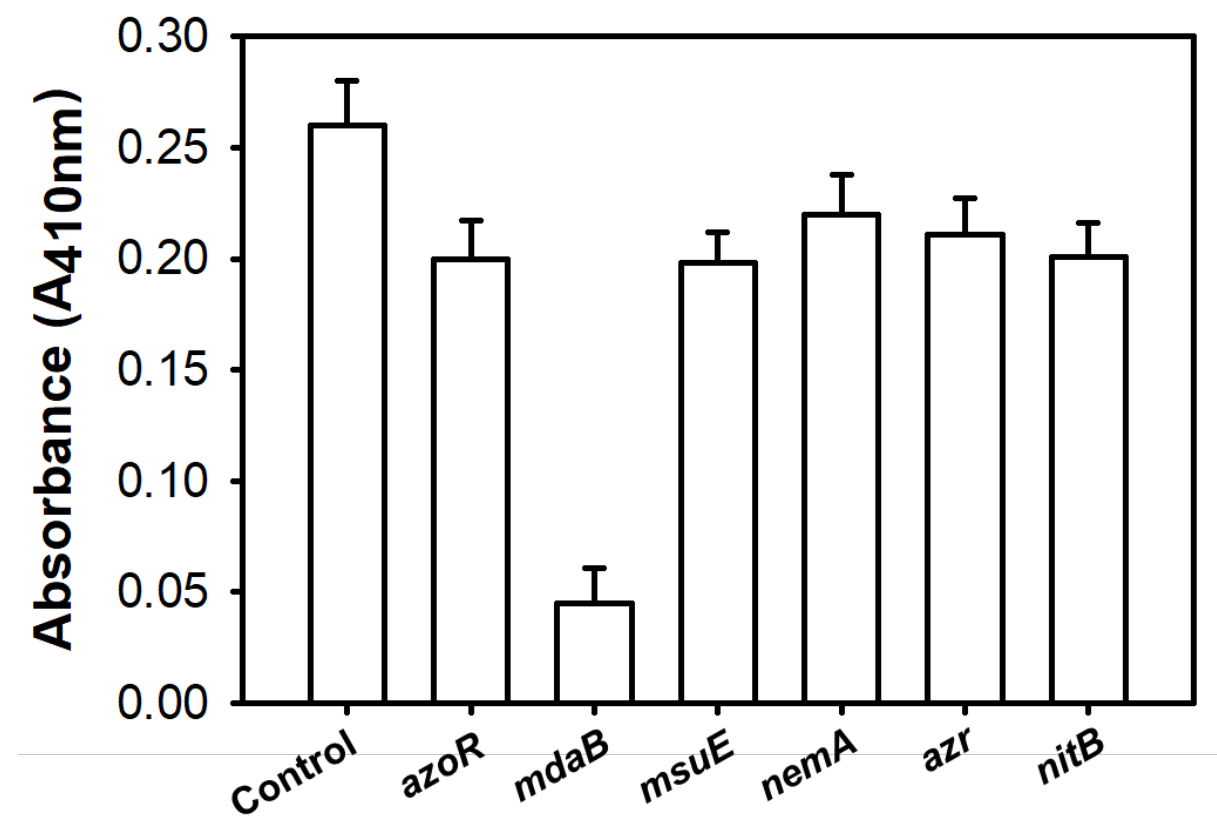

Figure 8. Nitroreduction of Rox(III) by E. coli AW3110 cells expressing candidate nitroreductase genes. Roxarsone nitroreductase activity of $E$. coli AW3110 cells that heterologously express each of the indicated candidate nitroreductase genes was estimated by the decrease of Rox(III) $\lambda_{\max }$ $\left(\mathrm{A}_{410 \mathrm{~nm}}\right)$ and compared with that of the non-expressing cells (Control) as described under Methods and Materials.

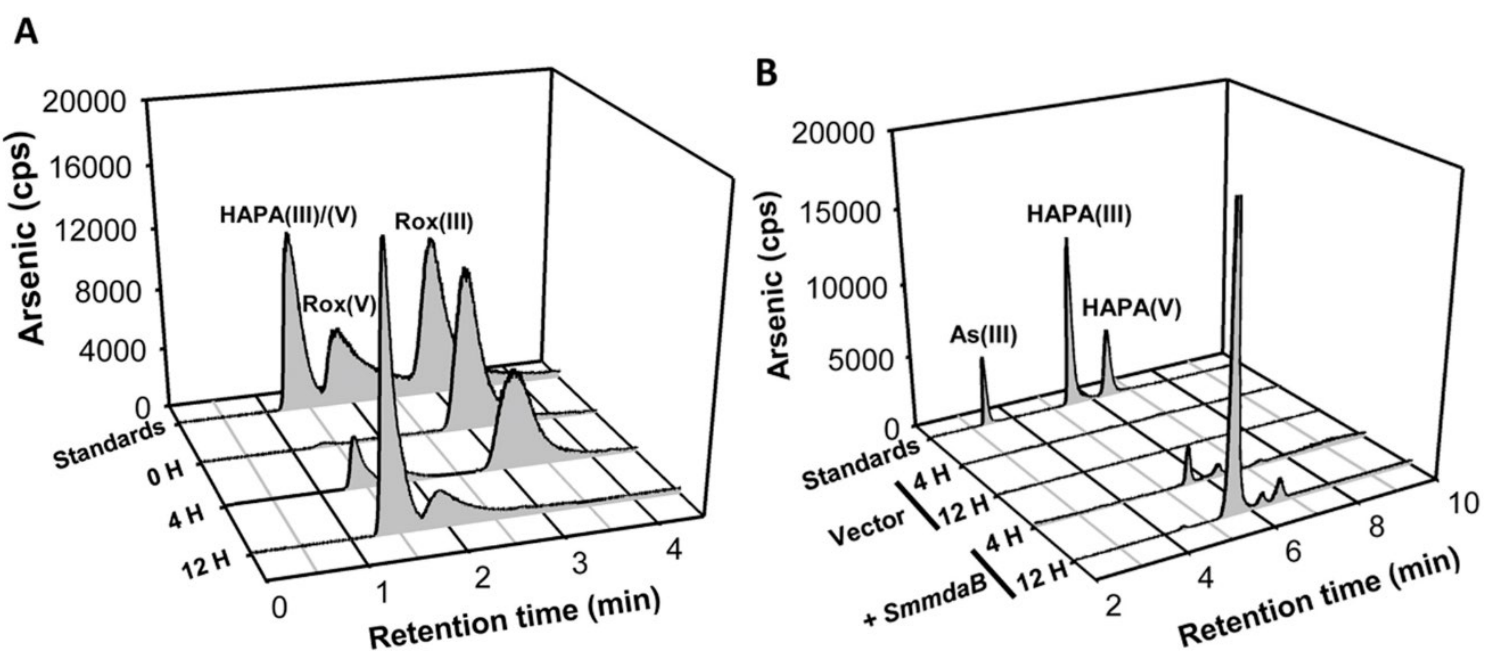

Figure 9. Roxarsone nitroreductase activity of SmMdaB in vivo. Nitroreduction of Rox(III) by SmmdaB-expressing AW3110 cells was analyzed by HPLC-ICP-MS as described under the Materials and methods section. As described in the legend to Figure 4, arsenic species in the culture of AW3110 cells carrying pET28a-SmmdaB after the indicated hours was first analyzed by a C4 column (A) and subsequently analyzed with a C18 column (B) to separate As(III), HAPA(III), and HAPA(V). Vector, AW3110 cells carrying the empty vector (pET28a); +SmmdaB, AW3110 cells carrying pET28a-SmmdaB. 


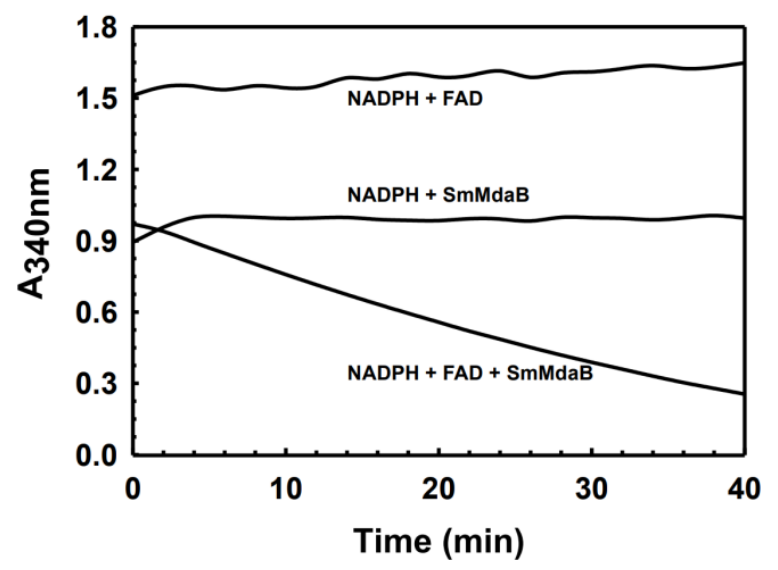

Figure 10. SmMdaB exhibits NADPH-dependent FAD reductase activity. Purified SmMdaB $(1 \mu \mathrm{M})$ was assayed for NADPH:FAD reductase activity with $0.2 \mathrm{mM}$ NADPH and $25 \mu \mathrm{M} \mathrm{FAD}$, as indicated. $\mathrm{NADPH}$ oxidation was followed from the decrease in absorption at $340 \mathrm{~nm}$.
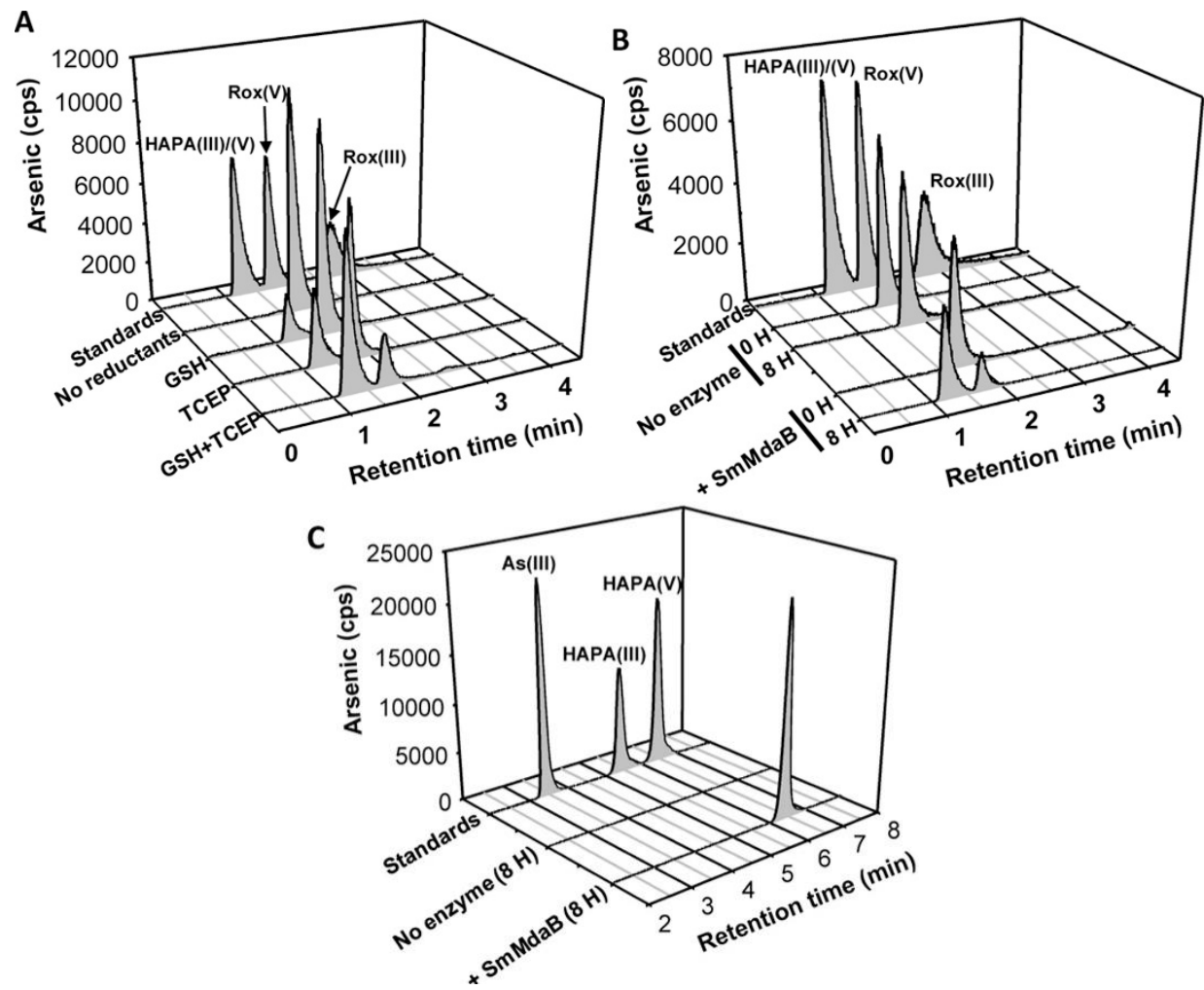

Figure 11. Roxarsone nitroreductase activity of $S m M d a B$ in vitro. Nitroreduction of Rox $(\mathrm{V})$ by purified SmMdaB was assayed as described under the Materials and methods section. (A) Effect of GSH and TCEP on nitroreduction of Rox $(\mathrm{V})$. Nitroreduction of Rox $(\mathrm{V})$ by SmMdaB was carried out with or without $5 \mathrm{mM} \mathrm{GSH}$ and/or $1 \mathrm{mM}$ TCEP, and the products were analyzed by HPLC-ICPMS with a $\mathrm{C} 4$ column. $(B, C)$ Nitroreduction of Rox $(V)$ by purified SmMdaB was carried out with 5 $\mathrm{mM} \mathrm{GSH}$ and $1 \mathrm{mM}$ TCEP and analyzed by HPLC-ICP-MS. As described in the legend to Figure 4, arsenic species in the reaction mixtures after the indicated time was first analyzed with a $\mathrm{C} 4$ reverse-phase column $(B)$ and subsequently analyzed on a C18 column (C) to separate As(III), HAPA(III), and HAPA(V). 

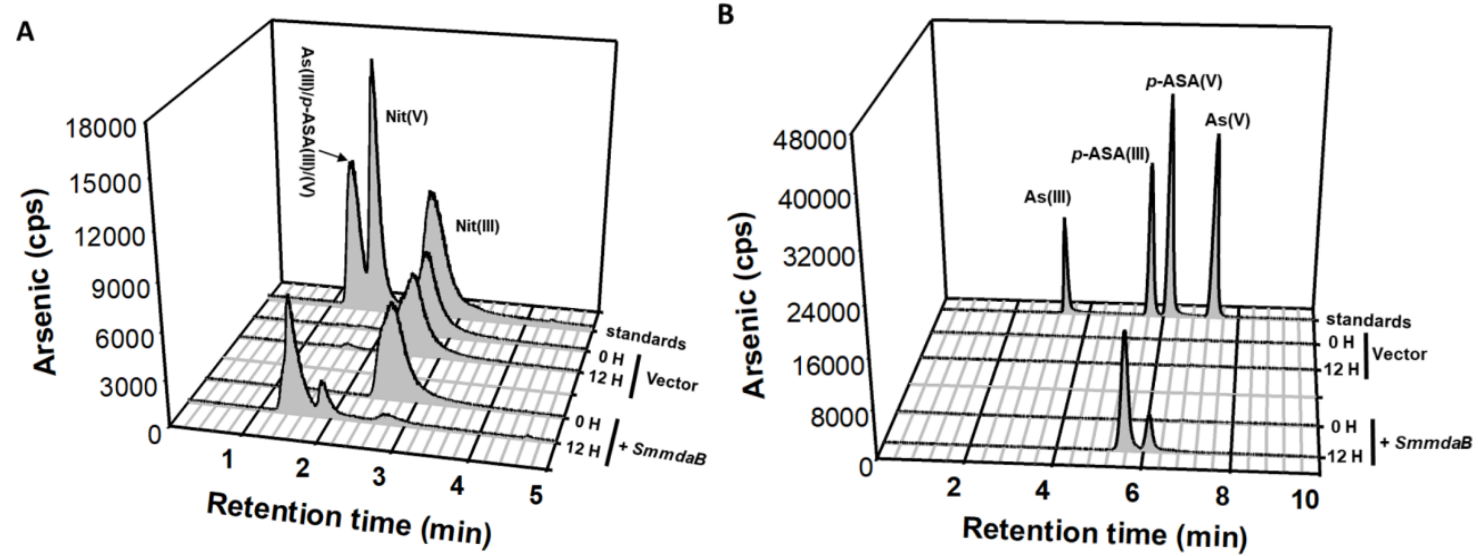

Figure 12. Nitroreduction of Nit(III) by SmmdaB-expressing AW3110 cells was analyzed by HPLCICP-MS as described under Materials and methods. Arsenic species in the culture after the indicated hours was first analyzed by a $\mathrm{C} 4$ column (A) and subsequently analyzed with a $\mathrm{C} 18$ column (B) to separate As(III), $p$-ASA(III) and $p$-ASA(V). Vector, AW3110 cells carrying the empty vector (pET28a); + SmmdaB, AW3110 cells carrying pET28a-SmmdaB.
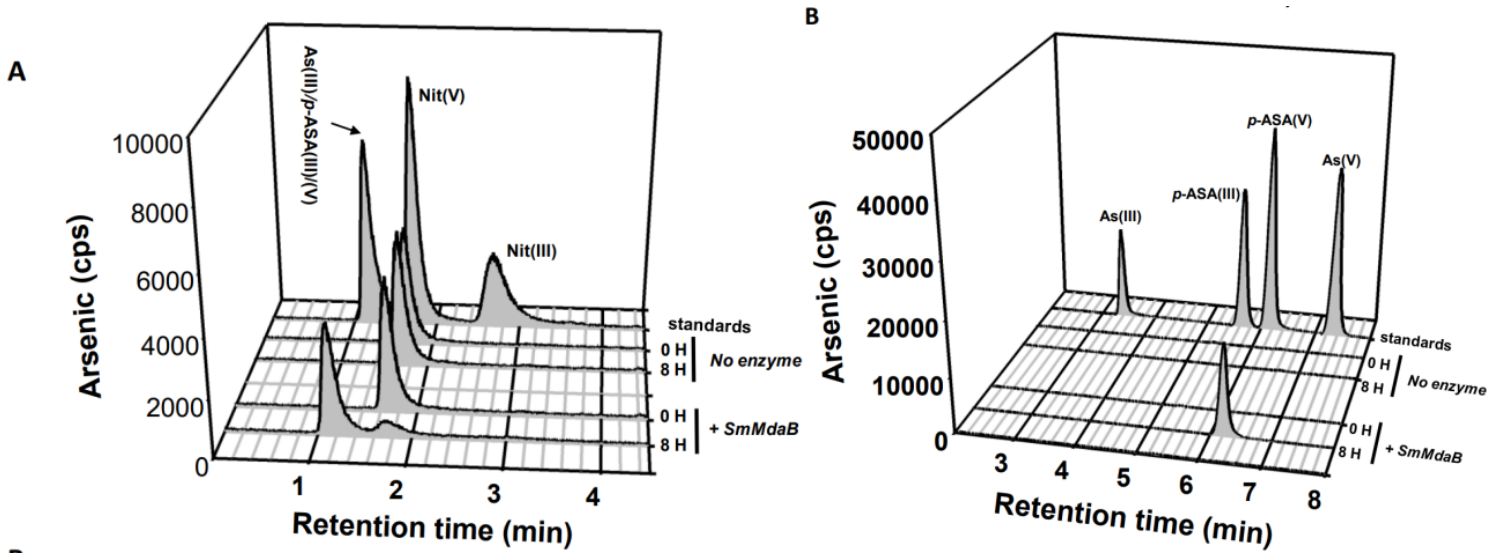

Figure 13. Nitroreduction of $\mathrm{Nit}(\mathrm{V})$ in vitro. $4 \mu \mathrm{M}$ of $\mathrm{Nit}(\mathrm{V})$ was incubated at $37^{\circ} \mathrm{C}$ in the presence (+ SmMdaB) or absence (No enzyme) of $1 \mu \mathrm{M} \mathrm{SmMdaB}$ in a reaction solution and arsenic species after the indicated hours were analyzed by HPLC-ICP-MS with a C4 column (A) or a C18 column (B) as described under Methods and Materials.

Table 3. Oligonucleotide primers used in plasmid constructions.

\begin{tabular}{ll}
\hline Primers & Sequences \\
\hline SmAzoR forward & 5'-TTTTGCTAGCAAAATCCTTCACATCGACTCC-3' (Nhel site underlined) \\
SmAzoR reverse & 5'-TTTTAAGCTTTTAGCTCGCGAGCTTCAGAAC-3' (Hindll site underlined) \\
SmNitB forward & 5'-CATGCCATGGCAACAGAAATCAACCATAG-3' (Ncol site underlined) \\
SmNitB reverse & 5'-TTTTTTCTCGAGTTCGCCCGTGAAACGTC-3' (Xhol site underlined) \\
SmNemA forward & 5'-TTTTCCATGGCAATGGCCTCTCTCTTCGAC-3' (Ncol site underlined) \\
SmNemA reverse & 5'-TTTT $\underline{\text { CTCGAGGGCGACGTTTTCGAGCGAC-3' (Xhol site underlined) }}$ \\
\hline
\end{tabular}




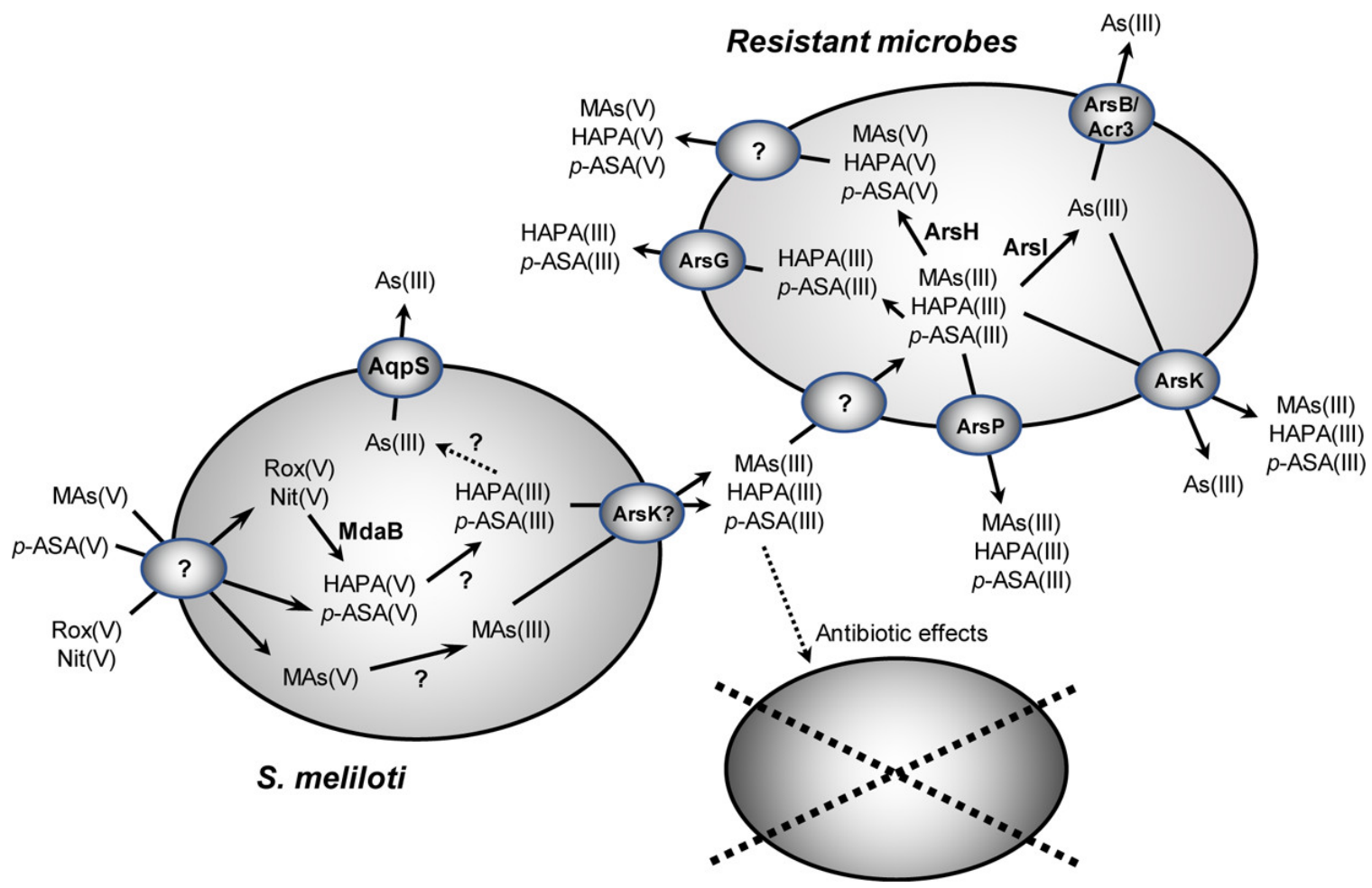

Figure 14. Degradation of pentavalent aromatic arsenicals by an aerobic microbial community is a multistep process. S. meliloti takes up pentavalent aromatic arsenicals by unknown transporters, reduces the nitro group by MdaB and the arsenate moiety by unknown reductases. The trivalent aminoaromatic arsenical products are extruded from the cells, possibly by ArsK. The secreted trivalent organoarsenicals act as antibiotics to kill competitors. A small portion of the aromatic arsenicals are degraded into As(III), which flows out of the cell by ArsK or by downhill movement through AqpS (Liu et al., 2016). Some community members detoxify the organoarsenical antibiotics by a variety of organoarsenical resistance mechanisms, as described in the text. $S$. meliloti degrades the pentavalent aromatic arsenicals by sequential reduction of the nitro and arsenate groups. C-As bond cleavage of the trivalent aminoaromatic arsenicals is carried out by other members of microbial communities such as Streptomyces species that carry an ars/gene. This is similar to the pathway of reduction of and resistance to the pentavalent methylarsenical herbicide MSMA.

\subsection{Discussion}

With the exception of only a few natural products as typified by chloramphenicol, most nitroaromatic compounds, including roxarsone and nitarsone, are produced and released into the environment via industrial processes or other human activities (Roldán et al., 2008). Synthetic nitroaromatic compounds are substrates for a number of bacterial nitroreductases and azoreductases, which 
play key roles in the degradation/detoxification/cometabolism process, suggesting that the environmental pollution could have posed a selective pressure for adaptive rapid evolution of the bacterial enzymes. Alternatively, these enzymes, which are more ancient than their synthetic substrates, may have evolved to reduce as-yet unidentified nitroaromatic natural products. We recently showed that arsEFG, widely distributed in anaerobes, confer resistance to trivalent aromatic arsenicals but not to other natural occurring inorganic and organic arsenicals (Oden et al., 1994), which is another example of rapid adaptation to the introduction of anthropogenic organoarsenical. In this study, we demonstrate that $S$. meliloti Rm1021 is capable of reduction of both the nitro and arsenate groups of pentavalent nitroaromatic arsenicals, producing trivalent aminoaromatic arsenicals as final products (Figures 4 and 6). In analogy with methylarsenicals, pentavalent aromatic arsenicals are much less toxic than inorganic arsenicals, while their trivalent forms are much more toxic than inorganic species (Chen et al., 2015a), suggesting that reduction of aromatic arsenicals is also an activation process. Thus, we propose that $S$. meliloti $\mathrm{Rm} 1021$ has gained the capacity to utilize the artificial aromatic arsenicals as an antibiotic to enhance their competitive advantage in contaminated sites-another way of bacterial rapid adaptation to synthetic arsenical contaminants. Trivalent aromatic arsenicals exhibit higher toxicity to bacteria compared to MAs(III) (Chen et al., 2015a; Chen et al., 2015b; Chen et al., 2019b), indicating that trivalent aromatic arsenicals would be more potent antibiotics and give a better competitive advantage to the reducers. Similar to the Caco-2 cell (Liu et al., 2016), both Burkholderia sp. MR1 and $P$. 
putida KT2440 poorly take up pentavalent aromatic arsenicals (Figure 5). Given that, one of the critical features that enables S. meliloti Rm1021 to reduce pentavalent aromatic arsenicals should be the effective uptake systems, which will be an important future research objective to be elucidated. There are several genes known to confer resistance to trivalent aromatic arsenicals (Figure 14). As mentioned above, arsEFG confers resistance specifically against trivalent nitroaromatic arsenicals via sequential reactions of nitroreduction by ArsEF and extrusion of the resulting amine derivatives by ArsG (Chen et al., 2019b). Both the MAs(III) oxidase ArsH and the MAs(III) efflux pump ArsP also detoxify Rox(III), although their catalytic efficiency is relatively lower compared to that for MAs(III) (Chen et al., 2015a; Chen et al., 2015b). In contrast, the MAs(III) demethylase ArsI is less selective and effectively degrades both MAs(III) and Rox(III) (Yoshinaga and Rosen, 2014). In addition, a recent study shows that arsK, the newly identified ars gene from Agrobacterium tumefaciens GW4 that encodes a novel arsenic efflux pump (AtArsK), confers resistance to $\mathrm{As}(\mathrm{III})$, antimonite ( $\mathrm{Sb}(\mathrm{III})$ ), MAs(III), and Rox(III) (Shi et al., 2018). Interestingly, S. meliloti 1021 carries an arsRK operon in one of the two megaplasmids pSymB (Finan et al., 2001). SmArsK shares $69 \%$ identities and $80 \%$ positives with AtArsK. SmArsK may function as an efflux pump for secretion of these trivalent organoarsenical antibiotics from S. meliloti 1021. In turn, other members of these microbial communities have acquired the resistance mechanisms described above. Given the recent but heavy usage of aromatic arsenicals in animal husbandry and the ubiquity of Sinorhizobium species in the rhizosphere, our results suggest that the 
agricultural application of aromatic arsenicals fuels bacterial competition for dominance and survival, especially in oxic environments. Microbial breakdown of organoarsenicals can lead to local arsenic contamination, which can alter the soil microbiome and retard plant growth.

\subsection{References}

Bagdasarian, M., Lurz, R., Rückert, B., Franklin, F.C.H., Bagdasarian, M.M., Frey, J., and Timmis, K.N. (1981). Specific-purpose plasmid cloning vectors II. Broad host range, high copy number, RSF 1010-derived vectors, and a host-vector system for gene cloning in Pseudomonas. Gene, 16:237-247.

Carlin, A., Shi, W., Dey, S., and Rosen, B.P. (1995). The ars operon of Escherichia coli confers arsenical and antimonial resistance. Journal of Bacteriology, 177:981-986.

Chen, J., Bhattacharjee, H., and Rosen, B.P. (2015a). ArsH is an organoarsenical oxidase that confers resistance to trivalent forms of the herbicide monosodium methylarsenate and the poultry growth promoter roxarsone. Molecular Microbiology, 96:1042-1052.

Chen, J., Madegowda, M., Bhattacharjee, H., and Rosen, B.P. (2015b). ArsP: a methylarsenite efflux permease. Molecular Microbiology, 98:625-635.

Chen, J., and Rosen, B.P. (2016). Organoarsenical Biotransformations by Shewanella putrefaciens. Environmental Science \& Technology, 50:79567963.

Chen, J., Yoshinaga, M., and Rosen, B.P. (2019a). The antibiotic action of methylarsenite is an emergent property of microbial communities. Molecular Microbiology, 111:487-494.

Chen, J., Zhang, J., and Rosen, B.P. (2019b). Role of ArsEFG in roxarsone and nitarsone detoxification and resistance. Environmental Science \& Technology, 53:6182-6191. 
Chen, S.-C., Sun, G.-X., Rosen, B.P., Zhang, S.-Y., Deng, Y., Zhu, B.-K., Rensing, C., and Zhu, Y.-G. (2017). Recurrent horizontal transfer of arsenite methyltransferase genes facilitated adaptation of life to arsenic. Scientific Reports, 7:7741.

Cortinas, I., Field, J.A., Kopplin, M., Garbarino, J.R., Gandolfi, A.J., and SierraAlvarez, R. (2006). Anaerobic Biotransformation of Roxarsone and Related $\mathrm{N}-\mathrm{Substituted}$ Phenylarsonic Acids. Environmental Science \& Technology, 40:2951-2957.

Crescente, V., Holland, Sinead M., Kashyap, S., Polycarpou, E., Sim, E., and Ryan, A. (2016). Identification of novel members of the bacterial azoreductase family in Pseudomonas aeruginosa. Biochemical Journal, 473:549-558.

D'Angelo, E., Zeigler, G., Beck, E.G., Grove, J., and Sikora, F. (2012). Arsenic species in broiler (Gallus gallus domesticus) litter, soils, maize (Zea mays L.), and groundwater from litter-amended fields. Science of the total environment, 438:286-292.

Deininger, P., 1990. Molecular cloning: A laboratory manual: Edited by J. Sambrook, EF Fritsch, and T. Maniatis. Cold Spring Harbor Laboratory Press, Cold Spring Harbor, NY, 1989 (in 3 volumes). Academic Press.

Feng, M., Schrlau, J.E., Snyder, R., Snyder, G.H., Chen, M., Cisar, J.L., and Cai, Y. (2005). Arsenic Transport and Transformation Associated with MSMA Application on a Golf Course Green. Journal of Agricultural and Food Chemistry, 53:3556-3562.

Finan, T.M., Weidner, S., Wong, K., Buhrmester, J., Chain, P., Vorhölter, F.J., Hernandez-Lucas, I., Becker, A., Cowie, A., Gouzy, J., Golding, B., and Pühler, A. (2001). The complete sequence of the 1,683-kb pSymB megaplasmid from the $\mathrm{N}_{2}$-fixing endosymbiont Sinorhizobium meliloti. Proceedings of the National Academy of Sciences, 98:9889-9894.

Fisher, E., Dawson, A.M., Polshyna, G., Lisak, J., Crable, B., Perera, E., Ranganathan, M., Thangavelu, M., Basu, P., and Stolz, J.F. (2008). Transformation of Inorganic and Organic Arsenic by Alkaliphilus oremlandii $s p$. nov. Strain OhILAs. Annals of the New York Academy of Sciences, 1125:230-241. 
Galibert, F., Finan, T.M., Long, S.R., Pühler, A., Abola, P., Ampe, F., BarloyHubler, F., Barnett, M.J., Becker, A., Boistard, P., Bothe, G., Boutry, M., Bowser, L., Buhrmester, J., Cadieu, E., Capela, D., Chain, P., Cowie, A., Davis, R.W., Dréano, S., Federspiel, N.A., Fisher, R.F., Gloux, S., Godrie, T., Goffeau, A., Golding, B., Gouzy, J., Gurjal, M., Hernandez-Lucas, I., Hong, A., Huizar, L., Hyman, R.W., Jones, T., Kahn, D., Kahn, M.L., Kalman, S., Keating, D.H., Kiss, E., Komp, C., Lelaure, V., Masuy, D., Palm, C., Peck, M.C., Pohl, T.M., Portetelle, D., Purnelle, B., Ramsperger, U., Surzycki, R., Thébault, P., Vandenbol, M., Vorhölter, F.-J., Weidner, S., Wells, D.H., Wong, K., Yeh, K.-C., and Batut, J. (2001). The Composite Genome of the Legume Symbiont Sinorhizobium meliloti. Science, 293:668-672.

Galleguillos, C., Aguirre, C., Miguel Barea, J., and Azcón, R. (2000). Growth promoting effect of two Sinorhizobium meliloti strains (a wild type and its genetically modified derivative) on a non-legume plant species in specific interaction with two arbuscular mycorrhizal fungi. Plant Science, 159:57-63.

Gannon, T.W., and Polizzotto, M.L. (2016). MSMA: Knowledge gaps to aid appropriate regulation of an efficacious herbicide. Agricultural \& Environmental Letters, 1.

Garbarino, J.R., Bednar, A.J., Rutherford, D.W., Beyer, R.S., and Wershaw, R.L. (2003). Environmental Fate of Roxarsone in Poultry Litter. I. Degradation of Roxarsone during Composting. Environmental Science \& Technology, $37: 1509-1514$.

González-Pérez, M.M., Van Dillewijn, P., Wittich, R.-M., and Ramos, J.L. (2007). Escherichia coli has multiple enzymes that attack TNT and release nitrogen for growth. Environmental Microbiology, 9:1535-1540.

Green, L.K., Storey, M.A., Williams, E.M., Patterson, A.V., Smaill, J.B., Copp, J.N., and Ackerley, D.F. (2013). The flavin reductase MsuE is a novel nitroreductase that can efficiently activate two promising next-generation prodrugs for gene-directed enzyme prodrug therapy. Cancers, 5:985-997.

Han, J.-C., Zhang, F., Cheng, L., Mu, Y., Liu, D.-F., Li, W.-W., and Yu, H.-Q. (2017). Rapid Release of Arsenite from Roxarsone Bioreduction by Exoelectrogenic Bacteria. Environmental Science \& Technology Letters, 4:350-355. 
Huang, K., Peng, H., Gao, F., Liu, Q., Lu, X., Shen, Q., Le, X.C., and Zhao, F.-J. (2019). Biotransformation of arsenic-containing roxarsone by an aerobic soil bacterium Enterobacter sp. CZ-1. Environmental Pollution, 247:482487.

Kutty, R., and Bennett, G.N. (2005). Biochemical characterization of trinitrotoluene transforming oxygen-insensitive nitroreductases from Clostridium acetobutylicum ATCC 824. Archives of Microbiology, 184:158-167.

Lehr, C.R., Polishchuk, E., Radoja, U., and Cullen, W.R. (2003). Demethylation of methylarsenic species by Mycobacterium neoaurum. Applied Organometallic Chemistry, 17:831-834.

Li, J., Pawitwar, S.S., and Rosen, B.P. (2016). The organoarsenical biocycle and the primordial antibiotic methylarsenite. Metallomics, 8:1047-1055.

Liu, G., Zhou, J., Lv, H., Xiang, X., Wang, J., Zhou, M., and Qv, Y. (2007). Azoreductase from Rhodobacter sphaeroides AS1.1737 is a flavodoxin that also functions as nitroreductase and flavin mononucleotide reductase. Applied Microbiology and Biotechnology, 76:1271-1279.

Liu, Q., Leslie, E.M., and Le, X.C. (2016). Accumulation and Transport of Roxarsone, Arsenobetaine, and Inorganic Arsenic Using the Human Immortalized Caco-2 Cell Line. Journal of Agricultural and Food Chemistry, 64:8902-8908.

Maki, T., Hasegawa, H., Watarai, H., and Ueda, K. (2004). Classification for Dimethylarsenate-decomposing Bacteria Using a Restrict Fragment Length Polymorphism Analysis of 16S rRNA Genes. Analytical Sciences, 20:61-68.

Maki, T., Takeda, N., Hasegawa, H., and Ueda, K. (2006). Isolation of monomethylarsonic acid-mineralizing bacteria from arsenic contaminated soils of Ohkunoshima Island. Applied Organometallic Chemistry, 20:538544.

Meade, H.M., Long, S.R., Ruvkun, G.B., Brown, S.E., and Ausubel, F.M. (1982). Physical and genetic characterization of symbiotic and auxotrophic mutants of Rhizobium meliloti induced by transposon Tn5 mutagenesis. Journal of Bacteriology, 149:114-122. 
Nadar, V.S., Yoshinaga, M., Pawitwar, S.S., Kandavelu, P., Sankaran, B., and Rosen, B.P. (2016). Structure of the Arsl C-As Lyase: Insights into the Mechanism of Degradation of Organoarsenical Herbicides and Growth Promoters. Journal of Molecular Biology, 428:2462-2473.

Oden, K.L., Gladysheva, T.B., and Rosen, B.P. (1994). Arsenate reduction mediated by the plasmid-encoded ArsC protein is coupled to glutathione. Molecular Microbiology, 12:301-306.

Parker, G.F., Higgins, T.P., Hawkes, T., and Robson, R.L. (1999). Rhizobium (Sinorhizobium) meliloti phn Genes: Characterization and Identification of Their Protein Products. Journal of Bacteriology, 181:389-395.

Peng, H., Hu, B., Liu, Q., Li, J., Li, X.-F., Zhang, H., and Le, X.C. (2017). Methylated Phenylarsenical Metabolites Discovered in Chicken Liver. Angewandte Chemie International Edition, 56:6773-6777.

Prosser, G.A., Copp, J.N., Mowday, A.M., Guise, C.P., Syddall, S.P., Williams, E.M., Horvat, C.N., Swe, P.M., Ashoorzadeh, A., Denny, W.A., Smaill, J.B., Patterson, A.V., and Ackerley, D.F. (2013). Creation and screening of a multi-family bacterial oxidoreductase library to discover novel nitroreductases that efficiently activate the bioreductive prodrugs CB1954 and PR-104A. Biochemical pharmacology, 85:1091-1103.

Prosser, G.A., Copp, J.N., Syddall, S.P., Williams, E.M., Smaill, J.B., Wilson, W.R., Patterson, A.V., and Ackerley, D.F. (2010). Discovery and evaluation of Escherichia coli nitroreductases that activate the anti-cancer prodrug CB1954. Biochemical pharmacology, 79:678-687.

Qin, J., Rosen, B.P., Zhang, Y., Wang, G., Franke, S., and Rensing, C. (2006). Arsenic detoxification and evolution of trimethylarsine gas by a microbial arsenite S-adenosylmethionine methyltransferase. Proceedings of the National Academy of Sciences, 103:2075-2080.

Quinn, J.P., and McMullan, G. (1995). Carbon-arsenic bond cleavage by a newly isolated Gram-negative bacterium, strain ASV2. Microbiology, 141:721727. 
Race, P.R., Lovering, A.L., Green, R.M., Ossor, A., White, S.A., Searle, P.F., Wrighton, C.J., and Hyde, E.I. (2005). Structural and Mechanistic Studies of Escherichia coli Nitroreductase with the Antibiotic Nitrofurazone. Journal of Biological Chemistry, 280:13256-13264.

Roldán, M.D., Pérez-Reinado, E., Castillo, F., and Moreno-Vivián, C. (2008). Reduction of polynitroaromatic compounds: the bacterial nitroreductases. FEMS Microbiology Reviews, 32:474-500.

Shi, K., Li, C., Rensing, C., Dai, X., Fan, X., and Wang, G. (2018). Efflux transporter ArsK is responsible for bacterial resistance to arsenite, antimonite, trivalent roxarsone, and methylarsenite. Appl. Environ. Microbiol., 84:e0184201818.

Stice, S., Liu, G., Matulis, S., Boise, L.H., and Cai, Y. (2016). Determination of multiple human arsenic metabolites employing high performance liquid chromatography inductively coupled plasma mass spectrometry. Journal of Chromatography B, 1009-1010:55-65.

Stolz, J.F., Perera, E., Kilonzo, B., Kail, B., Crable, B., Fisher, E., Ranganathan, M., Wormer, L., and Basu, P. (2007). Biotransformation of 3-Nitro-4hydroxybenzene Arsonic Acid (Roxarsone) and Release of Inorganic Arsenic by Clostridium Species. Environmental Science \& Technology, 41:818-823.

Suzuki, H. (2019). Remarkable diversification of bacterial azoreductases: primary sequences, structures, substrates, physiological roles, and biotechnological applications. Applied Microbiology and Biotechnology, 103:3965-3978.

Yan, Y., Ye, J., Xue, X.-M., and Zhu, Y.-G. (2015). Arsenic Demethylation by a C.As Lyase in Cyanobacterium Nostoc sp. PCC 7120. Environmental Science \& Technology, 49:14350-14358.

Yang, H.-C., 2008. Functional and structural studies of a novel arsenic detoxification pathway in the legume symbiont Sinorhizobium meliloti. Wayne State University. 
Yang, H.-C., Cheng, J., Finan, T.M., Rosen, B.P., and Bhattacharjee, H. (2005). Novel Pathway for Arsenic Detoxification in the Legume Symbiont Sinorhizobium meliloti. Journal of Bacteriology, 187:6991-6997.

Yang, Y., Chen, J., Qiu, D., and Zhou, J. (2013). Roles of UndA and MtrC of Shewanella putrefaciens W3-18-1 in iron reduction. BMC Microbiology, 13:267.

Yao, L., Huang, L., He, Z., Zhou, C., Lu, W., and Bai, C. (2016). Delivery of roxarsone via chicken diet $\rightarrow$ chicken $\rightarrow$ chicken manure $\rightarrow$ soil $\rightarrow$ rice plant. Science of the total environment, 566-567:1152-1158.

Yoshinaga, M., Cai, Y., and Rosen, B.P. (2011). Demethylation of methylarsonic acid by a microbial community. Environmental Microbiology, 13:1205-1215.

Yoshinaga, M., and Rosen, B.P. (2014). A C. As lyase for degradation of environmental organoarsenical herbicides and animal husbandry growth promoters. Proceedings of the National Academy of Sciences, 111:77017706.

Zhu, Y.-G., Xue, X.-M., Kappler, A., Rosen, B.P., and Meharg, A.A. (2017). Linking genes to microbial biogeochemical cycling: lessons from arsenic. Environmental Science \& Technology, 51:7326-7339.

Zhu, Y.-G., Yoshinaga, M., Zhao, F.-J., and Rosen, B.P. (2014). Earth abides arsenic biotransformations. Annual Review of Earth and Planetary Sciences, 42:443-467. 


\section{Chapter 4. ORGANOARSENICALS INHIBIT BACTERIAL PEPTIDOGLYCAN BIOSYNTHESIS BY TARGETING THE ESSENTIAL ENZYME MurA}

\subsection{Introduction}

Arsenic is among the most prevalent toxic elements in the environment. Life first arose in environments with substantial concentrations of inorganic arsenic. Although evolution of genes for arsenic tolerance was a first priority for primordial life, the ubiquity of arsenic provided an opportunity for microbes to adapt those pathways to produce organoarsenical antimicrobial compounds that could give them a competitive advantage over other members of microbial communities (Zhu et al., 2014). Microbial arsenic biotransformations include redox cycles, methylation, thiolation and incorporation into complex organic molecules such as arsenolipids and arsenosugars, creating a global arsenic biogeochemical cycle (Zhu et al., 2017). As a result, several organisms produce a variety of arseniccontaining natural products that differ in toxicity. In general pentavalent methylarsenicals are less toxic than inorganic As(III), with the exception of thiolated species (Fan et al., 2018) and the recently-discovered pentavalent organoarsenical antibiotic arsinothricin (Nadar et al., 2019). In contrast, trivalent organoarsenical natural products such as $\operatorname{MAs}(\mathrm{III})$ and dimethylarsenite (DMAs(III)) are much more toxic than As(III) (Petrick et al., 2000; Naranmandura et al., 2011; Yoshinaga and Rosen, 2014). These organoarsenicals are products of the enzyme As(III) S-adenosylmethionine (SAM) methyltransferase (ArsM in microbes and AS3MT in animals). ArsM is postulated to have co-evolved with the MAs(III) efflux permease ArsP in an anoxic environment prior to the GOE (Chen 
et al., 2017). We proposed that the antibiotic-like properties of its products provided a competitive advantage for producers, over other members of anaerobic microbial communities (Li et al., 2016; Chen et al., 2018). Following the GOE, trivalent arsenicals were generally oxidized to their less toxic pentavalent forms such as methylarsenate $(\mathrm{MAs}(\mathrm{V}))$. In response, members of aerobic microbial communities evolved mechanisms to reduce $M A s(V)$, giving them a competitive advantage over MAs(III)-sensitive microbes (Yoshinaga et al., 2011). Yet other members of aerobic microbial communities developed oxygen-dependent resistance to MAs(III) such as $\mathrm{ArsH}$, which oxidizes MAs(III) to MAs(V) (Chen et al., 2015a) and the C-As bond lyase Arsl, which demethylates MAs(III) to less toxic As(III) (Yoshinaga and Rosen, 2014), suggesting that this competition between microbial communities is a driving force behind the arsenic biogeocycle. Indeed, the MAs(III) efflux permease ArsP is another pathway for resistance (Chen et al., 2015b).

The goal of this study was to identify possible targets of MAs(III) inhibition that can explain its strong antibiotic properties. We chose to search for new genes in the environmentally ubiquitous gram-negative facultative anaerobe $S$. putrefaciens 200 because it has a number of ars operons with many known and putative genes for arsenic resistance and a wide capacity for organoarsenic biotransformation and transport, suggesting evolution in an environment containing MAs(III) (Chen et al., 2015b; Chen and Rosen, 2016). We constructed a genomic expression library from S. putrefaciens 200 and selected for MAs(III) resistance clones in E. coli. Overexpression of target enzymes have been shown to confer resistance to antibiotics such as triclosan, trimethoprim, penicillin, and 
other $\beta$-lactams (Henze and Berger-Bächi, 1996; Palmer and Kishony, 2014). One resistance clone with an insert of $2.8 \mathrm{~kb}$ was sequenced and shown to express the S. putrefaciens murA gene. MurA catalyzes transfer of enolpyruvate from phosphoenolpyruvate (PEP) to uridine diphosphate $\mathrm{N}$-acetylglucosamine (UDPGlcNAc), the first committed step in peptidoglycan biosynthesis (Barreteau et al., 2008). Thus, we considered the possibility that MurA is a target of MAs(III), which could inhibit peptidoglycan biosynthesis, and increasing MurA expression could overcome the antimicrobial activity of MAs(III). From the use of arsenic-containing minerals in ancient China to Paul Ehrlich's synthesis of the aromatic arsenical salvarsan, the first chemotherapeutic agent for syphilis, arsenic-containing drugs have been used extensively throughout history (Lloyd et al., 2005; Liu et al., 2008) In modern medicine, arsenic trioxide (ATO) is an FDA-approved, effective anticancer agent for promyelocytic leukemia (APL) (Ralph, 2008). With the increasing threats posed by antibiotic resistance, the bacterial peptidoglycan biosynthetic pathway has been a recent focus for development of new inhibitors (Brackman et al., 2016; Chang et al., 2017). The identification of cell wall biosynthesis as a target of MAs(III) affords the prospect for development of new arsenic-containing antimicrobial agents.

\subsection{Materials and methods}

\subsubsection{Chemicals}

All chemicals were obtained from MilliporeSigma (Burlington, MA) unless otherwise mentioned. For in vivo assays, $\mathrm{MAs}(\mathrm{V})$ was reduced to $\mathrm{MAs}(\mathrm{III})$ by a slight modification of a previous procedure (Johnson, 1971). Briefly, $0.2 \mathrm{mM}$ 
$\mathrm{MAs}(\mathrm{V})$ was mixed with $27 \mathrm{mM} \mathrm{Na} 2 \mathrm{~S}_{2} \mathrm{O}_{3}, 66 \mathrm{mM} \mathrm{Na}_{2} \mathrm{~S}_{2} \mathrm{O}_{5}$, and $82 \mathrm{mM} \mathrm{H}_{2} \mathrm{SO}_{4}$, followed by $\mathrm{pH}$ adjustment to 6 using $\mathrm{NaOH}$. For in vitro assays, because the reagents used to reduce $\mathrm{MAs}(\mathrm{V})\left(\mathrm{Na}_{2} \mathrm{~S}_{2} \mathrm{O}_{3}, \mathrm{Na}_{2} \mathrm{~S}_{2} \mathrm{O}_{5}\right.$, and $\left.\mathrm{H}_{2} \mathrm{SO}_{4}\right)$ ablated MurA activity, the methylarsonous acid iodide derivative (MAs $\left.(\mathrm{III}) \mathrm{I}_{2}\right)$ was synthesized as previously described (Stice et al., 2016).

\subsubsection{Strains, plasmids, media, and growth conditions}

S. putrefaciens 200 used for total DNA extraction was provided to us as a gift from Flynn Picardal, Indiana University. Expression vector pET26b containing S. aureus SH1000 (WP_000358012.1) MurA was kindly provided by Dr. Alex O'Neill (University of Leeds, Leeds, UK). E. coli One Shot ${ }^{\mathrm{TM}}$ TOP10 (Thermo Fisher Scientific, Waltham, MA) (F- mcrA $\Delta$ (mrr-hsdRMS-mcrBC) Ф80lacZ $\Delta$ M15 $\Delta$ lacX74 recA1 araD139 $\Delta($ araleu)7697 galU galK rpsL (StrR) endA1 nupG) was used for library construction and in vivo arsenical resistance assays. E. coli strain BL21 (fhuA2 [lon] ompT gal ( $\lambda$ DE3) [dcm] $\Delta$ hsdS $\lambda$ DE3 $=\lambda$ sBamHlo $\Delta$ EcoRI-B int::(lacl::PlacUV5::T7 gene1) i21 $\Delta$ nin5) was used for expression and purification of S. putrefaciens 200 wild-type and C117D MurA, as well as in vivo fosfomycin resistance assays. E. coli strains were grown aerobically at either $30^{\circ} \mathrm{C}$ or $37^{\circ} \mathrm{C}$ in either lysogeny broth (LB) or 2x ST medium (20-fold concentrated ST 10-1 media, $10 \mathrm{~g} \mathrm{l}^{-1}$ Difco Bacto Peptone and $1 \mathrm{~g} \mathrm{l}^{-1}$ yeast extract) supplemented with $0.2 \%$ glucose (Maki et al., 2006). 


\subsubsection{Isolation of $S$. putrefaciens 200 DNA fragment conferring MAs(III) resistance}

To construct a genomic library of $S$. putrefaciens 200, total DNA was extracted using DNeasy Blood \& Tissue kit (QIAGEN, Hilden, Germany) and digested with HindlII (New England Biolabs, Ipswich, MA). Following digestion and ethanol precipitation, the pelleted DNA was suspended in water and layered on a discontinuous sucrose gradient $(10 \%, 20 \%, 30 \%, 40 \%)$ buffer containing $50 \mathrm{mM}$ Tris, adjusted to $\mathrm{pH} 8.0$ by HCl, $0.1 \mathrm{M} \mathrm{EDTA}$, and $0.1 \mathrm{M} \mathrm{NaCl}$. The gradients were then centrifuged at $210,000 \times g$ for $5 \mathrm{~h}$ at $17^{\circ} \mathrm{C}$ to separate DNA fragments by size. After centrifugation the solution was carefully removed from the top of the layer and separated into fractions. Fractions were electrophoresed on $1 \%$ agarose gels to confirm their size, and fractions containing DNA fragments larger than 2 kbp were combined and concentrated via ethanol precipitation. The resulting DNA fragment mixture was ligated overnight at $16^{\circ} \mathrm{C}$ into HindllI-digested cloning vector pUC118 using LONG ligase (TaKaRa, Kusatsu, Japan). Ligase mixture was transformed into E. coli TOP10 using electroporation, and transformants were spread on LB media agar plates containing $100 \mu \mathrm{g} / \mathrm{ml}$ ampicillin. Ligation and transformation steps were repeated twice more to attain a total of 3 plates of approximately 2,000 colonies each. A glycerol stock of the library was made from LB plates and aliquoted, followed by flash freezing and storage at $-80^{\circ} \mathrm{C}$. To ensure complete coverage of the S. putrefaciens 200 genome during MAs(III) resistance selection, average fragment sizes were calculated by purifying plasmid DNA from several transformants using E.Z.N.A.® Plasmid Mini Kit I (Omega Bio- 
Tek, Norcross, GA), and digesting plasmids with Hindlll, followed by gel electrophoresis using $1 \%$ agarose gels. Average insert size was found to be 6.7 $\mathrm{kbp}$, hence approximately 2,000 colonies were spread to cover the $5 \mathrm{Mbp}$ of the S. putrefaciens 200 genome.

Clones were selected for resistance to $\operatorname{MAs}(\mathrm{III})$. After obtaining approximately 2,000 colonies on LB plates, colonies were replicated onto 1,2 , and $3 \mu \mathrm{M}$ MAs(III) ST $10^{-1}$ media (0.5 $\mathrm{g} \mathrm{l}^{-1}$ Difco Bacto Peptone and $0.05 \mathrm{~g} \mathrm{l}^{-1}$ yeast extract) agar plates supplemented with $50 \mu \mathrm{g} / \mathrm{ml}$ ampicillin and $0.2 \%$ glucose, and incubated at $30^{\circ} \mathrm{C}$ for 48 hours. To exclude MAs(III) clones that had acquired the gene for the ArsP MAs(III)-selective efflux pump (of which S. putrefaciens 200 has two copies), colonies growing on 2 and $3 \mu \mathrm{M}$ MAs(III) plates were picked and analyzed for the presence of the arsP gene by colony PCR using forward primers GATGATGATCCATGGGGATGAATCCTGAAACCCTAGCC (arsP1) and GATGATGATCCATGGGGATGCTGCAAATATTTTCAGATTTAGCGAGTTGG $\begin{array}{llll}(\operatorname{ars} P 2) & \text { and } & \text { reverse }\end{array}$ GATGATGATGTCGACGCTAAATACATAGCTATAAAGAAACCCAGAGCCG (arsP1) and GATGATGATGTCGACCAAAATGGGGCTGATCCCGTT (arsP2). Colonies lacking ars $P$ genes were assayed for their arsenic biotransformation capacity using high performance liquid chromatography (HPLC) (Series 2000; PerkinElmer, Waltham, MA) coupled with inductively coupled plasma mass spectrometry (ICP-MS) (ELAN DRC-e; PerkinElmer, Waltham, MA) (vide infra). A single clone isolated lacking both ars $P$ genes and arsenic biotransformation activity was streaked to confirm homogeneity, plasmid DNA was purified from two 
colonies, and partial sequence information of the insert fragment was determined. The whole sequence of the insert fragment was obtained through nucleotide BLAST search against the S. putrefaciens 200 genome (GCA_000169215.2), and the same fragment was obtained from plasmids of both colonies.

To compare the level of MAs(III) resistance conferred by the DNA fragments to known MAs(III) resistance mechanisms, pTrcHis2A vector carrying $S$. putrefaciens 200 arsP (pTrcHis2A-SpArsP) (Chen et al., 2015b) and pUC19 vector carrying Bacillus sp. MD1 arsl (pUC19-Arsl) (Yoshinaga and Rosen, 2014) were transformed into E. coli TOP10 and grown overnight in LB media supplemented with $100 \mu \mathrm{g} / \mathrm{ml}$ ampicillin. Overnight cultures were washed by 2x ST medium, and cell density was adjusted to a starting absorbance (A600nm) of 0.05 in $2 x$ ST media containing indicated concentrations of MAs(III) and supplemented with $50 \mu \mathrm{g} / \mathrm{ml}$ ampicillin and $0.2 \%$ glucose. Cells were incubated at $30^{\circ} \mathrm{C}$ shaking for 5 hours, after which growth was estimated from the absorbance at $600 \mathrm{~nm}$.

\subsubsection{Arsenic transformation by HPLC-ICP-MS}

To determine whether the DNA fragment isolated from S. putrefaciens 200 conferred the ability to transform MAs(III) into less toxic species, cells with that construct were compared with cells expressing the ArsI C-As lyase. E. coli TOP10 cells carrying pUC19-ArsI (Yoshinaga and Rosen, 2014), and two colonies of E. coli pUC118 cells carrying the S. putrefaciens 200 DNA fragment, and the parent plasmid (pUC118) were cultured overnight in $3 \mathrm{~mL}$ LB media supplemented with $100 \mu \mathrm{g} / \mathrm{mL}$ ampicillin. Overnight cultures were centrifuged and suspended in $2 \mathrm{~mL}$ ST $10^{-1}$ medium supplemented with $0.2 \%$ glucose containing $2 \mu \mathrm{M}$ MAs(III). Cells 
were incubated for $4 \mathrm{~h}$ at $30^{\circ} \mathrm{C}$. After incubation, culture media was filtered by centrifugation at $20,000 \times \mathrm{g}$ for $10 \mathrm{~min}$ at $4{ }^{\circ} \mathrm{C}$ using Amicon Ultra Centrifugal Filters with a $3 \mathrm{kDa}$ membrane (MilliporeSigma, Burlington, MA). Arsenic from filtrates was speciated by HPLC-ICP-MS using a reverse-phase C18 column $(250 \mathrm{~mm} \times$ 4.6 mm; Thermo-Fisher, Waltham, MA), as described previously (Qin et al., 2006).

\subsubsection{Identifying the gene responsible for MAs(III) inhibition}

Tyrosine-to-stop codon mutations were introduced individually into bolA and murA genes in the purified plasmid DNA via site-directed mutagenesis using forward primers 5'TCGgATGGTAGCCATTAGAAAGTCATCGCCGTAG-3' (bolA) and 5'CGTTATTGGCACGCTAGGGTACCGCTGACG-3' (murA) and reverse primers 5'CTACGGCGATGACTTTCTAATGGCTACCATCCGA-3' (bolA) and 5'CGTCAGCGGTACCCTAGCGTGCCAATAACG-3' (murA). Primers were designed using the QuikChange ${ }^{\circledR}$ primer design tool (https://www.agilent.com/store/primerDesignProgram.jsp). For mutagenesis, a PCR mixture containing $180 \mathrm{ng}$ of template DNA, $0.5 \mu \mathrm{M}$ of forward and reverse primers, $2.5 \mathrm{mM}$ of dNTP mix, 5\% DMSO, and $100 \mathrm{U}$ of Pfu Turbo (with the appropriate buffer) was used. An initial denaturing step was performed at $94{ }^{\circ} \mathrm{C}$ for $5 \mathrm{~min}$, followed by 18 cycles of denaturing $\left(50 \mathrm{~s}\right.$ at $94{ }^{\circ} \mathrm{C}$ ), annealing ( $50 \mathrm{~s}$ at $60.4^{\circ} \mathrm{C}$ ), and elongation $\left(4 \mathrm{~min}\right.$ at $72^{\circ} \mathrm{C}$ ). A final elongation step was performed at $72{ }^{\circ} \mathrm{C}$ for $10 \mathrm{~min}$. Following mutagenesis, plasmids were digested with $\mathrm{Dpnl}$ at $37^{\circ} \mathrm{C}$ overnight. Digestion mixtures were concentrated and transformed into E. coli TOP10 using heat-shock. Transformants were spread on LB plates 
supplemented with $100 \mu \mathrm{g} / \mathrm{mL}$ ampicillin and incubated overnight at $37^{\circ} \mathrm{C}$. Plasmid DNA was purified from several colonies and sequenced using forward primers 5'-GATGATGATGAGCTCATGGAATGCAGCTTAATCGAACAG-3' (bolA) and 5'-GATGATGATGAGCTCATGGCGgGAGTATTGGCAGAGACC-3' (murA) and reverse primers 5'-GATGATGATCGGCCGTCACTAGCTAGGCATGTTGAA3' (bolA) and 5'-GATGATGATCGGCCGTTATTGTACGCGCTCTACATGCGC-3' (murA). After obtaining the appropriate mutants, MAs(III) resistance assays were assayed in 2x ST media, as described previously. DNA sequencing was performed by Sequetech (Mountain View, CA).

\subsubsection{S. putrefaciens 200 MurA expression and purification}

Codon-optimized S. putrefaciens 200 wildtype murA was commercially synthesized and cloned into expression vector pET28a (GenScript, Piscataway, NJ). This construct was transformed into $E$. coli BL21 using heat-shock. Transformants were cultured in $10 \mathrm{~mL}$ of LB media supplemented with $25 \mu \mathrm{g} / \mathrm{mL}$ kanamycin and incubated at $37^{\circ} \mathrm{C}$ overnight. An overnight culture was used to inoculate $1 \mathrm{~L}$ of LB media supplemented with $25 \mu \mathrm{g} / \mathrm{mL}$ kanamycin, and MurA expression was induced using $0.3 \mathrm{mM}$ of Isopropyl $\beta$-d-1-thiogalactopyranoside (IPTG) for $1.5 \mathrm{~h}$ at $37^{\circ} \mathrm{C}$ at an $\mathrm{A}_{600 \mathrm{~nm}}=0.6$. Cells were collected and suspended in $5 \mathrm{~mL}$ per gram of wet cells in buffer A (50 mM MOPS, $20 \%$ glycerol (vol/vol), $0.5 \mathrm{M} \mathrm{NaCl}, 20 \mathrm{mM}$ imidazole, $10 \mathrm{mM}$ 2-mercaptoethanol). Cells were broken by a single passage through a French press cell at 20,000 psi. The cell lysate was ultra-centrifuged at $160,000 \times \mathrm{g}$ for $1 \mathrm{~h}$ at $4{ }^{\circ} \mathrm{C}$, and the supernatant was loaded onto a nickel-NTA resin column (Thermo-Fisher Scientific, Waltham, MA) at a flow 
rate of $1.0 \mathrm{~mL} / \mathrm{min}$. The column was washed with buffer $A$ and eluted with buffer $A$ containing $100 \mathrm{mM}$ imidazole. MurA purity was analyzed by sodium dodecyl sulfate (SDS) polyacrylamide gel electrophoresis (PAGE), and fractions containing MurA were combined and concentrated using an Amicon Ultra-30 centrifugal filter (MilliporeSigma, Burlington, MA) by centrifugation at 5,000 $\times \mathrm{g}$. Imidazole was removed from MurA fractions by diluted to sub-micromolar concentrations and concentration twice with buffer A without imidazole. Protein concentration was estimated using the Bradford assay using bovine serum albumin as standard (Bradford, 1976). MurA was aliquoted, flash frozen, and stored at $-80^{\circ} \mathrm{C}$.

A cysteine 117 to aspartic acid (C117D) mutation was introduced into the expression construct via site-directed mutagenesis. Primers used were 5'ATTGCCGGGCGGCGATGCCATTGGCGCG-3' (forward) and 5'CGCGCCAATGGCATCGCCGCCCGGCAAT-3' (reverse). Plasmid digestion with $D p n l$, purification, and sequencing was performed as described previously, as were expression and purification of C117D MurA.

\subsubsection{In vitro MurA activity and inhibition}

MurA activity was determined from the release of inorganic phosphate $\left(P_{i}\right)$ with purine-nucleoside phosphorylase (PNP), as previously described with minor modifications (Blake et al., 2009). Briefly, $760 \mu \mathrm{l}$ of reaction mixture containing $50 \mathrm{mM}$ HEPES, $100 \mu \mathrm{M}$ dithiothreitol (DTT), $90 \mathrm{nM}$ MurA, $300 \mu \mathrm{M}$ UDP- $N$ acetylglucosamine (UDP-GlcNAc), $250 \mu \mathrm{M}$ 7-methyl-6-thioguanosine (MESG), 0.1U/mL PNP and inhibitors (Fos, MAs(III), PhAs(III)) was added to wells on a 96well plates $(190 \mu \mathrm{L})$, and the reaction was started by adding $10 \mu \mathrm{l}$ of $2 \mathrm{mM}$ 
phosphoeno/pyruvate (PEP) at a final concentration of $100 \mu \mathrm{M}$. The increase in absorbance at $360 \mathrm{~nm}$ was monitored at room temperature in real time using a Synergy $^{\mathrm{TM}} \mathrm{H} 4$ (BioTek, Winooski, VT) plate reader. For co-incubation of MAs(III) $(50 \mu \mathrm{M})$ and $N$-ethylmaleimide $(\mathrm{NEM})(450 \mu \mathrm{M})$, DTT was removed from the reaction mixture to allow for NEM binding to cysteine residues, and mixtures were incubated with NEM for 15 min at room temperature prior to adding MAs(III).

\subsection{Results}

\subsubsection{Selection of an S. putrefaciens 200 gene that confers MAs(III) resistance}

Most bacterial genes involved in arsenic detoxification and transformation are found in ars operons; however, we expected that the targets of antimicrobial compounds such as MAs(III) would more likely be unrelated to arsenic biochemistry. Thus, to isolate potential targets of $\mathrm{MAs}(\mathrm{III})$ inhibition, a genomic library of S. putrefaciens 200 was constructed and expressed in E. coli. Selection for resistance to $3 \mu \mathrm{M}$ MAs(III) yielded a colony (Clone 1) that was confirmed to confer MAs(III) resistance after purification by streaking onto LB agar plates (Figure 15). Clone 1 did not biotransform MAs(III) (Figure 16). Plasmid DNA was isolated from Clone 1, and the DNA insert was sequenced and aligned to the $S$. putrefaciens 200 genome (Accession number GCA_000169215.2). A 2.8 kilobase pair fragment was identified, which contained two full-length open reading frames that were annotated as bolA encoding a transcriptional regulator, and murA, annotated to encode a UDP- $N$-acetylglucosamine enolpyruvyl transferase. Neither

gene was in an ars operon of S. putrefaciens 200 , and neither has been previously 
reported to be involved in arsenic resistance. To determine which of these genes confers the MAs(III)-resistant phenotype, stop codons were introduced via sitedirected mutagenesis into the sequences of each gene. Cells carrying the mutant bolA plasmid remained resistant to $\mathrm{MAs}(\mathrm{III})$, whereas cells carrying the mutant murA plasmid lost resistance (Figure 17), demonstrating that murA is responsible for the MAs(III)-resistance phenotype.

\subsubsection{MurA is selectively inhibited by organoarsenicals}

MurA catalyzes the first committed step of bacterial peptidoglycan biosynthesis and is essential for both gram-negative and gram-positive bacteria (Barreteau et al., 2008). The enzyme catalyzes the transfer of the enolpyruvate moiety of phosphoenolpyruvate (PEP) to the 3' hydroxyl group of UDP-Nacetylglucosamine (UDP-GIcNAc), generating UDP-N-acetylglucosamineenolpyruvate and inorganic phosphate $\left(\mathrm{Pi}_{\mathrm{i}}\right)$ (Eschenburg et al., 2003). SpMurA was purified from cells of $E$. coli and assayed for $\mathrm{P}_{\mathrm{i}}$ release using a coupled assay (Webb, 1992; Blake et al., 2009). MurA activity was inhibited by MAs(III) but not inorganic As(III) (Figure 18). The aromatic organoarsenical PhAs(III) inhibited MurA more strongly than MAs(III), consistent with the observation that aromatic arsenicals have higher affinity for arsenic-binding enzymes than $\operatorname{MAs}(\mathrm{III})$ (Pawitwar et al., 2017).

\subsubsection{Cysteine 117 is not required for organoarsenical inhibition of SpMurA} activity

MurA is inhibited by the broad-spectrum antibiotic fosfomycin (Fos) (Kahan et al., 1974), which is a competitive inhibitor of PEP that covalently binds to a 
cysteine residue conserved in most but not all bacterial species (Figure 19). Overexpression of MurA confer resistances to Fos (Couce et al., 2012). Growth of cells of $E$. coli expressing a wild-type S. putrefaciens 200 murA gene was inhibited by Fos (Figure 20A). Similarly, the activity of purified wild-type MurA was inhibited by Fos (Figure 20B). The murA gene of Mycobacterium tuberculosis has an aspartic acid residue in the position of this cysteine, and this bacterium is resistant to Fos (De Smet et al., 1999). E. coli cells, which have a chromosomally-encoded wild-type EcMurA with Cys115, are sensitive to Fos, and a C115D mutation has been shown to confer Fos resistance (Kim et al., 1996). To examine whether Cys117 in SpMurA is involved in organoarsenical inhibition of S. putrefaciens 200 MurA, Cys 117 was changed by mutagenesis to an aspartic acid residue. Cells expressing the C117D mutant are resistant to Fos (Figure 20A), and purified SpMurAc117D was not inhibited by Fos (Figure 20B). In contrast, both wild-type SpMurA and the C117D derivative are equally sensitive to inhibition by either MAs(III) or PhAs(III) (Figure 21). These results indicate that Cys117 is not involved in inhibition by trivalent organoarsenicals, suggesting that MAs(III) and fosfomycin have different mechanisms of action.

\subsubsection{Organoarsenical inhibition of SpMurA involves cysteine residues}

While Cys 117 is apparently not involved in MAs(III) inhibition, $S$. putrefaciens 200 MurA and various homologs have several other non-conserved cysteine residues (Figure 19). SpMurA has eight other cysteine residues in addition to Cys 117 . To examine whether any cysteine residues are involved in organoarsenical inhibition, purified SpMurA activity assayed in the presence of the 
cysteine modifying reagent $N$-ethylmaleimide (NEM), which completely inhibited enzymatic activity (Figure 22). In contrast, MurA from Staphylococcus aureus (SaMurA) contains only the single conserved cysteine. The SamurA gene was expressed in E. coli, and SaMurA purified. SaMurA was sensitive to Fos (Figure 23) but relatively resistant to trivalent organoarsenicals compared with SpMurA (Figure 24). These results are consistent with our idea that the conserved cysteine residue is not involved in MAs(III) inhibition, in contrast to its role in Fos inhibition. These results indicate that organoarsenicals, while not dependent on the canonical conserved cysteine used for PEP binding, still inhibit MurA in a cysteine-dependent manner, and that one or more of the other cysteine residues in MurA sequences may play a structural role or be otherwise indirectly involved in catalysis. 


\subsection{Figures and tables}

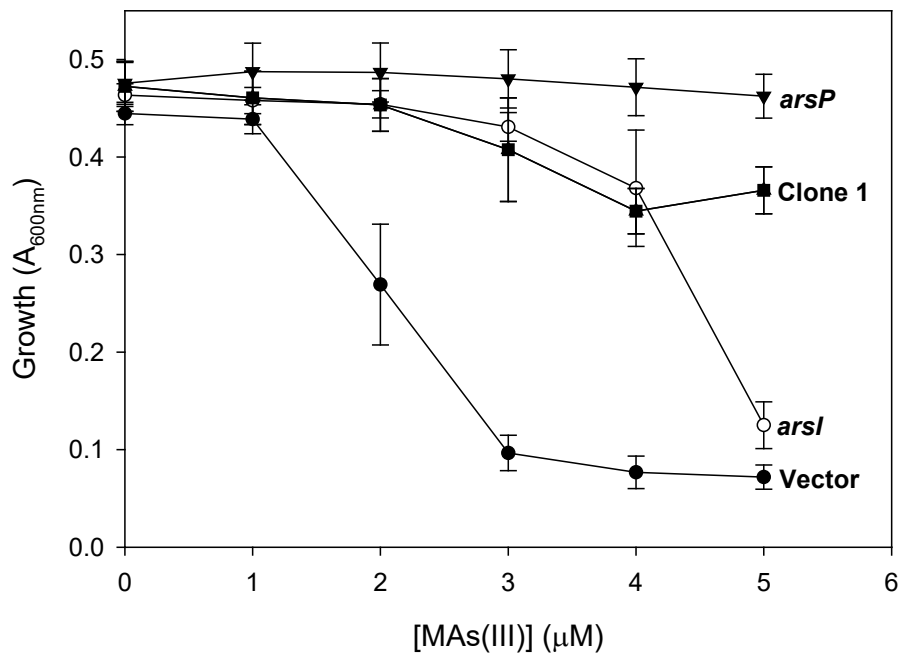

Figure 15. DNA isolated from an S. putrefaciens 200 genomic library confers MAs(III) resistance. Overnight cultures of E. coli TOP10 carrying either, pUC118-Clone 1 (घ), pUC19-ArsI (0), pTrcHis2A-ArsP $(\boldsymbol{\nabla})$, or plasmid pUC118 $(\bullet)$ were adjusted to a starting absorbance at $600 \mathrm{~nm}$ of 0.05 in $2 \times$ ST media supplemented with $0.2 \%$ glucose containing the indicated concentrations of MAs(III). Growth was estimated from $A_{600} \mathrm{~nm}$ after $5 \mathrm{~h}$ of incubation at $30^{\circ} \mathrm{C}$. Data are the mean \pm SE $(n=3)$.

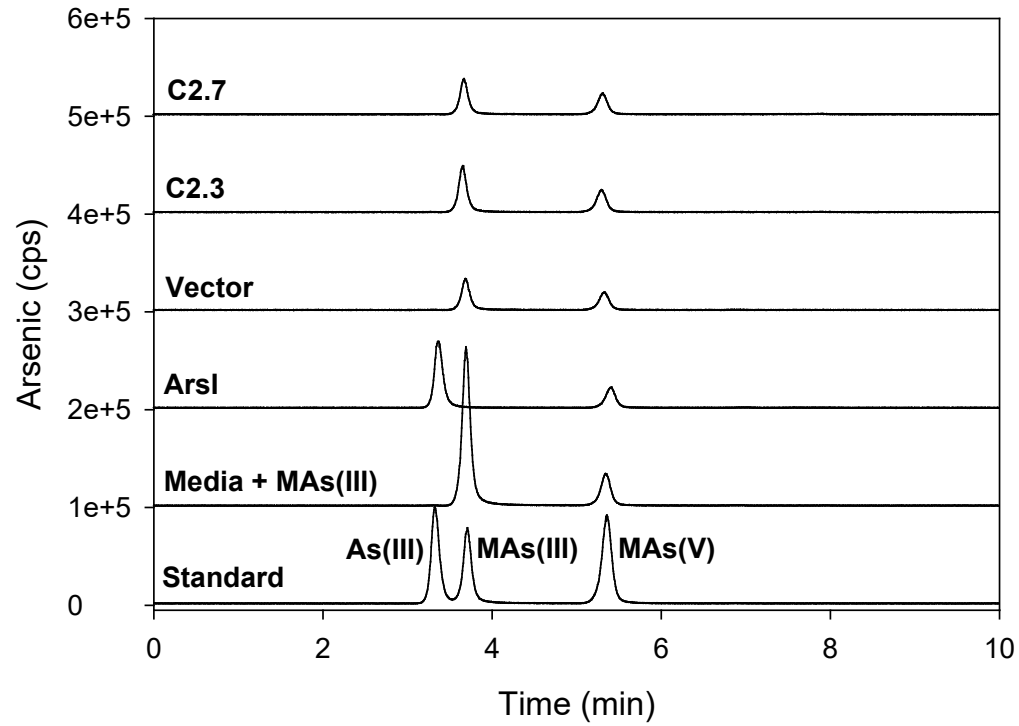

Figure 16. Arsenic transformation by fragment isolated from S. putrefaciens 200 genomic library. Overnight cultures of E. coli TOP10 cells carrying pUC118-Clone 1 (Clone 1), pUC19-ArsI (ArsI), or the parent plasmid pUC118 (Vector) were collected and washed and resuspended by ST 10-1 media supplemented with $0.2 \%$ glucose. $2 \mu \mathrm{M}$ of MAs(III) was added to the culture media and samples were incubated at $30^{\circ} \mathrm{C}$ for $4 \mathrm{~h}$. HPLC-ICP-MS was done as described in Materials and methods. The $\mathrm{x}$-axis represents the retention time of various arsenicals through a C18 column, and the $y$-axis represents relative amounts of arsenic expressed in counts per second (cps). 


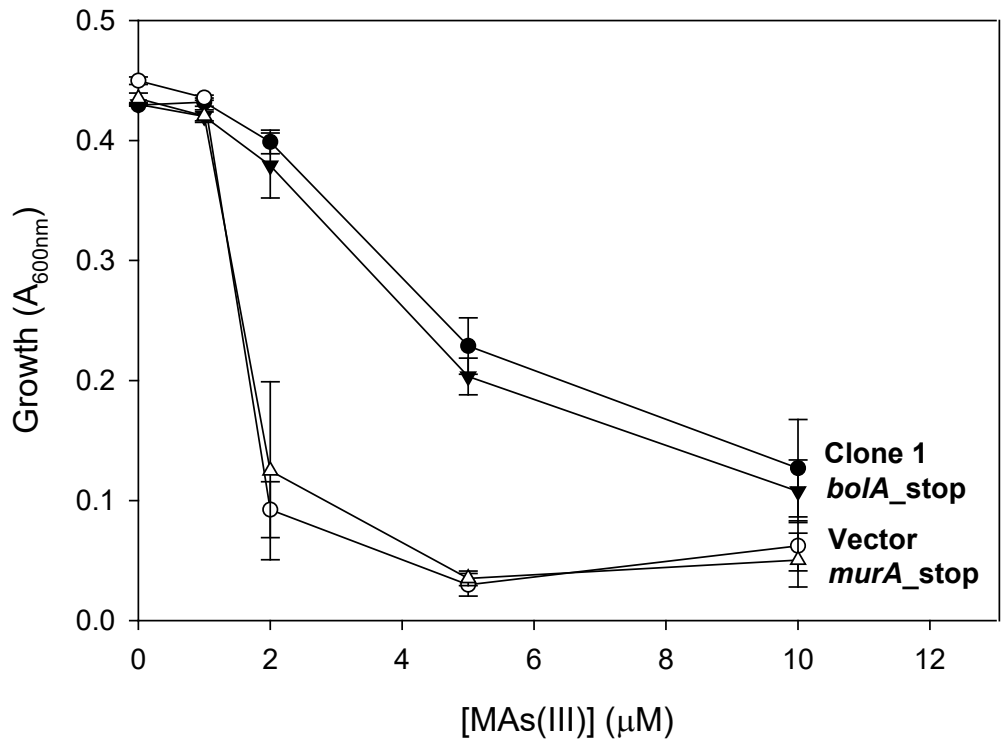

Figure 17. Expression of murA confers resistance to MAs(III) in vivo. Overnight cultures of E. coli TOP10 carrying either pUC118-Clone 1, which contains wildtype S. putrefaciens 200 murA and bolA (•), vector carrying a murA tyrosine-to-stop codon mutant $(\Delta)$, vector carrying a bolA tyrosine-to-stop codon mutation $(\boldsymbol{\nabla})$, or parental plasmid pUC118 (०) were adjusted to a starting $A_{600} \mathrm{~nm}$ of 0.05 in $2 x$ ST media supplemented with $0.2 \%$ glucose containing the indicated concentrations of MAs(III). Growth was estimated from the A600 nm after $5 \mathrm{~h}$ incubation at $30^{\circ} \mathrm{C}$. Data are the mean $\pm \operatorname{SE}(n=3)$.

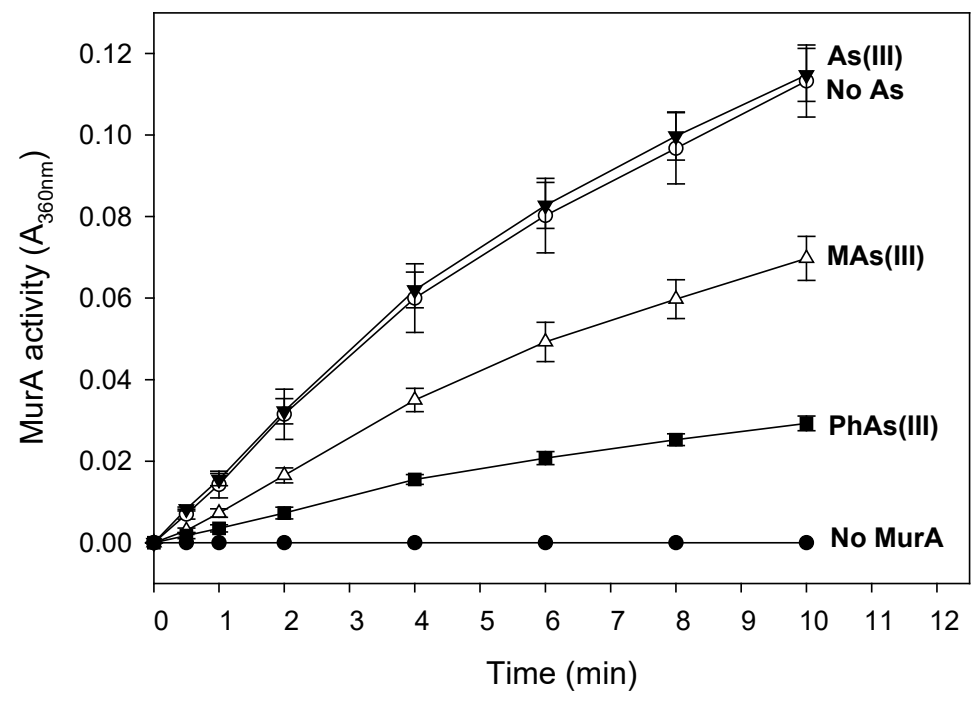

Figure 18. SpMurA is selectively inhibited by organoarsenicals. Purified wildtype S. putrefaciens 200 SpMurA and UDP-N-acetylglucosamine (UDP-GlcNAc) were incubated with purine-nucleoside phosphorylase (PNP) and its substrate, methylthioguanosine (MESG), whose purine base product absorbs at $\lambda=360 \mathrm{~nm}$. The reaction was initiated by addition of PEP at a final concentration of $0.1 \mathrm{mM}$, and the release of $P_{i}$ in the absence $(\circ)$ or presence of $20 \mu \mathrm{M}$ $\operatorname{As}(\mathrm{III})(\boldsymbol{\nabla}), 20 \mu \mathrm{M}$ MAs(III) $(\Delta)$, or $20 \mu \mathrm{M}$ PhAs(III) (घ) was monitored by the increase in $\mathrm{A}_{360} \mathrm{~nm}$. Data were normalized to the activity of the control reaction lacking MurA $(\bullet)$. Data are the mean \pm SE $(n=3)$. 

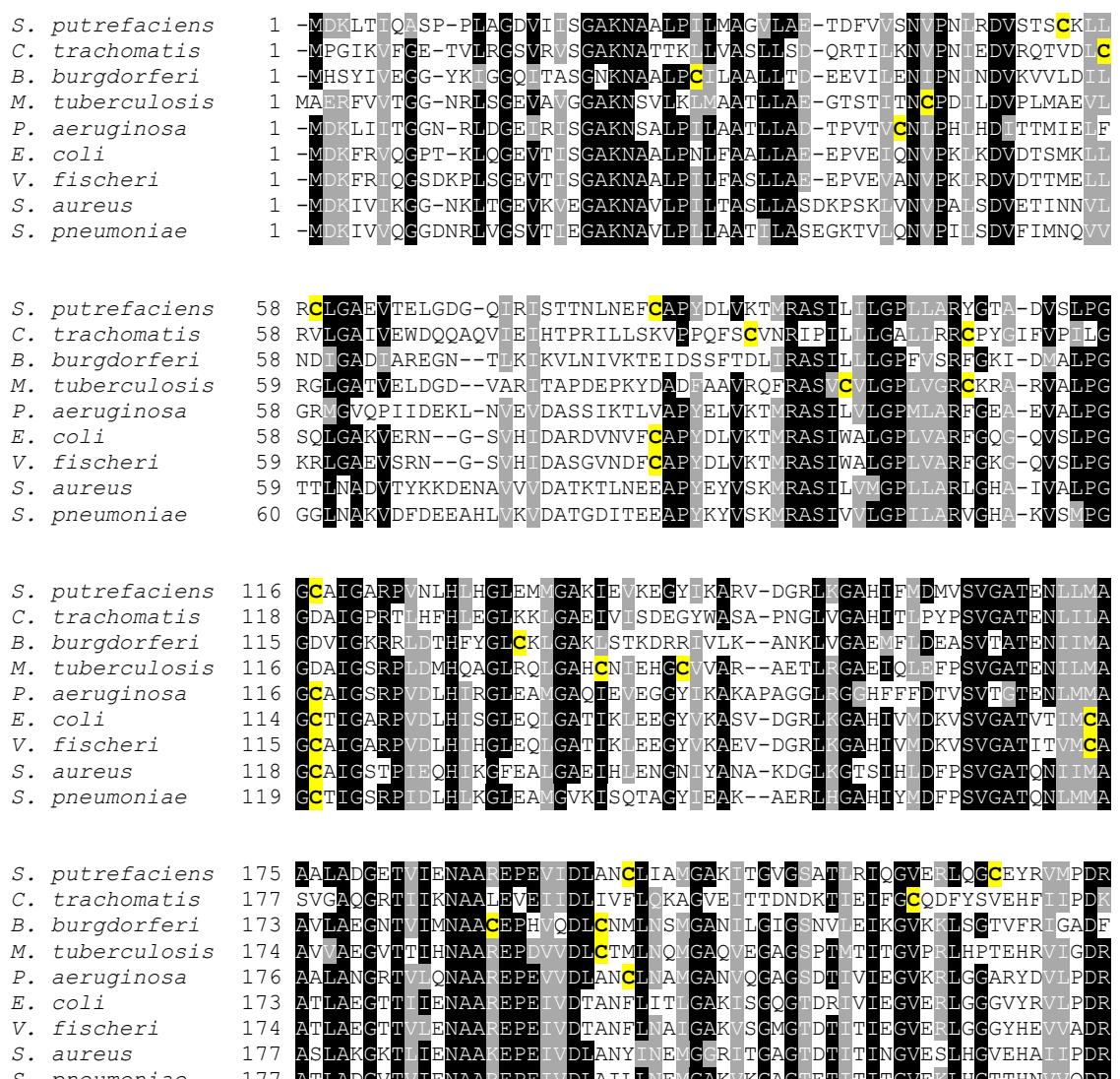

S. pneumoniae
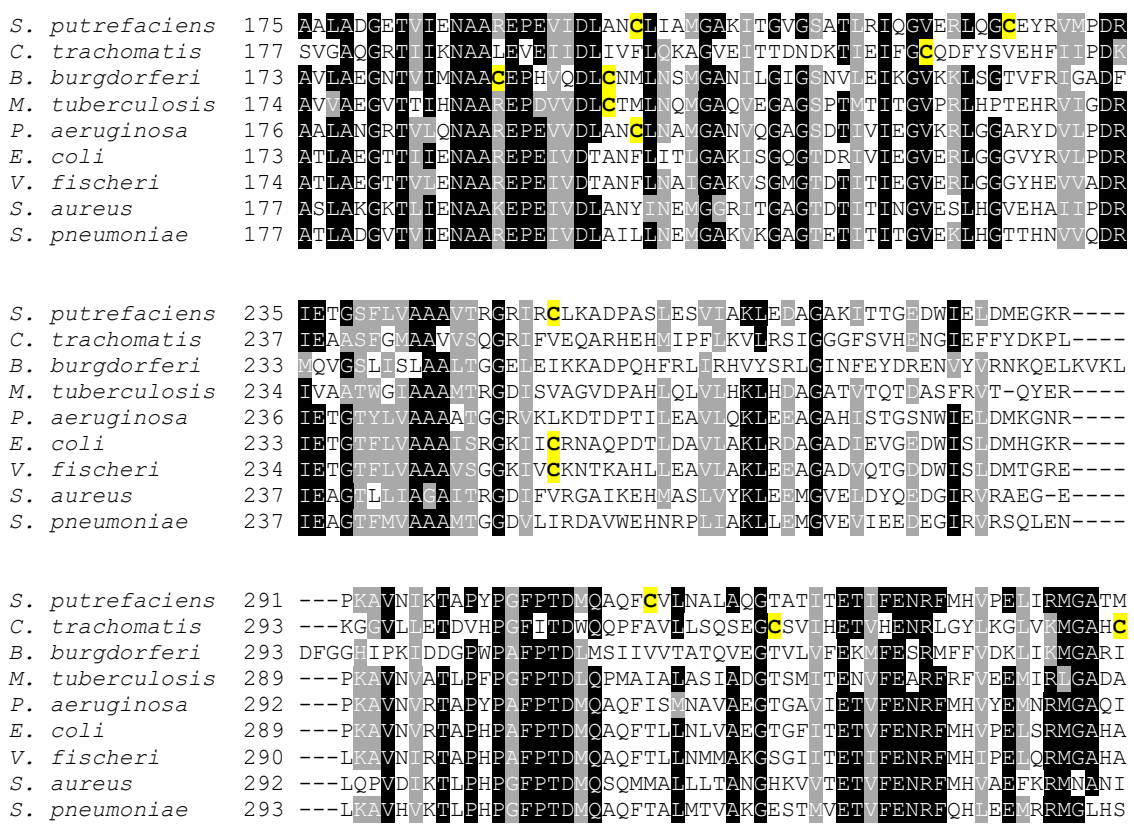

Figure 19. MurA sequence alignment of bacterial strains. The protein sequence of $\mathrm{S}$. putrefaciens 200 MurA (WP_011790698.1) is compared with MurA homologs studied in existing literature. The source strain and $\mathrm{NCBI}$ accession number (in parenthesis) of aligned sequences are Chlamydia trachomatis L2 (AGJ64824.1), Borreliella burgdorferi B31 (NP_212606.2), Mycobacterium tuberculosis R37v (WP_003406845.1), Pseudomonas aeruginosa PA01 (NP_253140.1), Escherichia coli K-12 (WP_000357281.1), Aliivibrio fischeri MJ11 (3VCY_A), Staphylococcus aureus SH1000 (WP_000358012.1), and Streptococcus pneumoniae R6 (WP_000358027.1). Multiple sequence alignment was done using Clustal Omega (https://www.ebi.ac.uk/Tools/msa/clustalo/). Amino acids shown in black or gray indicate sequence identity or similarity, respectively. Cysteine residues within each sequence are highlighted in yellow, and the conserved cysteine required for fosfomycin inhibition is indicated by a red asterisk. 

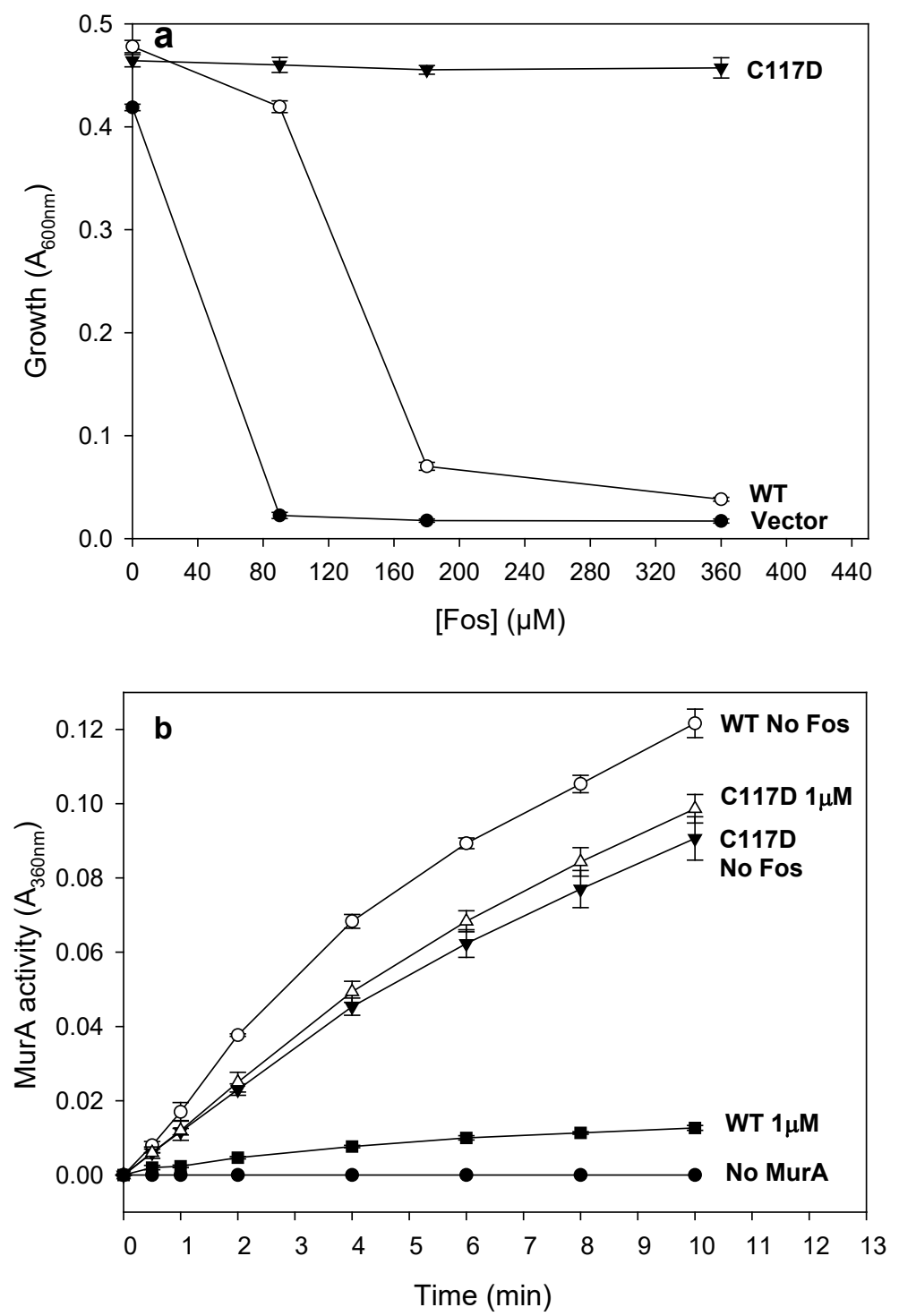

Figure 20. In vivo and in vitro inhibition of wild-type and C117D S. putrefaciens 200 SpMurA by fosfomycin. (a) To confirm SpMurA overexpression confers fosfomycin resistance in vivo, overnight cultures of E. coli BL21 cells carrying pET28a-MurA wild-type (o) or the C117D mutant ( $\boldsymbol{\nabla})$, and the parent plasmid $(\bullet)$ were diluted 100 -fold and induced with $0.3 \mu \mathrm{M}$ of IPTG for 90 min. Following induction, cells were adjusted to a starting growth ( $\left.\mathrm{A}_{600 \mathrm{~nm}}\right)$ of 0.05 in $2 \mathrm{x}$ ST media supplemented with $0.2 \%$ glucose containing the indicated concentrations of fosfomycin. Growth was measured after a $5 \mathrm{~h}$ incubation at $30^{\circ} \mathrm{C}$. (b) To confirm that wild-type SpMurA is inhibited by fosfomycin, and that the C117D mutant is resistant in vitro, purified SpMurA proteins were incubated with one of its substrates, UDP- $N$-acetylglucosamine (UDP-GIcNAc) and with purine-nucleoside phosphorylase (PNP) along $a b$ its substrate, methylthioguanosine (MESG), whose purine base product absorbs at $\lambda=360 \mathrm{~nm}$. The reaction was started by addition of the second MurA substrate phosphenolpyruvate (PEP), and the release of inorganic phosphate (Pi) from the MurA reaction in the absence $((\circ)$, wild-type; $(\boldsymbol{\nabla}), \mathrm{C} 117 \mathrm{D})$ or presence of $1 \mu \mathrm{M}$ fosfomycin $((\mathbf{\square})$, wild-type; $(\Delta)$, C117D) was monitored by the increase in absorbance at 360nm (A360nm). Data was normalized to the activity of the control reaction lacking $\operatorname{MurA}(\bullet)$. Data are the mean $\pm \operatorname{SE}(n=3)$. 

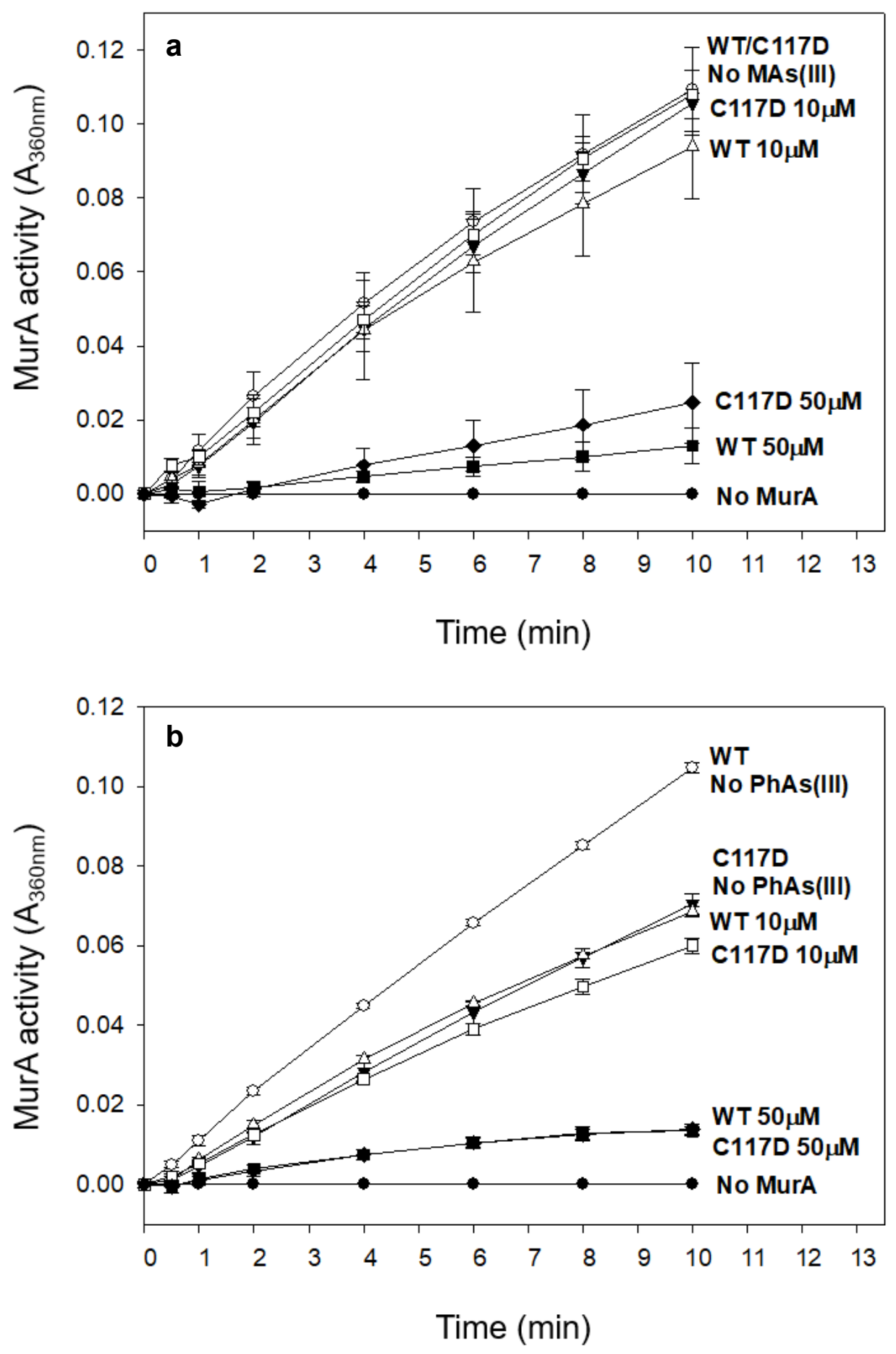

Figure 21. Cys 117 is not required for organoarsenical inhibition. The C117D SpMurA was purified, and inhibition by MAs(III) compared with wild-type SpMurA. As described in the legend to Figure 18 , activity of SpMurA was monitored in the absence ((o), wild-type; $(\boldsymbol{\nabla}), C 117 \mathrm{D})$ or presence of either MAs(III) (a) or PhAs(III) (b) at either $10 \mu \mathrm{M}((\Delta)$, wild type; (口), C117D) or $50 \mu \mathrm{M}((\mathbf{\square})$, wild type; (๑), C117D). Data were normalized to the activity of the control reaction lacking MurA $(\bullet)$. Data are the mean \pm SE $(n=3)$. 


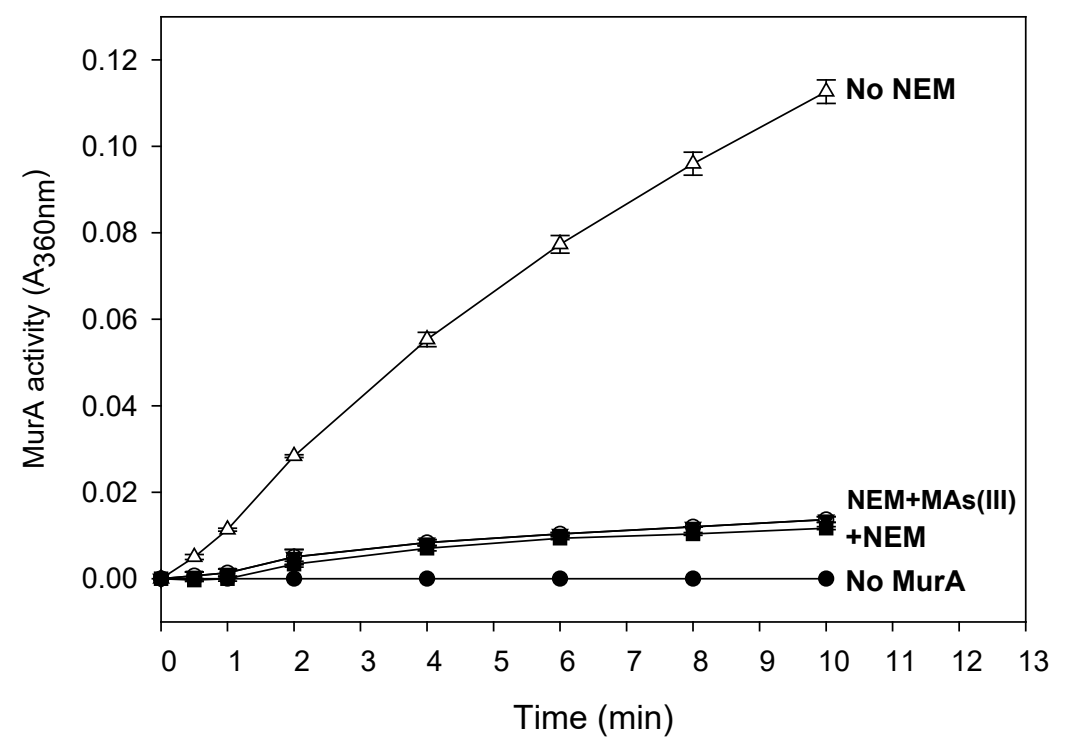

Figure 22. NEM modification of cysteine residues in SpMurA results in loss of activity. Purified wild type SpMurA was assayed, as described in the legend to Figure 18., in the presence (०) or absence $(\nabla)$ of NEM or in the presence of both $50 \mu \mathrm{M} \mathrm{MAs}(\mathrm{III})$ and $450 \mu \mathrm{M}$ NEM $(\Delta)$. Data were normalized to the activity of the control reaction lacking $\operatorname{MurA}(\bullet)$. Data are the mean $\pm \operatorname{SE}(n=3)$.

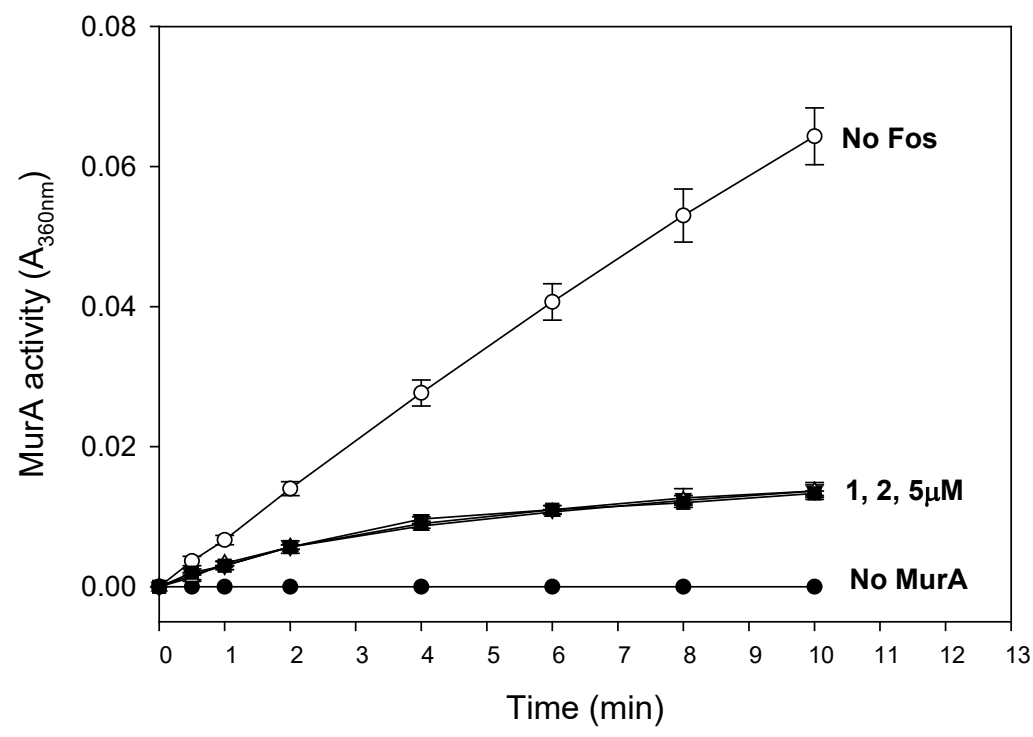

Figure 23. In vitro inhibition of $S$. aureus $\mathrm{SH} 1000$ MurA (SaMurA) by fosfomycin. To confirm that the MAs(III)-resistant SaMurA is sensitive to fosfomycin, purified SaMurA was used for organoarsenical inhibition. MurA and one of its substrates, UDP-N-acetylglucosamine (UDPGIcNAc), were incubated with purine-nucleoside phosphorylase (PNP) and its substrate, methylthioguanosine (MESG), whose purine base product absorbs at $\lambda=360 \mathrm{~nm}$. The reaction was started by addition of the second MurA substrate, phosphenolpyruvate (PEP), and the release of inorganic phosphate $(\mathrm{Pi})$ from the MurA reaction in the absence (O) or presence of fosfomycin at $1 \mu \mathrm{M}(\boldsymbol{\nabla}), 2 \mu \mathrm{M}(\Delta)$, or $5 \mu \mathrm{M}(\mathbf{\square})$ was monitored by the increase in A360 $\mathrm{nm}$. Data was normalized to the activity of the control reaction lacking $\operatorname{MurA}(\bullet)$. Data are the mean $\pm \operatorname{SE}(n=3)$. 

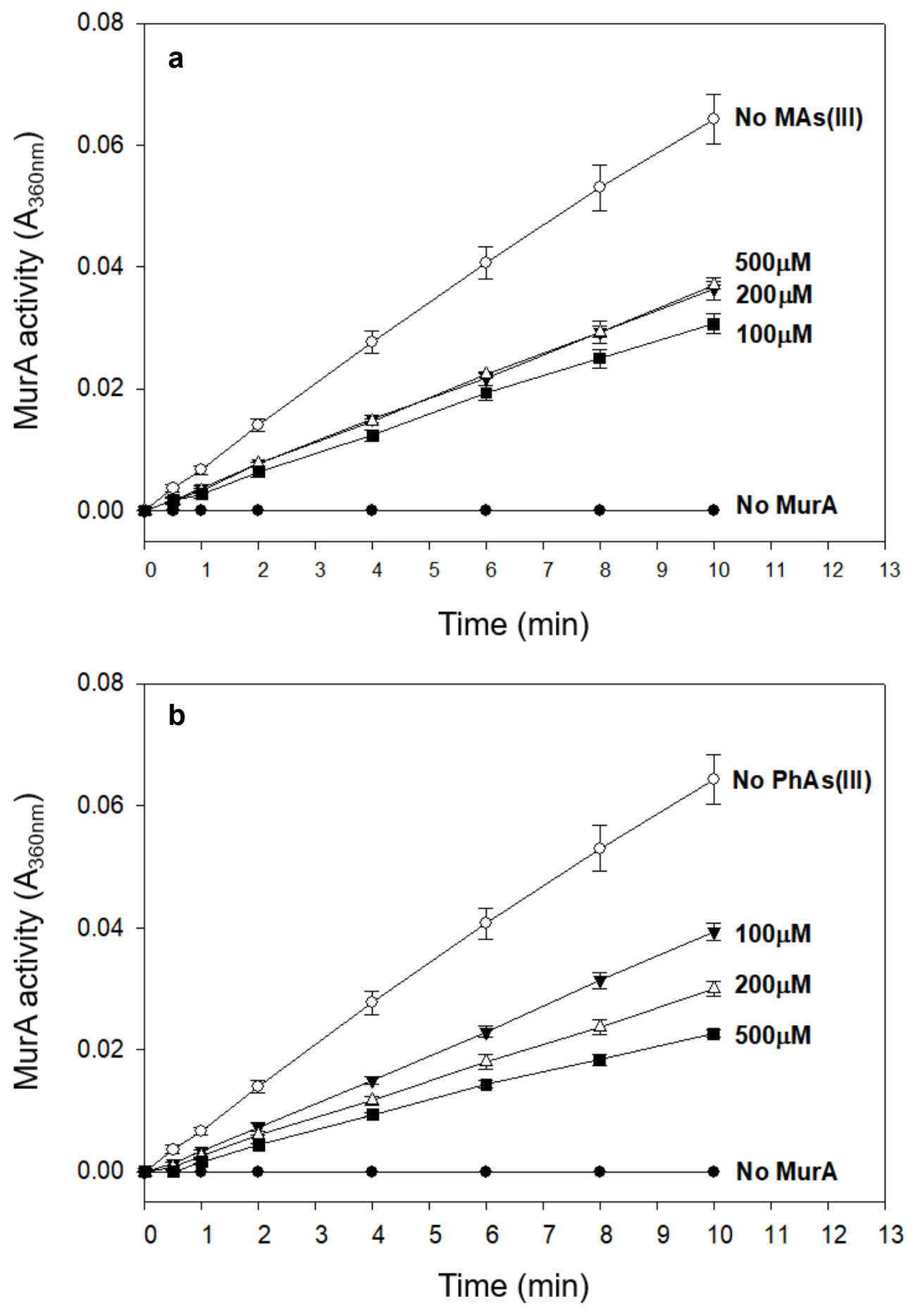

Figure 24. A MurA ortholog with a single conserved cysteine confers trivalent organoarsenical resistance. Purified $S$. aureus SaMurA that contains only the single conserved cysteine required for fosfomycin inhibition was assayed for organoarsenical inhibition in the absence ( $\circ$ ) or presence of either MAs(III) (a) or PhAs(III) (b) at $100 \mu \mathrm{M}(\mathbf{\nabla}), 200 \mu \mathrm{M}(\Delta)$, or $500 \mu \mathrm{M}(\mathbf{\square})$. Data were normalized to the activity of the control reaction lacking MurA $(\bullet)$. Data are the mean $\pm \operatorname{SE}(n=3)$. 


\subsection{Discussion}

MAs(III) has antibiotic-like properties and is produced by a number of bacterial species in microbial communities as a way to gain a competitive advantage (Chen et al., 2018). Trivalent arsenicals, including As(III) and MAs(III), have rather nonspecific toxic effects by depletion of cellular glutathione and small thiol proteins such as thioredoxin and glutaredoxin (Lin et al., 2001), and inhibition of thiol-containing enzymes such as lipoamide dehydrogenase (Bergquist et al., 2009). These shut down energy metabolism and increase reactive oxygen species. However, targets specific for bacteria, which could be used for the development of new antibiotics or antimicrobial drugs, have not been identified. In this report we identify the inhibition of MurA UDP- $N$-acetylglucosamine enolpyruvyl transferase by the trivalent natural product $\mathrm{MAs}(\mathrm{III})$ and the synthetic organoarsenical $\mathrm{PhAs}(\mathrm{III})$, and propose their antibiotic properties are at least partially a result of this inhibition.

As the first committed step in that pathway, MurA is an essential enzyme for many bacteria, which makes it an excellent drug target. Several classes of inhibitors such as sesquiterpene lactones, 2-aminotetralones and quinazolinones have been developed against MurA (Bachelier et al., 2006; Dunsmore et al., 2008; Hrast et al., 2017). MurA is also inhibited by fosfomycin, a broad-spectrum antibiotic used to combat Staphylococci, Pseudomonads, and other enteric gramnegative pathogens (Raz, 2012). A genome-wide screen using the complete E. coli open reading frame library identified murA as the only chromosomal gene that confers clinical-level of fosfomycin resistance by 
overexpression, and resistance is achieved at a low fitness cost (Couce et al., 2012). Nonetheless, only a few reports have described enhanced murA expression associated with fosfomycin resistance in clinical isolates, suggesting that overexpression of murA is rare in clinical settings (Castañeda-García et al., 2013). However, the mechanism of action of those MurA inhibitors requires a cysteine residue that is conserved in many but not all bacteria. Species that lack the conserved cysteine residue such as $M$. tuberculosis are resistant to these antibiotics (De Smet et al., 1999). Furthermore, in limited cases, even MurA orthologs that possess the conserved cysteine exhibit fosfomycin resistance via other amino acid substitutions (Kumar et al., 2009; Takahata et al., 2010). Thus, it is important to develop new antibiotics that act on MurA independent of the consensus cysteine residue. Thus, it is important to develop new antibiotics that act on MurA independent of the consensus cysteine residue. It is significant that trivalent organoarsenicals do not require the consensus cysteine residue to inhibit the S. putrefaciens 200 MurA enzyme. We propose that inhibition of peptidoglycan biosynthesis is the primary bacterial target of the biologically generated antibiotic MAs(III). Future goals are to determine how MAs(III) binds to and inhibits SpMurA, and to examine whether MurA inhibition by trivalent organoarsenicals is widespread among pathogenic bacteria. These studies will advance our understanding of arsenical targets in bacteria and provide valuable information to design new MurA inhibitors. 


\subsection{References}

Bachelier, A., Mayer, R., and Klein, C.D. (2006). Sesquiterpene lactones are potent and irreversible inhibitors of the antibacterial target enzyme MurA. Bioorganic \& Medicinal Chemistry Letters, 16:5605-5609.

Barreteau, H., Kovač, A., Boniface, A., Sova, M., Gobec, S., and Blanot, D. (2008). Cytoplasmic steps of peptidoglycan biosynthesis. FEMS Microbiology Reviews, 32:168-207.

Bergquist, E.R., Fischer, R.J., Sugden, K.D., and Martin, B.D. (2009). Inhibition by methylated organoarsenicals of the respiratory 2-oxo-acid dehydrogenases. Journal of Organometallic Chemistry, 694:973-980.

Blake, K.L., O'Neill, A.J., Mengin-Lecreulx, D., Henderson, P.J.F., Bostock, J.M., Dunsmore, C.J., Simmons, K.J., Fishwick, C.W.G., Leeds, J.A., and Chopra, I. (2009). The nature of Staphylococcus aureus MurA and MurZ and approaches for detection of peptidoglycan biosynthesis inhibitors. Molecular Microbiology, 72:335-343.

Brackman, G., Breyne, K., De Rycke, R., Vermote, A., Van Nieuwerburgh, F., Meyer, E., Van Calenbergh, S., and Coenye, T. (2016). The Quorum Sensing Inhibitor Hamamelitannin Increases Antibiotic Susceptibility of Staphylococcus aureus Biofilms by Affecting Peptidoglycan Biosynthesis and eDNA Release. Scientific Reports, 6:20321.

Bradford, M.M. (1976). A rapid and sensitive method for the quantitation of microgram quantities of protein utilizing the principle of protein-dye binding. Analytical Biochemistry, 72:248-254.

Castañeda-García, A., Blázquez, J., and Rodríguez-Rojas, A. (2013). Molecular mechanisms and clinical impact of acquired and intrinsic fosfomycin resistance. Antibiotics, 2:217-236.

Chang, J.D., Foster, E.E., Thadani, A.N., Ramirez, A.J., and Kim, S.J. (2017). Inhibition of Staphylococcus aureus Cell Wall Biosynthesis by DesleucylOritavancin: a Quantitative Peptidoglycan Composition Analysis by Mass Spectrometry. Journal of Bacteriology, 199:e00278-00217. 
Chen, J., Bhattacharjee, H., and Rosen, B.P. (2015a). ArsH is an organoarsenical oxidase that confers resistance to trivalent forms of the herbicide monosodium methylarsenate and the poultry growth promoter roxarsone. Molecular Microbiology, 96:1042-1052.

Chen, J., Madegowda, M., Bhattacharjee, H., and Rosen, B.P. (2015b). ArsP: a methylarsenite efflux permease. Molecular Microbiology, 98:625-635.

Chen, J., and Rosen, B.P. (2016). Organoarsenical Biotransformations by Shewanella putrefaciens. Environmental Science \& Technology, 50:79567963.

Chen, J., Yoshinaga, M., and Rosen, B.P. (2018). The antibiotic action of methylarsenite is an emergent property of microbial communities. Molecular Microbiology, 0:1-8.

Chen, S.-C., Sun, G.-X., Rosen, B.P., Zhang, S.-Y., Deng, Y., Zhu, B.-K., Rensing, C., and Zhu, Y.-G. (2017). Recurrent horizontal transfer of arsenite methyltransferase genes facilitated adaptation of life to arsenic. Scientific Reports, 7:7741.

Couce, A., Briales, A., Rodríguez-Rojas, A., Costas, C., Pascual, Á., and Blázquez, J. (2012). Genomewide Overexpression Screen for Fosfomycin Resistance in Escherichia coli: MurA Confers Clinical Resistance at Low Fitness Cost. Antimicrobial Agents and Chemotherapy, 56:2767-2769.

De Smet, K.A.L., Kempsell, K.E., Gallagher, A., Duncan, K., and Young, D.B. (1999). Alteration of a single amino acid residue reverses fosfomycin resistance of recombinant MurA from Mycobacterium tuberculosis. Microbiology, 145:3177-3184.

Dunsmore, C.J., Miller, K., Blake, K.L., Patching, S.G., Henderson, P.J.F., Garnett, J.A., Stubbings, W.J., Phillips, S.E.V., Palestrant, D.J., Angeles, J.D.L., Leeds, J.A., Chopra, I., and Fishwick, C.W.G. (2008). 2-Aminotetralones: Novel inhibitors of MurA and MurZ. Bioorganic \& Medicinal Chemistry Letters, 18:1730-1734.

Eschenburg, S., Kabsch, W., Healy, M.L., and Schönbrunn, E. (2003). A new view of the mechanisms of UDP-N-acetylglucosamine enolpyruvyl transferase 
(MurA) and 5-Enolpyruvylshikimate-3-phosphate synthase (AroA) derived from X-ray structures of their tetrahedral reaction intermediate states. Journal of Biological Chemistry, 278:49215-49222.

Fan, C., Liu, G., Long, Y., Rosen, B., and Cai, Y. (2018). Thiolation in arsenic metabolism: a chemical perspective. Metallomics, 10:1368-1382.

Henze, U.U., and Berger-Bächi, B. (1996). Penicillin-binding protein 4 overproduction increases beta-lactam resistance in Staphylococcus aureus. Antimicrobial Agents and Chemotherapy, 40:2121-2125.

Hrast, M., Rožman, K., Jukič, M., Patin, D., Gobec, S., and Sova, M. (2017). Synthesis and structure-activity relationship study of novel quinazolinonebased inhibitors of MurA. Bioorganic \& Medicinal Chemistry Letters, 27:3529-3533.

Johnson, D.L. (1971). Simultaneous determination of arsenate and phosphate in natural waters. Environmental Science \& Technology, 5:411-414.

Kahan, F.M., Kahan, J.S., Cassidy, P.J., and Kropp, H. (1974). The mechanism of action of fosfomycin (phosphonomycin). Annals of the New York Academy of Sciences, 235:364-386.

Kim, D.H., Lees, W.J., Kempsell, K.E., Lane, W.S., Duncan, K., and Walsh, C.T. (1996). Characterization of a Cys115 to Asp substitution in the Escherichia coli cell wall biosynthetic enzyme UDP-GlcNAc enolpyruvyl transferase (MurA) that confers resistance to inactivation by the antibiotic fosfomycin. Biochemistry, 35:4923-4928.

Kumar, S., Parvathi, A., Hernandez, R.L., Cadle, K.M., and Varela, M.F. (2009). Identification of a novel UDP-N-acetylglucosamine enolpyruvyl transferase (MurA) from Vibrio fischeri that confers high fosfomycin resistance in Escherichia coli. Archives of Microbiology, 191:425-429.

Li, J., Pawitwar, S.S., and Rosen, B.P. (2016). The organoarsenical biocycle and the primordial antibiotic methylarsenite. Metallomics, 8:1047-1055. 
Lin, S., Del Razo, L.M., Styblo, M., Wang, C., Cullen, W.R., and Thomas, D.J. (2001). Arsenicals inhibit thioredoxin reductase in cultured rat hepatocytes. Chemical Research in Toxicology, 14:305-311.

Liu, J., Lu, Y., Wu, Q., Goyer, R.A., and Waalkes, M.P. (2008). Mineral Arsenicals in Traditional Medicines: Orpiment, Realgar, and Arsenolite. Journal of Pharmacology and Experimental Therapeutics, 326:363-368.

Lloyd, N.C., Morgan, H.W., Nicholson, B.K., and Ronimus, R.S. (2005). The composition of Ehrlich's salvarsan: resolution of a century - old debate. Angewandte Chemie International Edition, 44:941-944.

Maki, T., Watarai, H., Kakimoto, T., Takahashi, M., Hasegawa, H., and Ueda, K. (2006). Seasonal dynamics of dimethylarsenic acid degrading bacteria dominated in lake Kibagata. Geomicrobiology Journal, 23:311-318.

Nadar, V.S., Chen, J., Dheeman, D.S., Galván, A.E., Yoshinaga-Sakurai, K., Kandavelu, P., Sankaran, B., Kuramata, M., Ishikawa, S., Rosen, B.P., and Yoshinaga, M. (2019). Arsinothricin, an arsenic-containing nonproteinogenic amino acid analog of glutamate, is a broad-spectrum antibiotic. Communications Biology, 2:131.

Naranmandura, H., Carew, M.W., Xu, S., Lee, J., Leslie, E.M., Weinfeld, M., and Le, X.C. (2011). Comparative toxicity of arsenic metabolites in human bladder cancer EJ-1 cells. Chemical Research in Toxicology, 24:15861596.

Palmer, A.C., and Kishony, R. (2014). Opposing effects of target overexpression reveal drug mechanisms. Nature Communications, 5:4296.

Pawitwar, S.S., Nadar, V.S., Kandegedara, A., Stemmler, T.L., Rosen, B.P., and Yoshinaga, M. (2017). Biochemical characterization of Arsl: A novel C-As lyase for degradation of environmental organoarsenicals. Environmental Science \& Technology, 51:11115-11125.

Petrick, J.S., Ayala-Fierro, F., Cullen, W.R., Carter, D.E., and Vasken Aposhian, H. (2000). Monomethylarsonous acid (MMA ${ }^{\text {III })}$ Is more toxic than arsenite in Chang human hepatocytes. Toxicology and Applied Pharmacology, 163:203-207. 
Qin, J., Rosen, B.P., Zhang, Y., Wang, G., Franke, S., and Rensing, C. (2006). Arsenic detoxification and evolution of trimethylarsine gas by a microbial arsenite S-adenosylmethionine methyltransferase. Proceedings of the National Academy of Sciences, 103:2075-2080.

Ralph, S.J. (2008). Arsenic-based antineoplastic drugs and their mechanisms of action. Metal-based drugs, 2008.

Raz, R. (2012). Fosfomycin: an old-new antibiotic. Clinical Microbiology and Infection, 18:4-7.

Stice, S., Liu, G., Matulis, S., Boise, L.H., and Cai, Y. (2016). Determination of multiple human arsenic metabolites employing high performance liquid chromatography inductively coupled plasma mass spectrometry. Journal of Chromatography B, 1009-1010:55-65.

Takahata, S., Ida, T., Hiraishi, T., Sakakibara, S., Maebashi, K., Terada, S., Muratani, T., Matsumoto, T., Nakahama, C., and Tomono, K. (2010). Molecular mechanisms of fosfomycin resistance in clinical isolates of Escherichia coli. International Journal of Antimicrobial Agents, 35:333-337.

Webb, M., R. (1992). A continuous spectrophotometric assay for inorganic phosphate and for measuring phosphate release kinetics in biological systems. Proceedings of the National Academy of Sciences, USA, 89:48844887.

Yoshinaga, M., Cai, Y., and Rosen, B.P. (2011). Demethylation of methylarsonic acid by a microbial community. Environmental Microbiology, 13:1205-1215.

Yoshinaga, M., and Rosen, B.P. (2014). A C.As lyase for degradation of environmental organoarsenical herbicides and animal husbandry growth promoters. Proceedings of the National Academy of Sciences, USA, 111:7701-7706.

Zhu, Y.-G., Xue, X.-M., Kappler, A., Rosen, B.P., and Meharg, A.A. (2017). Linking genes to microbial biogeochemical cycling: Lessons from arsenic. Environmental Science \& Technology, 51:7326-7339. 
Zhu, Y.-G., Yoshinaga, M., Zhao, F.-J., and Rosen, B.P. (2014). Earth abides arsenic biotransformations. Annual Review of Earth and Planetary Sciences, 42:443-467.

\section{Chapter 5. A PRELIMINARY STUDY ON THE SUBSTRATE SELECTIVITY OF THE TRIVALENT ORGANOARSENICAL PERMEASE ArsP}

\subsection{Introduction}

Arsenic permeases and efflux pumps are among the most common and most efficient mechanisms of arsenic detoxification, especially in bacteria (Garbinski et al., 2019). These transport systems are generally either substrateselective, transporting one arsenic species more efficiently than others, or substrate-specific. Most arsenic efflux systems confer resistance to trivalent arsenicals, with the exception of ArsJ, which confers resistance to $A s(V)$ when coupled to glyceraldehyde 3-phosphate dehydrogenase (GAPHD) (Chen et al., 2016). Arsenic transporters can be found across various protein families; While the As(III)-specific antiporter Acr3 (Villadangos et al., 2012) and the antimonite $(\mathrm{Sb}(\mathrm{III})) / \mathrm{As}(\mathrm{III})$ antiporter ArsB (Meng et al., 2004) are both commonly found in ars operons and serve a similar physiological function, Acr3 is a member of the bile/arsenite/riboflavin transporter (BART) family, whereas ArsB belongs to the ion transporter superfamily (Garbinski et al., 2019). This diversity suggests that arsenic detoxification by efflux transporters is an ancient pathway that has since evolved to include a wide variety of substrates, and it is likely many more transporters and their substrates remain undiscovered. With the recent identification of the organoarsenical antibiotic arsinothricin (AST) (Nadar et al., 
2019), we predict that a transporter of this natural product is able to confer AST resistance to the producer strain.

Organoarsenicals are arsenic compounds with one or more aliphatic, riboside, or aromatic side chain(s), and the recent discovery and characterization of several enzymes involved in degradation, transport, and synthesis of these compounds suggests that they are a major component of the arsenic biogeocycle. Organoarsenical compounds can be products of bacterial metabolism as well as anthropogenic. Trivalent arsenicals like MAs(III) are natural product antibiotics, synthesized by bacteria to obtain a competitive advantage in their microbial communities (Chen et al., 2019a). Recently, it has been proposed that even synthetic organoarsenicals like $\operatorname{Rox}(\mathrm{V})$ and Nit( $\mathrm{V})$ can be "re-activated" by soil bacteria, increasing their toxicity, and subsequently extruding them (Chen et al., 2019b; Yan et al., 2019).

Among the first ars genes to evolve were the As(III) S-adenosylmethionine (SAM) methyltransferase or ArsM, which converts As(III) to MAs(III), DMAs(III) and TMAs(III), and an associated transporter ArsP (Chen et al., 2020). ArsP was first identified from roxarsone-resistant Campylobacter jejuni strains (Shen et al., 2014), where inactivation of this transporter resulted in loss of resistance, and expression into a $C$. jejuni strain lacking ars $P$ conferred resistance and decreased accumulation of roxarsone. Originally, it was proposed to be a novel roxarsone resistance mechanism due to its prevalent use in animal husbandry; however, it was later shown that ArsP transports MAs(III) much more efficiently than Rox(III) (Chen et al., 2015). Given the co-evolution of ArsM and ArsP, it is hypothesized 
that the synthesis of MAs(III) and subsequent efflux by ArsP gives microbial communities a competitive advantage, where they use MAs(III) as an antibiotic (Chen et al., 2019a).

ArsP is thought to belong to the major facilitator superfamily (MFS) of transporters, yet is predicted to contain eight transmembrane helices (Shen et al., 2014; Chen et al., 2015); not the twelve which are commonly found in other MFS transporters (Yan, 2015). ArsP has two conserved cysteine residues which are critical for resistance and transport of organoarsenicals (Chen et al., 2015); however, no residues involved in the selectivity of MAs(III) over aromatic arsenicals have been identified. In this study, we aim to test the existing hypotheses for how ArsP selectively transport MAs(III). Firstly, because it has been suggested that two conserved proline residues flanking the substrate binding site are involved in a conformational change that occurs on substrate binding (Chen et al., 2015), we predicted that these prolines may cause steric hindrance of binding of large aromatic arsenicals to the substrate binding site. We show that individual prolines are not critical for MAs(III) resistance; however, cells expressing ArsP lacking both prolines show a significant decrease in its resistance profile. Next, we considered whether the stronger affinity of aromatic arsenicals for vicinal cysteines compared to MAs(III) (Pawitwar et al., 2017) impacts the ability of ArsP to extrude these compounds. We hypothesized that introducing bulkier and/or more hydrophobic amino acid residues between the substrate binding cysteines would lower the binding affinity, and thus increase the resistance profile for aromatic arsenicals; however, all the examined amino acid substitutions resulted in a large 
decrease or loss of resistance. Together, these data suggest that the responsible residues/motifs for the MAs(III) of ArsP are likely found outside the predicted substrate binding site, and further structural and topological assays are needed to elucidate its properties.

\subsection{Materials and methods}

\subsubsection{Chemicals}

Unless otherwise indicated, all chemicals were of analytical or better grade from MilliporeSigma (Burlington, MA). Rox $(\mathrm{V})$ was purchased from Thermo Fisher Scientific (Waltham, MA). Rox(III) was prepared by chemical reduction of their corresponding pentavalent forms as previously described (Yoshinaga and Rosen, 2014). In brief, $0.2 \mathrm{mM}$ pentavalent arsenical was mixed with $27 \mathrm{mM} \mathrm{Na} \mathrm{S}_{2} \mathrm{O}_{3}, 66$ $\mathrm{mM} \mathrm{Na} \mathrm{S}_{2} \mathrm{O}_{5}$, and $82 \mathrm{mM} \mathrm{H}_{2} \mathrm{SO}_{4}$, following which the $\mathrm{pH}$ was adjusted to 6 with $\mathrm{NaOH}$. The methylarsonous acid iodide derivative $\left(\left.\mathrm{MAs}(\mathrm{III})\right|_{2}\right)$ synthesized as described (Stice et al., 2016) was used as MAs(III).

\subsubsection{Strains, media, and growth conditions}

Escherichia coli strain TOP10 (Invitrogen, Waltham, MA) used for plasmid replication and mutagenesis was cultured in lysogeny broth (LB) at $37^{\circ} \mathrm{C}$ in a shaking incubator at $200 \mathrm{rpm}$. E. coli strain AW3110(DE3) (Aars) (Carlin et al., 1995) used for in vivo MAs(III)/Rox(III) resistance assays was cultured in either LB

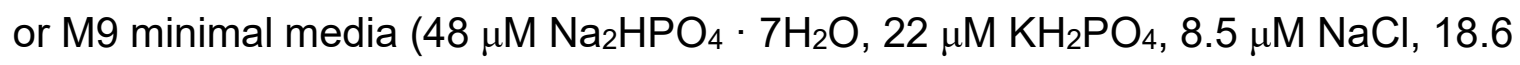
$\mu \mathrm{M} \mathrm{NH}_{4} \mathrm{Cl}, 2 \mathrm{mM} \mathrm{MgSO}_{4}, 100 \mu \mathrm{M} \mathrm{CaCl}_{2}$ ) supplemented with $0.2 \%$ glucose. 100 $\mu \mathrm{g} / \mathrm{ml}$ ampicillin was added as necessary in each culture. 


\subsubsection{Assaying effect of substrate binding site mutations}

Expression vector pTrcHis2A-SpArsP (pTrcHis2A carrying the gene that encodes Shewanella putrefaciens 200 ArsP (SpArsP, WP_014610144.1)) (Chen et al., 2015) was utilized as a template for all mutagenesis experiments. Mutations in the gene were carried out by PCR mutagenesis with primers designed using the QuikChange ${ }^{\circledR} \quad$ primer $\quad$ design tool (https://www.agilent.com/store/primerDesignProgram.jsp). Briefly, a reaction mixture containing $180 \mathrm{ng}$ of template DNA, $0.5 \mu \mathrm{M}$ of forward and reverse primers, $2.5 \mathrm{mM}$ of dNTP mix, 5\% DMSO, and 10U of Pfu Turbo (Agilent Technologies, Santa Clara, CA) with the provided buffer was run with the following PCR cycle conditions. An initial denaturing step was performed at $94{ }^{\circ} \mathrm{C}$ for $5 \mathrm{~min}$, followed by 18 cycles of denaturing $\left(50 \mathrm{~s}\right.$ at $94{ }^{\circ} \mathrm{C}$ ), annealing $\left(50 \mathrm{~s}\right.$ at $64.4{ }^{\circ} \mathrm{C}$ ), and elongation $\left(6.5 \mathrm{~min}\right.$ at $\left.72{ }^{\circ} \mathrm{C}\right)$. A final elongation step was performed at $72{ }^{\circ} \mathrm{C}$ for $10 \mathrm{~min}$. The codons for the proline residues in the predicted MAs(III)-binding site of SpArsP (Pro69 and Pro77) were individually mutated to alanine codons, generating derivatives P69A and P77A. A mutant with both prolines changed to alanine (P69/77A) was also created. The codon for the serine residue between the substrate binding cysteines Cys71 and Cys73 (Ser72) was mutated to alanine, valine, tyrosine, cysteine, or leucine, generating S72A, S72V, S72Y, S72C, and S72L. The primers used for mutagenesis are as follows, forward primers: 5'TGGAGCAAGAACAAAATGCGgtAATAGACCCAAGTAG-3' (P69A), 5'AAGTAGACCTTTTAAGAACGCAATAGTGGAGCAAGAACAAAATG-3' (P77A), 
5'-GTCTATTACCCCATTTTGTGCTTGCTCCACTATTCCGT-3' (S72A), 5'ACTTGGGTCTATTACCCCATTTTTGTGTTTGCTCCACTATTCCGT-3' (S72V), 5ACTTGGGTCTATTACCCCATTTTGTTATTGCTCCACTATTC-3' (S72Y), 5ACTTGGGTCTATTACCCCATTTTGTTGTTGCTCCACTATTC-3' (S72C), and 5GCTACTTGGGTCTATTACCCCATTTTGTTTATGCTCCACTATTCCG-3' (S72L); reverse primers: 5'-CTACTTGGGTCTATTACCGCATTTTGTTCTTGCTCCA-3' (P69A), 5-CATTTTGTTCTTGCTCCACTATTGCGTTCTTAAAAGGTCTACTT-3' (P77A) 5'ACGgAATAGTGGAGCAAGCACAAAATGGGGTAATAGAC-3' $(\mathrm{S} 72 \mathrm{~A})$, 5'ACGGAATAGTGGAGCAAACACAAAATGGGGTAATAGACCCAAGT-3' (S72V), 5'-GAATAGTGGAGCAATAACAAAATGGGGTAATAGACCCAAGT-3' (S72Y), 5'-GAATAGTGGAGCAACAACAAAATGgGgTAATAGACCCAAGT-3' (S72C), and 5'-CGGAATAGTGGAGCATAAACAAAATGGGGTAATAGACCCAAGTAGC3' (S72L). The proline double mutant was generated by sequential mutagenesis using the primers listed above. Each PCR reaction was digested with Dpnl, at 37 ${ }^{\circ} \mathrm{C}$ overnight. Digestion mixtures were concentrated and transformed into $E$. coli TOP10 using heat-shock. Transformants were spread on LB plates supplemented with $100 \mu \mathrm{g} / \mathrm{ml}$ ampicillin and incubated overnight at $37^{\circ} \mathrm{C}$. Plasmid DNA was purified from several colonies and sequenced using forward vector primer pSE3805 (5'-GGCTCGTATAATGTGTGG-3') and reverse vector primer pSE3083 (5'-GGCATGGGGTCAGGTGGG-3') to confirm the mutations. DNA sequencing was performed by Sequetech (Mountain View, CA). 


\subsubsection{Organoarsenical resistance assay}

AW3110(DE3) E. coli cells bearing pTrcHis2A (control) or pTrcHis2A-SpArsP (wild-type or mutant derivatives) were cultured overnight in LB supplemented with $100 \mu \mathrm{g} / \mathrm{ml}$ ampicillin at $37^{\circ} \mathrm{C}$ in a shaking incubator at $200 \mathrm{rpm}$. Overnight cultures of SpArsP-expressing cells were washed and diluted to an $\mathrm{A}_{600 \mathrm{~nm}}$ of $0.045 \mathrm{in} \mathrm{M9}$ minimal media supplemented with $0.2 \%$ glucose and $100 \mu \mathrm{g} / \mathrm{ml}$ ampicillin, while the control cells were diluted to an $A_{600} \mathrm{~nm}$ of 0.03 . After a 30 -minute recovery period, where cells were incubated at $37^{\circ} \mathrm{C}$ in a shaking incubator at $200 \mathrm{rpm}$, indicated concentrations of MAs(III) or Rox(III) were added and incubated at $30^{\circ} \mathrm{C}$ for 24 hours. After the incubation, cell growth was estimated from the absorbance at $600 \mathrm{~nm}$.

\subsection{Results and discussion}

\subsubsection{Proline residues flanking binding site are not critical for resistance}

The ArsP substrate binding motif (Table 4) is a highly conserved sequence of amino acids, which contains two absolutely conserved prolines. In membrane proteins, proline residues are common within transmembrane a-helices (Barlow and Thornton, 1988), and have been shown to twist the normal structure of helices by "kinking" the portions of the helices adjacent to the proline residue (Chang et al., 1999). In transporters, conformational changes on substrate binding which shift the protein from an "i" state with an open pore facing the cytosol, to an "e" state with the pore facing the extracellular space or the periplasm are suggested to be the molecular basis for transport (Klingenberg, 1981). Therefore it has been 
proposed that the conserved prolines in the ArsP substrate-binding motif, Pro69 and Pro77, kink the substrate binding helix from an inward-facing conformation to an outward-facing conformation (Chen et al., 2015), facilitating the transport of organoarsenicals. To test this hypothesis, we constructed $E$. coli cells expressing single and double mutants of Pro69 and Pro77 in SpArsP and examined the effects on the substrate selectivity. Either of the single mutants did not lose resistance to MAs(III), whereas the double mutant showed a decrease in the MAs(III) resistance profile (Figure 25). Furthermore, these mutants showed less resistance to Rox(III) when compared to the wild type (Figure 26).

We hypothesized that a pair of conserved proline residues flanking the substrate-binding cysteines kink the helix, causing conformational changes that drive transport of organoarsenicals. However, individual proline residues were not critical to confer resistance to neither MAs(III), nor Rox(III). The proline doublemutant did show a pronounced loss of resistance, though this may be due to lower protein expression, or structural aberrations. These conserved proline residues also do not seem to sterically hinder Rox(III) entry into the binding site, as neither of the mutants showed a stronger Rox(III)-resistant phenotype than the wild-type.

\subsubsection{Aromatic arsenical affinity to cysteines is not responsible for MAs(III) selectivity}

Substrate binding sites in some bacterial ars proteins, such as ArsR (Chen et al., 2014) and Arsl (Pawitwar et al., 2017), have higher affinity for trivalent aromatic arsenical compounds compared to MAs(III). Thus, another possibility would be that efflux of trivalent aromatic arsenicals is less efficient due to stronger 
interactions with the catalytic cysteines, hindering trivalent aromatic arsenicals from being preferable substrates for SpArsP. Therefore, we substituted Ser72, the conserved serine located between the two catalytic cysteines Cys71 and Cys73 (Table 4, highlighted in light green) to larger, smaller, or more hydrophobic residues, which we hypothesize weakens the strong affinity of the substratebinding cysteines and increases the efficiency of SpArsP for trivalent aromatic arsenical substrates. However, all the Ser72 mutation derivatives became more sensitive to $\operatorname{MAs}(\mathrm{III})$ (Figure 27). Differential MAs(III) resistance profiles were observed, with the strongest reduction in resistance caused by greatly increasing bulk, and the least caused by modifying hydrophobicity. These mutants were also less resistant to Rox(III); however, the serine-to-valine mutation had the least pronounced effect on resistance (Figure 28), similar to the profile for MAs(III).

Since low-affinity substrates can be transported at a higher rate than highaffinity substrates (Severance et al., 2017), it is possible that if the dissociation of substrates from the ArsP binding site is the rate-limiting step. Thus, substrates bound with higher affinity will be extruded less efficiently thus conferring lower amounts of resistance. When we mildly disrupted the substrate binding site by altering the properties of Ser72, we observed differing resistance profiles to Rox(III) depending on the substitution. However, none conferred higher resistance to Rox(III) than the wild-type protein. Furthermore, similar resistance profiles were observed in the presence of MAs(III), suggesting that the conserved Ser72 has a role for the basis of the transport mechanism rather than the substrate selectivity. 


\subsection{Figures and tables}

Table 4: Alignment of predicted substrate binding sites for bacterial ArsP homologs (mutated prolines highlighted in yellow, mutated serine in green)
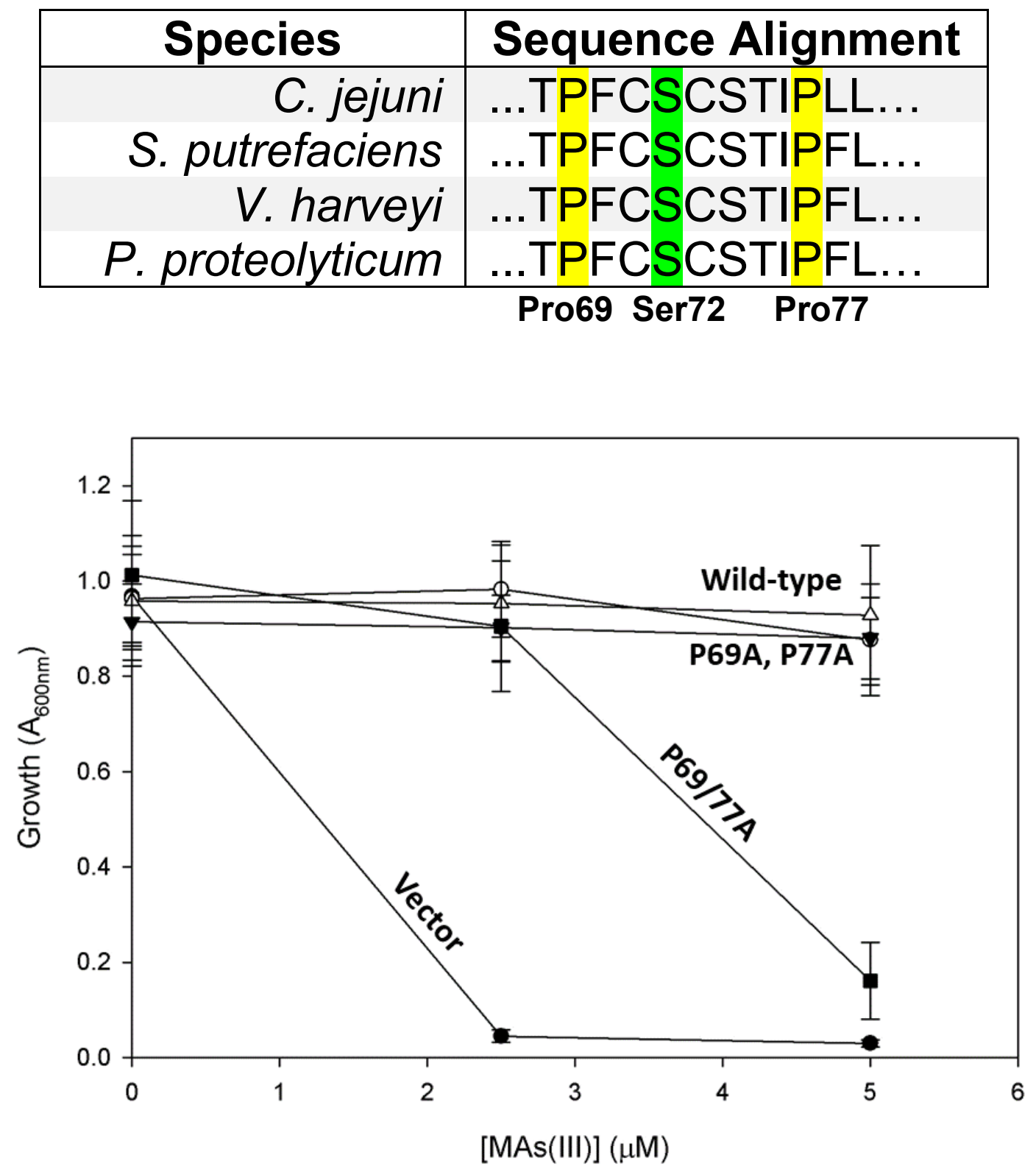

Figure 25: MAs(III) liquid media resistance profile of E. coli AW3110 containing ArsP wild-type and proline mutants. Single proline mutations in the predicted substrate binding site do not compromise the MAs(III)-resistant phenotype, whereas the double mutant shows stunted growth Data are the mean \pm SE $(n=3)$. 


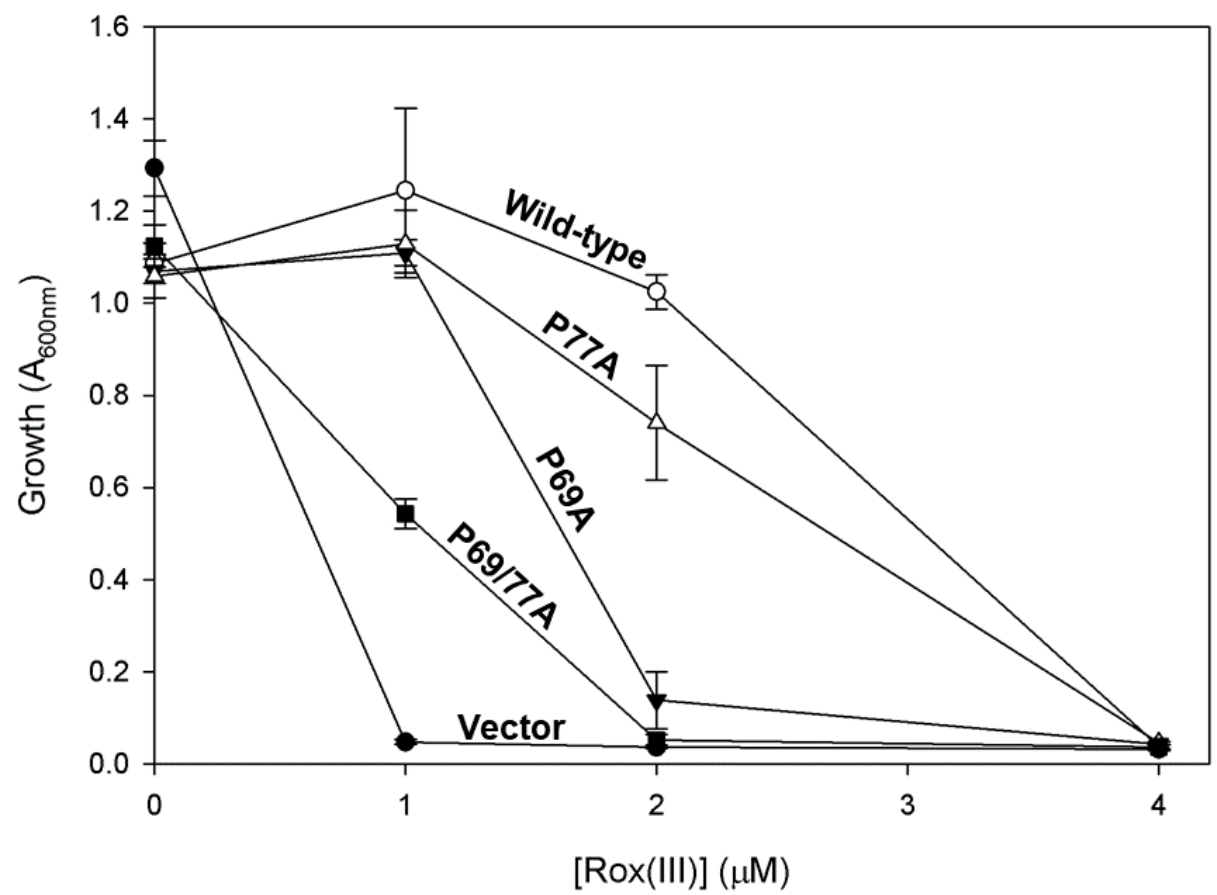

Figure 26: Rox(III) liquid media resistance profile of E. coli AW3110 containing ArsP and proline mutants. Each proline mutant shows a differential resistance profile to Rox(III), with the double mutant showing the most stunted growth. Data are the mean $\pm \operatorname{SE}(n=3)$.

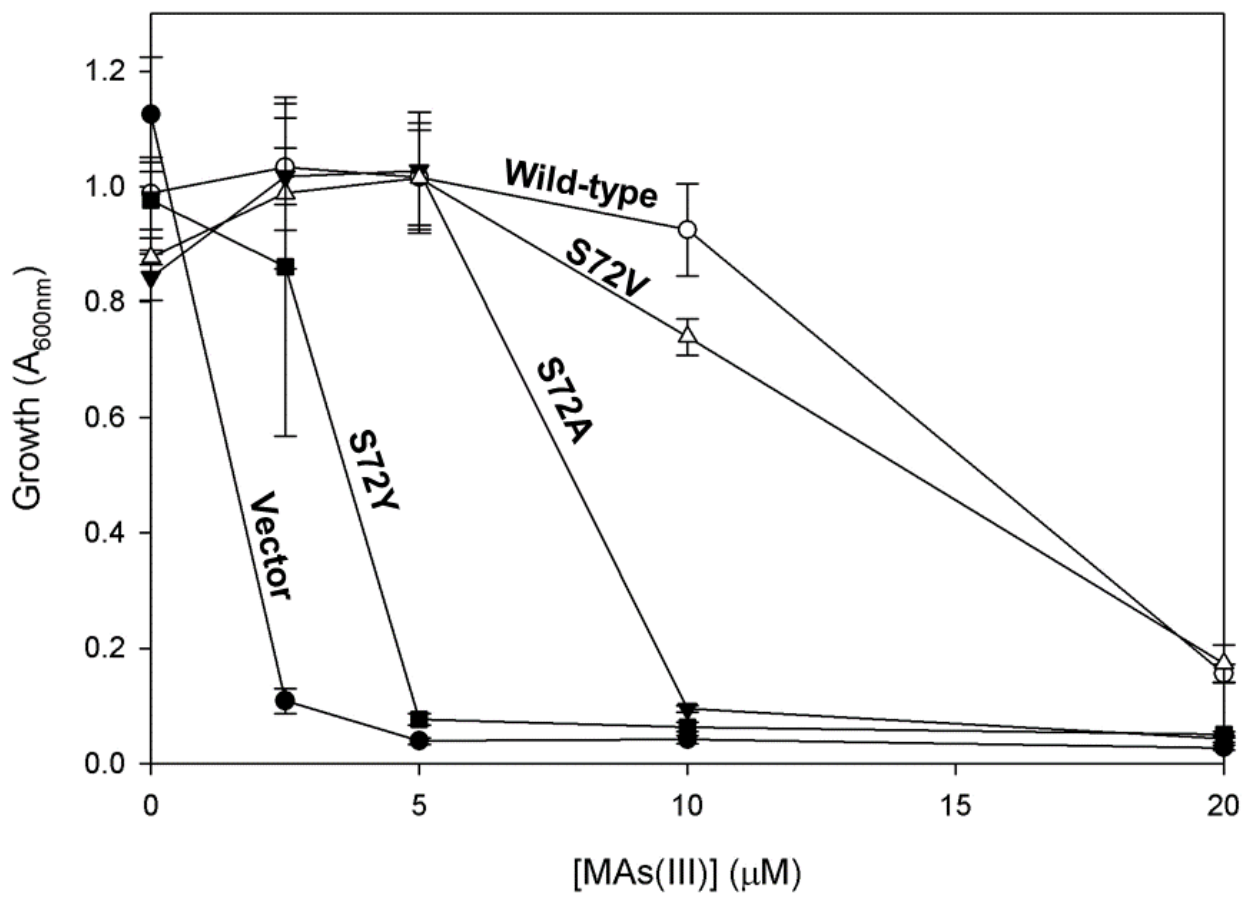

Figure 27: Effect of site-directed mutagenesis on conserved serine residue in predicted substrate binding site on MAs(III) resistance phenotype. Except for the valine substitution, each mutation introduced yielded a partially stunted MAs(III) resistance profile. Data are the mean \pm SE $(n=3)$. 


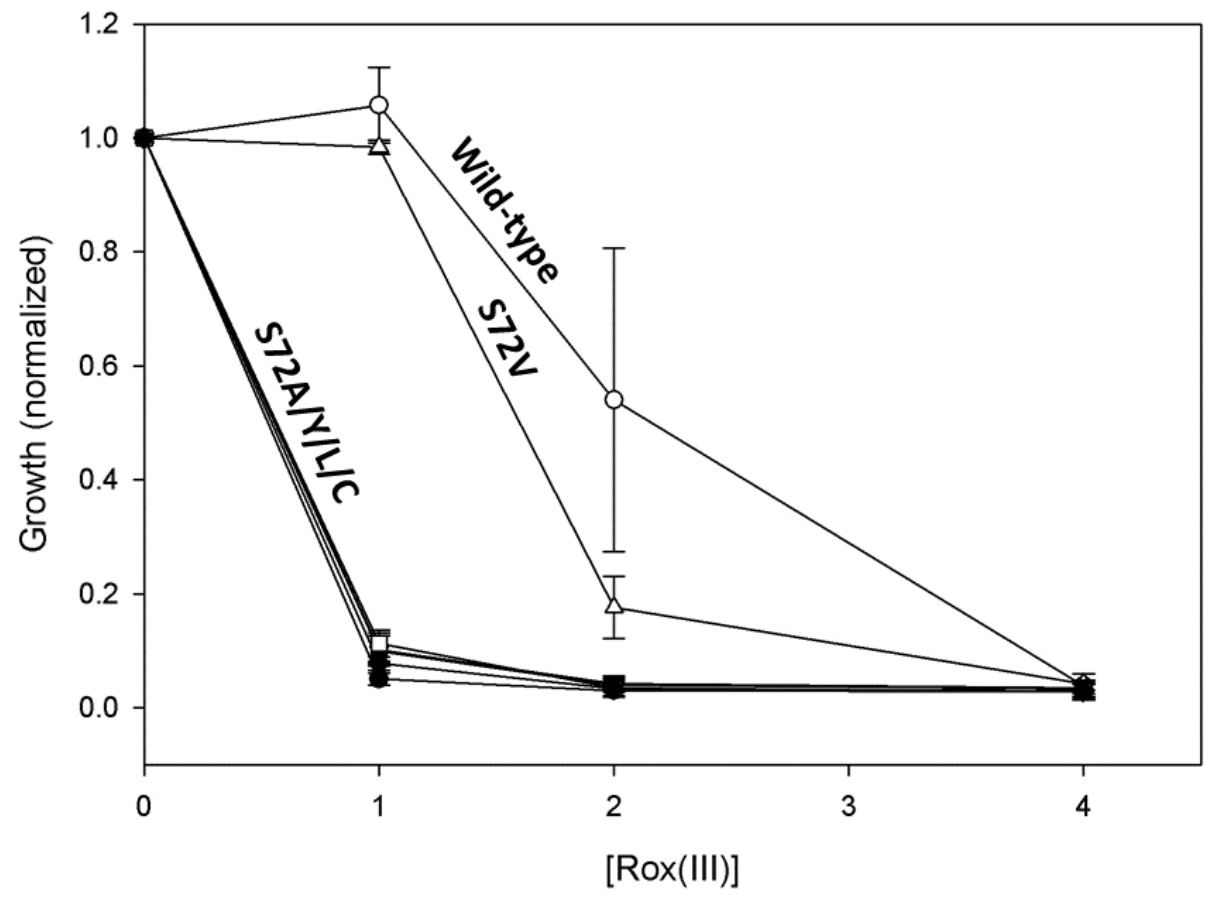

Figure 28: Effect of site-directed mutagenesis on conserved serine residue in predicted substrate binding site on Rox(III) resistance phenotype. Contrary to hypothesis that disrupting substrate binding site would yield higher Rox(III) resistance, with the exception of the valine substitution, each mutation introduced yielded a loss of the Rox(III) resistance phenotype. Data are the mean \pm SE $(n=3)$. Growth of each strain normalized to growth of no Rox(III) control.

\subsection{Significance and future directions}

Commercially used pentavalent compounds such as monosodium methylarsenate (MSMA) accumulate in soil and can leach into groundwater (Whitmore et al., 2008; Matteson et al., 2014). In soil, MSMA can also be reduced to methylarsenite (MAs(III)) (Yoshinaga et al., 2011), which is significantly more toxic than its inorganic counterpart (Petrick et al., 2000; Petrick et al., 2001). In addition, more complex aromatic organoarsenical compounds such as roxarsone and nitarsone used as antibiotics and growth promoters for livestock also have toxic trivalent forms and can be biologically degraded into inorganic arsenic, thus accumulating in the environment and ending up in the food chain (Fisher et al., 2015; Nachman et al., 2017). In vitro arsenic biotransformations by cecum 
microflora have been observed, and perturbations to gut microbiota composition have been correlated with lower inorganic arsenic detoxification capacity and higher arsenic toxicity in mice models (Kubachka et al., 2009; Lu et al., 2013; Lu et al., 2014), suggesting that bacterial arsenic metabolism may be directly related to individual arsenic resistance profiles in humans. The methylarsenite-selective transporter ArsP is, one of the few transporters currently known to confer resistance specifically to organoarsenicals, and it is unique among organoarsenical transporters as it can transport several structurally different species of trivalent organoarsenicals. However, it transports and confers resistance to $\mathrm{MAs}(\mathrm{III})$ more effectively than aromatic arsenicals like Rox(III), Nit(III), and p-ASA(III) (Chen et al., 2015).. It has been well established that substrate specificity and selectivity can be altered by modification of amino acid residues inside and outside substrate binding sites (Vasudevan et al., 2001; Vandenberg et al., 2007; Gökirmak et al., 2012; Srikant et al., 2020). Understanding the basis of selectivity of ArsP would give insight into the molecular basis for organoarsenical binding to transport proteins, and would help us identify either substrates for putative transporters in ars operons, or transporters for newly discovered organoarsenicals such as arsinothricin (Kuramata et al., 2016; Nadar et al., 2019). Furthermore, this data is necessary to the development of better bioremediation and/or arsenic detection strategies (Mohammed et al., 2011). The development of organoarsenic-specific biosensors (Chen et al., 2014), or genetically engineered arsenic bioaccumulating strains (Mateos et al., 2006) take 
us closer to the goal of bettering public health and reducing the risk that arsenic compounds pose.

Our results suggest that the molecular basis for selectivity of ArsP is likely outside of the substrate binding site. While determining the crystal structure of ArsP by X-ray crystallography or cryo-electron microscopy (CryoEM) would yield the most descriptive data about its transport mechanism, feasibility of this approach is a concern. Alternatively, scanning alanine mutagenesis (SCAM), which introduces sequential alanine residues in the amino acid sequence via mutagenesis has been previously utilized to determine critical residues (Childers et al., 2007). Screening alanine mutants for a more Rox(III)-resistant phenotype, followed by modeling of the 3D structures of these mutants would allow us to better assess whether steric hindrance plays a role in substrate selectivity.

\subsection{References}

Barlow, D.J., and Thornton, J.M. (1988). Helix geometry in proteins. Journal of Molecular Biology, 201:601-619.

Carlin, A., Shi, W., Dey, S., and Rosen, B.P. (1995). The ars operon of Escherichia coli confers arsenical and antimonial resistance. Journal of Bacteriology, 177:981-986.

Chang, D.-K., Cheng, S.-F., Trivedi, V.D., and Lin, K.-L. (1999). Proline Affects Oligomerization of a Coiled Coil by Inducing a Kink in a Long Helix. Journal of Structural Biology, 128:270-279.

Chen, J., Madegowda, M., Bhattacharjee, H., and Rosen, B.P. (2015). ArsP: a methylarsenite efflux permease. Molecular Microbiology, 98:625-635. 
Chen, J., Sun, S., Li, C.-Z., Zhu, Y.-G., and Rosen, B.P. (2014). Biosensor for Organoarsenical Herbicides and Growth Promoters. Environmental Science \& Technology, 48:1141-1147.

Chen, J., Yoshinaga, M., Garbinski, L.D., and Rosen, B.P. (2016). Synergistic interaction of glyceraldehydes - 3 - phosphate dehydrogenase and ArsJ, a novel organoarsenical efflux permease, confers arsenate resistance. Molecular Microbiology, 100:945-953.

Chen, J., Yoshinaga, M., and Rosen, B.P. (2019a). The antibiotic action of methylarsenite is an emergent property of microbial communities. Molecular Microbiology, 111:487-494.

Chen, J., Zhang, J., and Rosen, B.P. (2019b). Role of ArsEFG in roxarsone and nitarsone detoxification and resistance. Environmental Science \& Technology, 53:6182-6191.

Chen, S.-C., Sun, G.-X., Yan, Y., Konstantinidis, K.T., Zhang, S.-Y., Deng, Y., Li, X.-M., Cui, H.-L., Musat, F., Popp, D., Rosen, B.P., and Zhu, Y.-G. (2020). The Great Oxidation Event expanded the genetic repertoire of arsenic metabolism and cycling. Proceedings of the National Academy of Sciences.

Childers, B.M., Weber, G.G., Prouty, M.G., Castaneda, M.M., Peng, F., and Klose, K.E. (2007). Identification of Residues Critical for the Function of the Vibrio cholerae Virulence Regulator ToxT by Scanning Alanine Mutagenesis. Journal of Molecular Biology, 367:1413-1430.

Fisher, D.J., Yonkos, L.T., and Staver, K.W. (2015). Environmental Concerns of Roxarsone in Broiler Poultry Feed and Litter in Maryland, USA. Environmental Science \& Technology, 49:1999-2012.

Garbinski, L.D., Rosen, B.P., and Chen, J. (2019). Pathways of arsenic uptake and efflux. Environment International, 126:585-597.

Gökirmak, T., Campanale, J.P., Shipp, L.E., Moy, G.W., Tao, H., and Hamdoun, A. (2012). Localization and substrate selectivity of sea urchin multidrug (MDR) efflux transporters. Journal of Biological Chemistry, 287:4387643883. 
Klingenberg, M. (1981). Membrane protein oligomeric structure and transport function. Nature, 290:449-454.

Kubachka, K.M., Kohan, M.C., Herbin-Davis, K., Creed, J.T., and Thomas, D.J. (2009). Exploring the in vitro formation of trimethylarsine sulfide from dimethylthioarsinic acid in anaerobic microflora of mouse cecum using HPLC-ICP-MS and HPLC-ESI-MS. Toxicology and Applied Pharmacology, 239:137-143.

Kuramata, M., Sakakibara, F., Kataoka, R., Yamazaki, K., Baba, K., Ishizaka, M., Hiradate, S., Kamo, T., and Ishikawa, S. (2016). Arsinothricin, a novel organoarsenic species produced by a rice rhizosphere bacterium. Environmental Chemistry, 13:723-731.

Lu, K., Cable, P.H., Abo, R.P., Ru, H., Graffam, M.E., Schlieper, K.A., Parry, N.M.A., Levine, S., Bodnar, W.M., Wishnok, J.S., Styblo, M., Swenberg, J.A., Fox, J.G., and Tannenbaum, S.R. (2013). Gut Microbiome Perturbations Induced by Bacterial Infection Affect Arsenic Biotransformation. Chemical Research in Toxicology, 26:1893-1903.

Lu, K., Mahbub, R., Cable, P.H., Ru, H., Parry, N.M.A., Bodnar, W.M., Wishnok, J.S., Styblo, M., Swenberg, J.A., Fox, J.G., and Tannenbaum, S.R. (2014). Gut Microbiome Phenotypes Driven by Host Genetics Affect Arsenic Metabolism. Chemical Research in Toxicology, 27:172-174.

Mateos, L.M., Ordóñez, E., Letek, M., and Gil, J.A. (2006). Corynebacterium glutamicum as a model bacterium for the bioremediation of arsenic. International Microbiology, 9:207-215.

Matteson, A.R., Gannon, T.W., Jeffries, M.D., Haines, S., Lewis, D.F., and Polizzotto, M.L. (2014). Arsenic Retention in Foliage and Soil after Monosodium Methyl Arsenate (MSMA) Application to Turfgrass. Journal of environmental quality, 43:379-388.

Meng, Y.-L., Liu, Z., and Rosen, B.P. (2004). As (III) and Sb (III) uptake by GlpF and efflux by ArsB in Escherichia coli. Journal of Biological Chemistry, 279:18334-18341. 
Mohammed, A.S., Kapri, A., and Goel, R., 2011. Heavy Metal Pollution: Source, Impact, and Remedies. in: Khan, M.S., Zaidi, A., Goel, R., Musarrat, J. (Eds.). Biomanagement of Metal-Contaminated Soils. Springer Netherlands, Dordrecht, pp. 1-28.

Nachman, K.E., Love, D.C., Baron, P.A., Nigra, A.E., Murko, M., Raber, G., Francesconi, K.A., and Navas-Acien, A. (2017). Nitarsone, Inorganic Arsenic, and Other Arsenic Species in Turkey Meat: Exposure and Risk Assessment Based on a 2014 U.S. Market Basket Sample. Environmental health perspectives, 125:363-369.

Nadar, V.S., Chen, J., Dheeman, D.S., Galván, A.E., Yoshinaga-Sakurai, K., Kandavelu, P., Sankaran, B., Kuramata, M., Ishikawa, S., and Rosen, B.P. (2019). Arsinothricin, an arsenic-containing non-proteinogenic amino acid analog of glutamate, is a broad-spectrum antibiotic. Communications Biology, 2:1-12.

Pawitwar, S.S., Nadar, V.S., Kandegedara, A., Stemmler, T.L., Rosen, B.P., and Yoshinaga, M. (2017). Biochemical characterization of Arsl: a novel C-As Lyase for degradation of environmental organoarsenicals. Environmental Science \& Technology, 51:11115-11125.

Petrick, J.S., Ayala-Fierro, F., Cullen, W.R., Carter, D.E., and Aposhian, H.V. (2000). Monomethylarsonous acid (MMAIII) is more toxic than arsenite in Chang human hepatocytes. Toxicology and Applied Pharmacology, 163:203-207.

Petrick, J.S., Jagadish, B., Mash, E.A., and Aposhian, H.V. (2001). Monomethylarsonous Acid (MMAIII) and Arsenite: LD50 in Hamsters and In Vitro Inhibition of Pyruvate Dehydrogenase. Chemical Research in Toxicology, 14:651-656.

Severance, A.C., Sandoval, P.J., and Wright, S.H. (2017). Correlation between Apparent Substrate Affinity and OCT2 Transport Turnover. Journal of Pharmacology and Experimental Therapeutics, 362:405-412.

Shen, Z., Luangtongkum, T., Qiang, Z., Jeon, B., Wang, L., and Zhang, Q. (2014). Identification of a novel membrane transporter mediating resistance to organic arsenic in Campylobacter jejuni. Antimicrobial Agents and Chemotherapy, 58:2021-2029. 
Srikant, S., Gaudet, R., and Murray, A.W. (2020). Selecting for Altered Substrate Specificity Reveals the Evolutionary Flexibility of ATP-Binding Cassette Transporters. Current Biology, 30:1689-1702.e1686.

Stice, S., Liu, G., Matulis, S., Boise, L.H., and Cai, Y. (2016). Determination of multiple human arsenic metabolites employing high performance liquid chromatography inductively coupled plasma mass spectrometry. Journal of Chromatography B, 1009-1010:55-65.

Vandenberg, R.J., Shaddick, K., and Ju, P. (2007). Molecular basis for substrate discrimination by glycine transporters. Journal of Biological Chemistry, 282:14447-14453.

Vasudevan, G., Ullman, B., and Landfear, S.M. (2001). Point mutations in a nucleoside transporter gene from Leishmania donovani confer drug resistance and alter substrate selectivity. Proceedings of the National Academy of Sciences, 98:6092-6097.

Villadangos, A.F., Fu, H.-L., Gil, J.A., Messens, J., Rosen, B.P., and Mateos, L.M. (2012). Efflux permease CgAcr3-1 of Corynebacterium glutamicum is an arsenite-specific antiporter. Journal of Biological Chemistry, 287:723-735.

Whitmore, T.J., Riedinger-Whitmore, M.A., Smoak, J.M., Kolasa, K.V., Goddard, E.A., and Bindler, R. (2008). Arsenic contamination of lake sediments in Florida: evidence of herbicide mobility from watershed soils. Journal of Paleolimnology, 40:869-884.

Yan, N. (2015). Structural Biology of the Major Facilitator Superfamily Transporters. Annual Review of Biophysics, 44:257-283.

Yan, Y., Chen, J., Galván, A.E., Garbinski, L.D., Zhu, Y.-G., Rosen, B.P., and Yoshinaga, M. (2019). Reduction of Organoarsenical Herbicides and Antimicrobial Growth Promoters by the Legume Symbiont Sinorhizobium meliloti. Environmental Science \& Technology, 53:13648-13656.

Yoshinaga, M., Cai, Y., and Rosen, B.P. (2011). Demethylation of methylarsonic acid by a microbial community. Environmental Microbiology, 13:1205-1215. 
Yoshinaga, M., and Rosen, B.P. (2014). A C. As lyase for degradation of environmental organoarsenical herbicides and animal husbandry growth promoters. Proceedings of the National Academy of Sciences, 111:77017706.

\section{Chapter 6. SIGNIFICANCE AND FUTURE PROSPECTS}

\subsection{Organoarsenic-based antibiotics}

There is a wealth of information on the environmental prevalence, negative health effects and epidemiology of inorganic arsenic that spans decades. In contrast, organoarsenical metabolites were only detected in human urine in 2000 (Aposhian et al., 2000), and the first mechanism behind bacterial synthesis of organoarsenical compounds was first described in 2006 (Qin et al., 2006). Since then, many genes involved in organoarsenic metabolism and have been identified, and the proteins they encode characterized (Zhu et al., 2017). However, the discovery of novel organoarsenical compounds has been slower. Recently, a nonproteinogenic arsenic-containing glutamate analog was identified in arsenic metabolites of a bacterial isolate from the rice rhizosphere (Kuramata et al., 2016). This compound is the arsenic analog of the commercially used broad-spectrum herbicide phosphinothricin (PT) and was named arsinothricin (AST). While PT and AST both act as irreversible glutamine synthetase inhibitors, AST is 10 -fold more effective as an antibiotic against pathogens like Mycobacterium and Enterobacter compared with PT. (Nadar et al., 2019). Even before AST was discovered, a gene annotated to encode a phosphinothricin $N$-acetyltransferase was found in many ars operons, raising the question: Why would a gene involved in phosphate metabolism be present in ars operons? It is expected that the function of ars genes 
would be related to arsenic-containing compounds, not phosphate-containing compounds. Indeed, the gene (now more appropriately annotated as arsN1) encodes an $\mathrm{N}$-acetyltransferase found to acetylate AST with higher affinity compared to PT, and bacteria expressing this gene are resistance to AST (Nadar et al., 2019). Currently, the search for new organoarsenic-based antibiotics is limited by the general inaccessibility of analytical techniques that can detect the various metabolites and intermediates that are likely a biproduct of synthesis. The idea that compounds like AST belong to a novel class of antibiotics, and that their biosynthetic pathways are unknown also poses a challenge when utilizing modern computational predictive methods like genomic mining, as the accuracy of annotations across genomes is likely not sufficient to identify AST orthologs. Given that bacteria evolved in an arsenic-rich environment since the dawn of life (Chen et al., 2020), and that they often harness its toxicity to compete against other bacteria (Chen et al., 2019a), it is likely that many yet-to-be discovered organoarsenicals may have untapped potential to be lead antibiotic candidates.

\subsection{Unknown ars genes}

Since the discovery of the first arsenite resistance mechanisms in bacterial operons (Rosen and Borbolla, 1984), there has been considerable effort to identify and characterize bacterial mechanisms of arsenic metabolism. Since the identification of the first ars genes in the early 1980 , the alphabet has been nearly entirely assigned to new genes (Table 1 ). With the growing availability of bacterial genomes, it has become more feasible to scan ars operons to find gene pairs or clusters and experimentally probe their function (Chen et al., 2016; Chen et al., 
2019b). While many genes in ars operons have vague annotations. Even after cloning, their function remains unclear. One possibility for this observation is that the substrates of the enzymes/transporters/regulators encoded by such genes remain unknown, and the function cannot be derived simply from the annotation. This is particularly applicable to a group of transporters belonging to the major facilitator superfamily (MFS) found in ars operons, many of which have been characterized (Garbinski et al., 2019). Another possibility is that these genes are part of larger clusters and carry out an intermediate step in the overall reaction. One approach is to create a bacterial growth medium from arsenic-rich soil extracts and identify metabolites found in the soil that serve as substrates for the uncharacterized gene products. Overall, identifying and characterizing ars operons broadens our understanding of the capacity for bacterial arsenic metabolism and allows us to design new strategies such as biosensors (Chen et al., 2014) to limit exposure to this toxic metalloid.

\subsection{Conclusions and significance}

The goals of the research presented in this dissertation were to 1) identify how aromatic arsenicals elicit antimicrobial activity in the environment, 2) find cellular targets involved in bacterial organoarsenical toxicity, and 3) further characterize the ArsP permease, the most efficient resistance mechanism to organoarsenicals currently known. I investigated the capacity for Sinorhizobium meliloti Rm1021 to transform aromatic arsenicals such as roxarsone and found that S. meliloti Rm1021 is capable of activating them by reduction to trivalent forms. I identified the key bacterial cell wall synthesis enzyme MurA as a target of 
trivalent organoarsenicals and found that organoarsenicals inhibit using a different mechanism than current antibiotics that target MurA. Finally, I probed the substrate binding site of the ArsP permease by mutagenesis and found that highly conserved residues originally hypothesized to play a major role in transport are not essential. While the data presented here inches us forward in our understanding of organoarsenical metabolism in the environment, several gaps in our knowledge must be addressed to have a complete picture.

Arsenic, as a ubiquitous, non-essential environmental toxin, has provided selective pressure to survive in and utilize arsenic since the beginning of life on earth. As a result, nearly all living organisms have mechanisms to detoxify arsenic (Zhu et al., 2014). In particular, bacterial biotransformations of arsenic create a complex biogeocycle of arsenic in the environment. Redox and methylation cycles, thiolation, and synthesis of arsenic-based antibiotics create a web of both potential hazards and benefits to human health.

As a health hazard, the U.S. Environmental Protection Agency (EPA) and the International Agency for Research on Cancer (IARC) classify arsenic and arsenic compounds as Group A and Group 1, respectively, designating them as carcinogenic to humans. In particular, skin cancers such as basal cell and squamous cell carcinomas have been linked to arsenic exposure and arsenic content in urine (Hsueh et al., 1997). Furthermore, exposure to arsenic in drinking water has also been correlated to neurodevelopmental impairment in children and adolescents, as well as incidence and mortality of cardiovascular disease, especially among smokers (Chen et al., 2011; Rodríguez-Barranco et al., 2013). 
Due to these adverse health effects, and its prevalence in the environment, the Agency for Toxic Substances and Disease Registry (ATSDR) has consistently ranked arsenic as the top priority contaminant (https://www.atsdr.cdc.gov/spl/).

Paracelsus, the father of classical pharmacology, is credited with the adage "The dose makes the poison". This is interpreted to mean that a compound that is toxic at high dose can be a medicine at lower dosages, as long as kills the cancer cell or pathogen before it kills the host. Because of its toxicity, arsenic has a variety of medicinal uses: being a main line therapy for acute promyelocytic leukemia (LoCoco et al., 2013), used in the "magic bullet" antisyphilitic drug Salvarsan (Lloyd et al., 2005), and recently showing promise in the treatment of multidrug-resistant pathogens with the discovery of the non-proteinogenic organoarsenical glutamate analog arsinothricin (Nadar et al., 2019). While the mechanisms of its anticancer properties are a topic of debate, it is well-documented that, throughout history, natural arsenic-containing minerals such as realgar and orpiment have been used in traditional medicine (Liu et al., 2008). Arsenic and arsenic-based compounds, like a double-edged sword, have the potential to be candidates for new therapeutic agents, while also posing serious health threats to communities around the globe.

Observing microbial arsenic metabolism allows us to study both aspects of arsenic biology. One of the first mechanisms of arsenic resistance that evolved in bacteria is methylation (Chen et al., 2020). Using the As(III) S-adenosylmethione methyltransferase ArsM, early anaerobes could detoxify As(III) through three rounds of methylation, yielding the non-toxic gaseous product trimethylarsine, which is volatile and leaves the cells in its gaseous form (Qin et al., 2006). The 
trivalent intermediates of $\mathrm{As}(\mathrm{III})$ methylation are significantly more toxic than $\mathrm{As}(\mathrm{III})$ (Yoshinaga and Rosen, 2014). As a result, bacteria evolved an efflux permease, ArsP, specific for these trivalent intermediates which gained them a competitive advantage in microbial communities (Chen et al., 2019a). This suggests that methylarsenite (MAs(III)) was produced as a primordial antibiotic. Surprisingly, bacteria can also "re-activate" synthetic aromatic arsenic compounds even though these compounds have only been in the environment for less than 100 years. In the third chapter of this dissertation, I reported our characterization of the capacity for a soil legume symbiont, Sinorhizobium meliloti Rm1021, to transform methylarsenicals, as well as aromatic arsenicals. We found that S. meliloti Rm1021 can reduce the nitro group of pentavalent aromatic arsenicals such as Rox $(\mathrm{V})$ and $\mathrm{Nit}(\mathrm{V})$, followed by reduction of the arsenic group, yielding the toxic intermediates HAPA(III) and $p$-ASA(III). Furthermore, we identified $m d a B$ as the gene responsible for the reduction of the nitro group and determined that it is a FAD/NADPH-dependent nitroreductase with broad substrate selectivity for nitroaromatic compounds, requiring an electron donor like glutathione (GSH) to effectively reduce $\operatorname{Rox}(\mathrm{V})$. The mechanism by which S. meliloti Rm1021 can reduce the arsenic group remains unknown; however, these results suggest that environmental microbes can utilize existing cellular machinery to transform aromatic arsenicals to gain a competitive advantage, further showing the complexity of the arsenic biogeocycle and suggesting that this biotransformation should be considered when determining the environmental implications of roxarsone use. 
With the recent discovery of arsinothricin from the rice rhizosphere (Kuramata et al., 2016) and its newfound potential as an antimicrobial drug targeting multi-drug resistant (MDR) pathogens (Nadar et al., 2019), it is clear that there is untapped potential for new classes of organoarsenical antibiotics that are yet-to-be discovered. Even in the case of MAs(III), a primordial antibiotic (Chen et al., 2019a), there were no known cellular targets to explain its antibiotic properties. In the fourth chapter of this dissertation, we identified the first enzyme in the peptidoglycan biosynthesis pathway, MurA, as a target of aliphatic and aromatic arsenicals. We observed that overexpression of MurA conferred resistance to MAs(III), a phenomenon that had been previously observed with other antibiotics (Couce et al., 2012), and that purified enzyme activity was inhibited by either MAs(III) or the aromatic arsenical phenylarsenite (PhAs(III)), but not by $\mathrm{As}(\mathrm{III})$. Furthermore, we compared the mechanism of organoarsenical inhibition to the well-characterized, clinically relevant antibiotic fosfomycin, and found that a conserved cysteine required for fosfomycin inhibition of MurA is not required for organoarsenical inhibition. MurA homologs with low cysteine content in their amino acid sequence were observed to be more resistant to organoarsenical inhibition, suggesting that arsenicals bind to MurA in a cysteine-dependent manner. These findings suggest that the antimicrobial properties of $\mathrm{MAs}$ (III) can be attributed in part to cell wall synthesis inhibition and highlight the potential for new organoarsenical derivatives to serve as antimicrobial candidates.

Nobel Laureate Paul Ehrlich, who discovered the antisyphilitic drug Salvarsan, famously said: "Drug resistance follows the drug like a faithful shadow" 
(Ebrahim, 2010). ArsN1 was discovered even before the broad-spectrum antibiotic AST. ArsN1 was then was shown to be an AST-selective $N$-acetyltransferase that confers resistance to AST (Nadar et al., 2019). Similarly, multiple resistance mechanisms to MAs(III) have been identified: demethylation to As(III) by the C As lyase Arsl (Yoshinaga and Rosen, 2014), oxidation to $M A s(V)$ by the organoarsenical oxidase ArsH (Chen et al., 2015a), and efflux by the MAs(III)selective permease ArsP (Chen et al., 2015b). ArsP is unique among arsenic efflux systems as it transports MAs(III) with high efficiency. It can also transport and confer resistance to the trivalent aromatic arsenicals $\operatorname{Rox}(\mathrm{III})$, Nit(III) and $p$ ASA(III). The structural and topological properties of ArsP as well as the mechanisms behind its selectivity are a topic of debate. In the fifth chapter of this dissertation I tested two major hypotheses for ArsP selectivity for MAs(III): 1) A pair of highly conserved cysteines flanking the substrate binding site are proposed to kink the substrate-binding helix into an inward- and outward-facing conformation, facilitating transport, and 2) aromatic arsenicals bind with higher affinity to the vicinal cysteine pair in the ArsP substrate binding site, reducing transport efficiency for these compounds. I found that mutating each of the conserved prolines individually to alanine did not affect the level of MAs(III) resistance conferred by ArsP. However, mutating both prolines simultaneously caused a significant decrease in MAs(III) resistance. Furthermore, neither single proline-to-alanine mutants nor the double mutant showed higher resistance to Rox(III), suggesting that these residues are not required for MAs(III) selectivity. In addition, mild disruption of the substrate binding site by mutation of a conserved 
serine residue located directly between the substrate binding cysteines did not yield a higher Rox(III) resistant phenotype. Instead, more severe disruptions to the substrate binding site ablated MAs(III)/Rox(III) resistance. These results indicate that residues involved in the selectivity of ArsP for MAs(III) may be located outside the substrate binding site. The detailed mechanism of transport remains to be elucidated. Structural or topological studies of this transporter would yield the most descriptive data to understand both of these properties. Better understanding organoarsenical resistance mechanisms is critical for our ability to develop potential organoarsenical bioremediation methods and detection systems like biosensors (Chen et al., 2014). Furthermore, chemical modification of either resistance mechanisms or the antibiotic arsenical itself could allow development of combination therapies for microbial infections, highlighting the potential of new organoarsenical discovery.

In summary, this dissertation summarizes the current knowledge of bacterial organoarsenical metabolism and provide new perspectives on future uses of organoarsenical compounds. I highlight the current limitations of the studies performed and suggest alternative approaches which have the possibility to yield novel and descriptive data. Lastly, I challenge the view of arsenic as strictly a poison and suggest that the medicinal properties of arsenic have positively changed the field of modern medicine, and new arsenical drugs have the potential to do more in the future. 


\subsection{References}

Aposhian, H.V., Gurzau, E.S., Le, X.C., Gurzau, A., Healy, S.M., Lu, X., Ma, M., Yip, L., Zakharyan, R.A., Maiorino, R.M., Dart, R.C., Tircus, M.G., Gonzalez-Ramirez, D., Morgan, D.L., Avram, D., and Aposhian, M.M. (2000). Occurrence of Monomethylarsonous Acid in Urine of Humans Exposed to Inorganic Arsenic. Chemical Research in Toxicology, 13:693697.

Chen, J., Bhattacharjee, H., and Rosen, B.P. (2015a). ArsH is an organoarsenical oxidase that confers resistance to trivalent forms of the herbicide monosodium methylarsenate and the poultry growth promoter roxarsone. Molecular Microbiology, 96:1042-1052.

Chen, J., Madegowda, M., Bhattacharjee, H., and Rosen, B.P. (2015b). ArsP: a methylarsenite efflux permease. Molecular Microbiology, 98:625-635.

Chen, J., Sun, S., Li, C.-Z., Zhu, Y.-G., and Rosen, B.P. (2014). Biosensor for Organoarsenical Herbicides and Growth Promoters. Environmental Science \& Technology, 48:1141-1147.

Chen, J., Yoshinaga, M., Garbinski, L.D., and Rosen, B.P. (2016). Synergistic interaction of glyceraldehydes - 3 - phosphate dehydrogenase and ArsJ, a novel organoarsenical efflux permease, confers arsenate resistance. Molecular Microbiology, 100:945-953.

Chen, J., Yoshinaga, M., and Rosen, B.P. (2019a). The antibiotic action of methylarsenite is an emergent property of microbial communities. Molecular Microbiology, 111:487-494.

Chen, J., Zhang, J., and Rosen, B.P. (2019b). Role of ArsEFG in roxarsone and nitarsone detoxification and resistance. Environmental Science \& Technology, 53:6182-6191.

Chen, S.-C., Sun, G.-X., Yan, Y., Konstantinidis, K.T., Zhang, S.-Y., Deng, Y., Li, X.-M., Cui, H.-L., Musat, F., Popp, D., Rosen, B.P., and Zhu, Y.-G. (2020). The Great Oxidation Event expanded the genetic repertoire of arsenic metabolism and cycling. Proceedings of the National Academy of Sciences. 
Chen, Y., Graziano, J.H., Parvez, F., Liu, M., Slavkovich, V., Kalra, T., Argos, M., Islam, T., Ahmed, A., Rakibuz-Zaman, M., Hasan, R., Sarwar, G., Levy, D., van Geen, A., and Ahsan, H. (2011). Arsenic exposure from drinking water and mortality from cardiovascular disease in Bangladesh: prospective cohort study. BMJ, 342:d2431.

Couce, A., Briales, A., Rodríguez-Rojas, A., Costas, C., Pascual, Á., and Blázquez, J. (2012). Genomewide Overexpression Screen for Fosfomycin Resistance in Escherichia coli: MurA Confers Clinical Resistance at Low Fitness Cost. Antimicrobial Agents and Chemotherapy, 56:2767-2769.

Ebrahim, G.J. (2010). Bacterial resistance to antimicrobials. Journal of Tropical Pediatrics, 56:141-143.

Garbinski, L.D., Rosen, B.P., and Chen, J. (2019). Pathways of arsenic uptake and efflux. Environment International, 126:585-597.

Hsueh, Y.M., Chiou, H.Y., Huang, Y.L., Wu, W.L., Huang, C.C., Yang, M.H., Lue, L.C., Chen, G.S., and Chen, C.J. (1997). Serum beta-carotene level, arsenic methylation capability, and incidence of skin cancer. Cancer Epidemiology Biomarkers \&amp; Prevention, 6:589-596.

Kuramata, M., Sakakibara, F., Kataoka, R., Yamazaki, K., Baba, K., Ishizaka, M., Hiradate, S., Kamo, T., and Ishikawa, S. (2016). Arsinothricin, a novel organoarsenic species produced by a rice rhizosphere bacterium. Environmental Chemistry, 13:723-731.

Liu, J., Lu, Y., Wu, Q., Goyer, R.A., and Waalkes, M.P. (2008). Mineral Arsenicals in Traditional Medicines: Orpiment, Realgar, and Arsenolite. Journal of Pharmacology and Experimental Therapeutics, 326:363-368.

Lloyd, N.C., Morgan, H.W., Nicholson, B.K., and Ronimus, R.S. (2005). The composition of Ehrlich's salvarsan: resolution of a century - old debate. Angewandte Chemie International Edition, 44:941-944.

Lo-Coco, F., Avvisati, G., Vignetti, M., Thiede, C., Orlando, S.M., lacobelli, S., Ferrara, F., Fazi, P., Cicconi, L., Di Bona, E., Specchia, G., Sica, S., Divona, M., Levis, A., Fiedler, W., Cerqui, E., Breccia, M., Fioritoni, G., Salih, H.R., Cazzola, M., Melillo, L., Carella, A.M., Brandts, C.H., Morra, E., von 
Lilienfeld-Toal, M., Hertenstein, B., Wattad, M., Lübbert, M., Hänel, M., Schmitz, N., Link, H., Kropp, M.G., Rambaldi, A., La Nasa, G., Luppi, M., Ciceri, F., Finizio, O., Venditti, A., Fabbiano, F., Döhner, K., Sauer, M., Ganser, A., Amadori, S., Mandelli, F., Döhner, H., Ehninger, G., Schlenk, R.F., and Platzbecker, U. (2013). Retinoic Acid and Arsenic Trioxide for Acute Promyelocytic Leukemia. New England Journal of Medicine, 369:111-121.

Nadar, V.S., Chen, J., Dheeman, D.S., Galván, A.E., Yoshinaga-Sakurai, K., Kandavelu, P., Sankaran, B., Kuramata, M., Ishikawa, S., and Rosen, B.P. (2019). Arsinothricin, an arsenic-containing non-proteinogenic amino acid analog of glutamate, is a broad-spectrum antibiotic. Communications Biology, 2:1-12.

Qin, J., Rosen, B.P., Zhang, Y., Wang, G., Franke, S., and Rensing, C. (2006). Arsenic detoxification and evolution of trimethylarsine gas by a microbial arsenite S-adenosylmethionine methyltransferase. Proceedings of the National Academy of Sciences, 103:2075-2080.

Rodríguez-Barranco, M., Lacasaña, M., Aguilar-Garduño, C., Alguacil, J., Gil, F., González-Alzaga, B., and Rojas-García, A. (2013). Association of arsenic, cadmium and manganese exposure with neurodevelopment and behavioural disorders in children: A systematic review and meta-analysis. Science of the total environment, 454-455:562-577.

Rosen, B.P., and Borbolla, M.G. (1984). A plasmid-encoded arsenite pump produces arsenite resistance in Escherichia coli. Biochemical and biophysical research communications, 124:760-765.

Yoshinaga, M., and Rosen, B.P. (2014). A C. As lyase for degradation of environmental organoarsenical herbicides and animal husbandry growth promoters. Proceedings of the National Academy of Sciences, 111:77017706 .

Zhu, Y.-G., Xue, X.-M., Kappler, A., Rosen, B.P., and Meharg, A.A. (2017). Linking genes to microbial biogeochemical cycling: lessons from arsenic. Environmental Science \& Technology, 51:7326-7339. 
Zhu, Y.-G., Yoshinaga, M., Zhao, F.-J., and Rosen, B.P. (2014). Earth abides arsenic biotransformations. Annual Review of Earth and Planetary Sciences, 42:443-467. 
VITA

LUIS D GARBINSKI

EDUCATION AND AWARDS

$2012-2016$

Bachelor of Science in Environmental Science Florida International University

Miami, Florida, United States

$2016-2020$

Doctoral Candidate in Biomedical Sciences Herbert Wertheim College of Medicine

Florida International University

Miami, Florida, United States

Florida Caribbean Consortium for Agriculture Education (FCCAgE) Scholarship. 2012. Full tuition waiver and research stipend.

McKnight Doctoral Fellowship. 2016. Full tuition waiver, $\$ 24,000$ stipend over two years.

\section{PUBLICATIONS AND PRESENTATIONS}

"A Novel Mechanism of Methylarsenite Resistance in Shewanella putrefaciens." Poster. Presented at the Annual Biomedical Research Conference for Minority Students (ABRCMS), 2018, Phoenix, AZ.

Caobi, A., Dutta, R.K., Garbinski, L.D., Esteban-Lopez, M., Ceyhan, Y., Andre, M., Manevski, M., Ojha, C.R., Lapierre, J., Tiwari, S., Parira, T., El-Hage, N. (2020) The Impact of CRISPR-Cas9 on Age-related Disorders: From Pathology to Therapy, Aging and Disease (IF: 4.310), 11(4), 895-915.

Chen, J., Garbinski, L.D., Rosen, B.P., Zhang, J., Xiang, P., Ma, L.Q. (2019) Organoarsenical compounds: Occurrence, toxicology, and biotransformation, Critical Reviews in Environmental Science and Technology (IF: 8.302), 50(3), 217-243.

Chen. J., Yoshinaga, M., Garbinski, L.D., Rosen, B.P. (2016) Synergistic interaction of glyceraldehydes-3-phosphate dehydrogenase and Ars J, a novel organoarsenical efflux permease, confers arsenate resistance, Molecular Microbiology (IF: 3.816), 100(6), 945-953.

"Degradation of organoarsenical growth promoters." Poster. Presented at FIU's Agroecology Symposium, 2014, Miami, FL. 
Garbinski, L.D., Rosen, B.P., Yoshinaga, M. (2020) Organoarsenicals inhibit bacterial peptidoglycan biosynthesis by targeting the essential enzyme MurA. Chemosphere (IF: 5.778), 254, 126911.

Garbinski, L.D., Rosen, B.P., Chen, J. (2019) Pathways of arsenic uptake and efflux. Environment International (IF: 7.943), 126, 585-597.

"Organoarsenical inhibition of peptidoglycan biosynthesis." Oral. Presented at the Eastern-Atlantic Student Research Forum (ESRF), 2019, Miami, FL.

"Preventing a global health crisis: Our search for new antibiotics." Oral. Presented at Café Scientifique, 2020, online via Zoom.

Tiwari, S., Lapierre, J., Ojha, C.R., Martins, K., Parira, T., Dutta, R.K., Caobi, A., Garbinski, L., Ceyhan, Y., Esteban-Lopez, M., El-Hage, N. (2018) Signaling pathways and therapeutic perspectives related to environmental factors associated with multiple sclerosis, Journal of Neuroscience Research (IF: 4.699), 96(12), 1831-1846.

Yan, Y., Chen, J., Galván, A.E., Garbinski, L.D., Zhu, Y-G., Rosen, B.P., Yoshinaga, M. (2019) Reduction of Organoarsenical Herbicides and Antimicrobial Growth Promoters by the Legume Symbiont Sinorhizobium meliloti, Environmental Science \& Technology (IF: 7.864), 53(23), 13648-13656. 